Western Washington University Western CEDAR

Spring 2006

\title{
The Nature and Transport of the Fine-Grained Component of Swift Creek Landslide, Northwest Washington
}

Tovah M. (Tovah Michelle) Bayer

Western Washington University

Follow this and additional works at: https://cedar.wwu.edu/wwuet

Part of the Geology Commons

\section{Recommended Citation}

Bayer, Tovah M. (Tovah Michelle), "The Nature and Transport of the Fine-Grained Component of Swift Creek Landslide, Northwest Washington" (2006). WWU Graduate School Collection. 800.

https://cedar.wwu.edu/wwuet/800 accepted for inclusion in WWU Graduate School Collection by an authorized administrator of Western CEDAR. For more information, please contact westerncedar@wwu.edu. 


\title{
THE NATURE AND TRANSPORT OF THE FINE-GRAINED COMPONENT OF SWIFT CREEK LANDSLIDE, NORTHWEST WASHINGTON
}

\author{
by \\ Tovah M. Bayer \\ Accepted in Partial Completion \\ of the Requirements for the Degree \\ Master of Science \\ Geology
}

Dr. Moheb A. Ghali, Dean of Graduate School

\section{ADVISORY COMMITTEE}

Chair, Dr. Scott Linneman, Associate Professor $\cap 1-1-\cap$.

Dr. Christopher Sulczek, AssociatePryfessor 1 l

Dr. David Hirsch, Assistant Professor $\sim$

Mr. Paul Pittman, Whatcom County Public Works 


\section{MASTER'S THESIS}

In presenting this thesis in partial fulfillment of the requirements for a master's degree at Western Washington University, I agree that the Library shall make its copies freely available for inspection. I further agree that extensive copying of this thesis is allowable only for scholarly purposes. It is understood, however, that any copying or publication of this thesis for commercial purposes, or for financial gain, shall not be allowed without my written permission.

Signature

Date $6-22-06$ 


\title{
THE NATURE AND TRANSPORT OF THE FINE-GRAINED COMPONENT OF SWIFT CREEK LANDSLIDE, NORTHWEST WASHINGTON
}

\author{
A Thesis \\ Presented to \\ The Faculty of \\ Western Washington University
}

In Partial Fulfillment

Of the Requirements for the Degree

Master of Science

By

Tovah M. Bayer

June, 2006 


\section{MASTER'S THESIS}

In presenting this thesis in partial fulfillment of the requirements for a master's degree at Western Washington University, I grant to Western Washington University the non-exclusive royalty-free right to archive, reproduce, distribute, and display the thesis in any and all forms, including electronic format, via any digital library mechanisms maintained by WWU.

I represent and warrant this is my original work and does not infringe or violate any rights of others. I warrant that I have obtained written permissions from the owner of any third party copyrighted material included in these files.

I acknowledge that I retain ownership rights to the copyright of this work, including but not limited to the right to use all or part of this work in future works, such as articles or books.

Library users are granted permission for individual, research and non-commercial reproduction of this work for educational purposes only. Any further digital posting of this document requires specific permission from the author.

Any copying or publication of this thesis for commercial purposes, or for financial gain, is not allowed without my written permission.

Name:

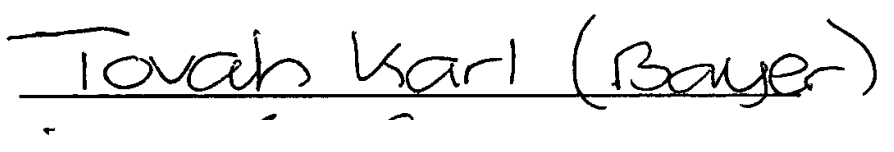

Signature:

Date:

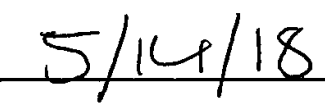




\begin{abstract}
Extreme sedimentation in Swift Creek, located in the Cascades foothills in NW Washington $\left(48^{\circ} 55^{\prime} \mathrm{N}, 122^{\circ} 16^{\prime} \mathrm{W}\right)$, results from erosion of the oversteepened, unvegetated toe of a large $\left(0.55 \mathrm{~km}^{2}\right)$ active earthflow. The amount of bedload in the creek has necessitated several mitigation projects in the channel including annual dredging and temporary sediment traps in an attempt to reduce the risk of flooding and damage to manmade structures downstream.

The bedload and suspended sediment in the creek are a direct result of the weathering process of the serpentinitic bedrock, in which the landslide is rooted. The serpentinite weathers to asbestiform chrysotile with minor amounts of chlorite, illite and hydrotalcite, all of which occur in clay seeps on the unvegetated surface of the landslide. The chrysotile fibers average $2 \mu \mathrm{m}$ in length and make up at least $50 \%$, by volume, of the suspended load transported in Swift Creek. The suspended sediment transported by Swift Creek poses a threat to downstream ecosystems in the Sumas River because of the turbidity and heavy metals that Swift Creek introduces into this fish-producing river. This study does not address the environmental or health implications of the asbestiform chrysotile transport or deposition.
\end{abstract}

During the sampled time between February 2005 and February 2006, the suspended sediment concentrations ranged from $0.02 \mathrm{~g} / \mathrm{L}$ to $41.6 \mathrm{~g} / \mathrm{L}$ and the discharge ranged from $0.00 \mathrm{~m}^{3} / \mathrm{s}$ to $0.51 \mathrm{~m}^{3} / \mathrm{s}$.

A nonlinear functional model estimated the total suspended sediment flux from detailed precipitation records and discrete suspended sediment concentration and discharge 
measurements to be $910 \mathrm{t} / \mathrm{km}^{2} / \mathrm{yr}$. That number, coupled with the bedload estimate of $17,600 \mathrm{t} / \mathrm{km}^{2} / \mathrm{yr}$, which is based on cross-sectional differences and dredged material, resulted in a total sediment yield of $18,510 \mathrm{t} / \mathrm{km}^{2} / \mathrm{yr}$.

The estimated erosion rate for the Swift Creek watershed is $11 \mathrm{~mm} / \mathrm{yr}$ and 158 $\mathrm{mm} / \mathrm{yr}$ for the Swift Creek landslide alone. The majority of the material entering Swift Creek is presumed to be originating on the unvegetated toe of the SCL, where the erosion rate is approximately $950 \mathrm{~mm} / \mathrm{yr}$. 


\section{PREFACE}

"Civilization exists by geological consent, subject to change without notice." -Will Durant

This thesis was written as a manuscript for submission to the journal Earth Surface Processes and Landforms. The extended introduction includes background information for the thesis only and was not included in the journal submission. The appendices contain the full dataset and the figures that were summarized in the journal submission but not included. The reference list includes the references from the extended introduction and the journal submission as well as the appendices. 


\section{ACKNOWLEDGEMENTS}

No thesis can be considered a product of a single person's efforts, and this one is certainly no exception. It never would have come to fruition without the expressed help and support of many friends and colleagues.

First and foremost, I would like to thank my advisor, Dr. Scott Linneman, who first introduced me to the wonders of the Swift Creek landslide. He kept me on task and helped me maintain a positive attitude, even when everything seemed to be going wrong. My committee members, Dr. Dave Hirsch, Dr. Chris Suczek and Mr. Paul Pittman, served as invaluable resources throughout the process and demonstrated a great deal of understanding and flexibility while I was trying to overcome numerous failed methodologies. Paul Pittman also opened my eyes to the true impact of my study area on the community. Thank you for allowing me to tag along on your expeditions.

Numerous faculty members at Western Washington University offered me suggestions and guidance along the way. I would be lost without George Mustoe's endless knowledge in the workings of the laboratory equipment. Both he and Erin Macri patiently worked with me (for hours) on the scanning electron microscope. Joan Vandersypen kindly granted me permission to use both her field and laboratory equipment. I could not have collected or analyzed any of my data without it.

All of the X-ray diffraction analyses of the clay seeps from the Swift Creek landslide were done at Portland State University under the guidance of Dr. Georg Grathoff. Dr. Scott Burns kindly got his hands dirty and taught me how to roll snakes as part of my lesson on the Atterberg limit tests. 
I owe my gratitude to a couple of outstanding undergraduate students at Western Washington University. Kiyo Peterman performed all of the nonlinear functional modeling and never got frustrated by my statistical ignorance. Joshua Fuller built and configured the Campbell Scientific Instrument weather station.

My fieldwork would not have been possible without Tom Westergreen of Great Western Lumber, who granted access to the Swift Creek landslide. He was always enthusiastic about my work and showed great interest in my progress. Dr. Scott Linneman, Mike Karl, Joshua Fuller and Noel Liner each braved the notorious clay to help me set up equipment and collect samples. They all made it out relatively unscathed; save for a shoe or two. Dr. Scott Linneman, Mike Karl, Todd Belanger, Niki Bowerman, and Kelsay Davis didn't complain when they were waist deep in Swift Creek attempting to retrieve buried equipment. Brendan Hodge, Owen Callahan and Brian Perttu constructed a cable line above Swift Creek, and along with the help of Niki Bowerman, helped me get over my fears of dangling over the "raging" waters.

I am especially indebted to my family and friends. They always encouraged me to chase after my dreams and never doubted my success. They were the support I needed when I didn't have the strength to continue.

This work was supported by the Geological Society of America, the National Science Foundation, the David A. Rahm scholarship, the Western Washington University Graduate School and the Western Washington University Geology Department. 


\section{TABLE OF CONTENTS}

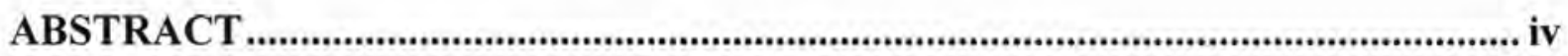

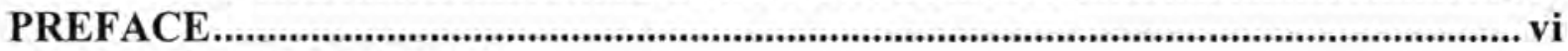

ACKNOWLEDGEMENTS ....................................................................................... vii

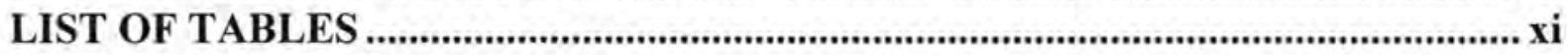

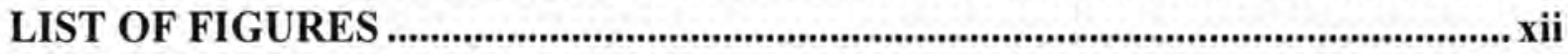

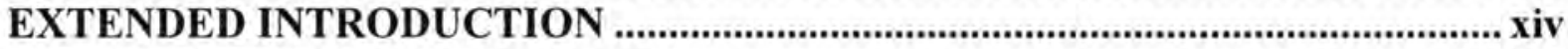

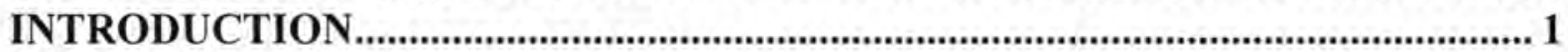

STUDY AREA

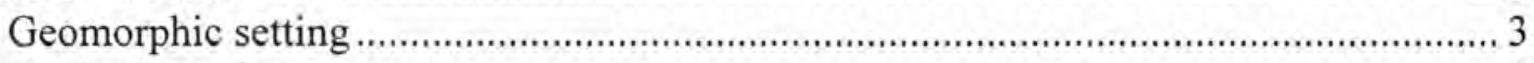

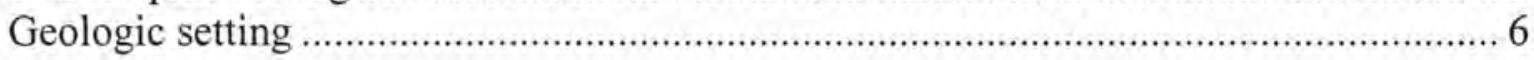

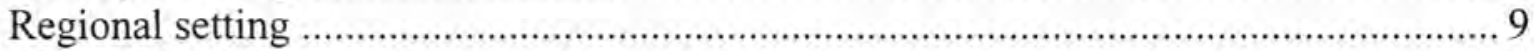

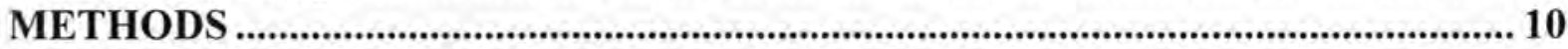

Characterization of sediment production process …................................................... 10

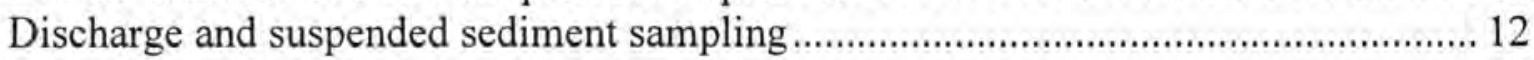

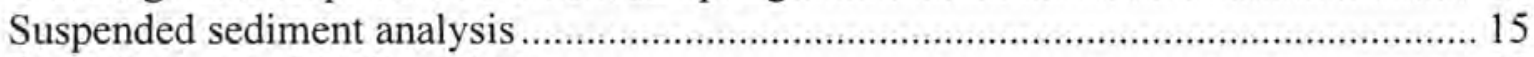

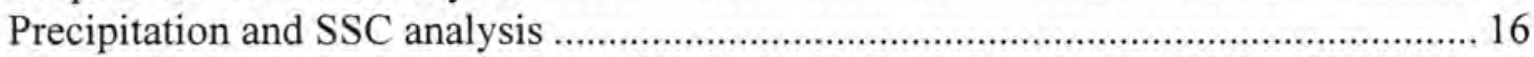

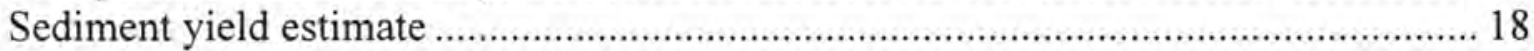

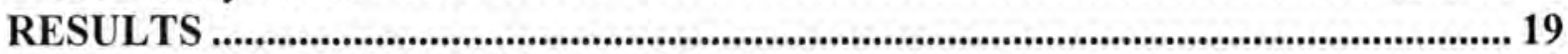

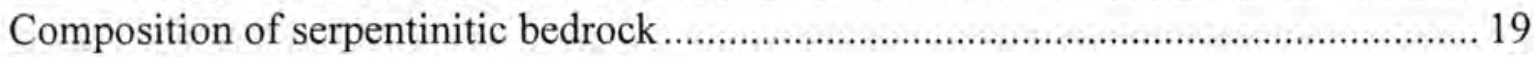

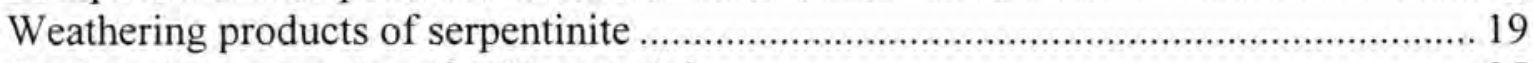

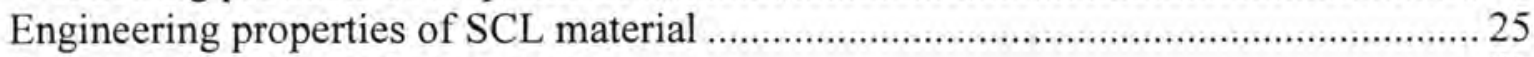

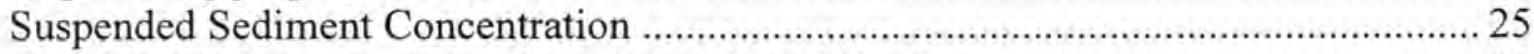

Relationship between SSC, discharge and precipitation.......................................... 25

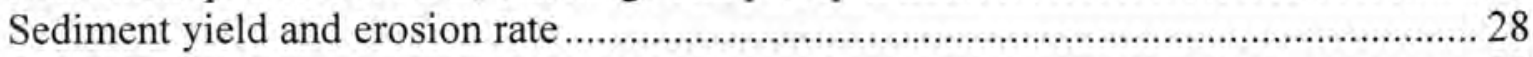

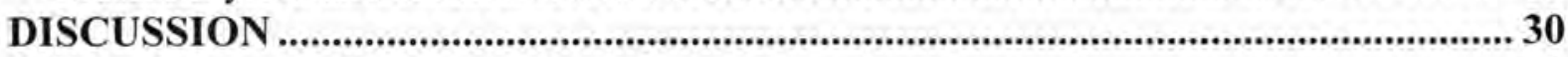

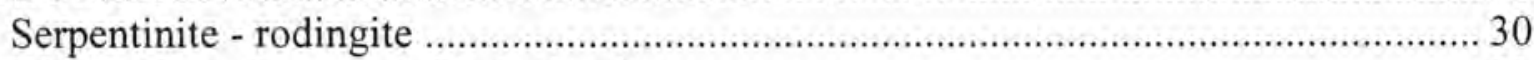

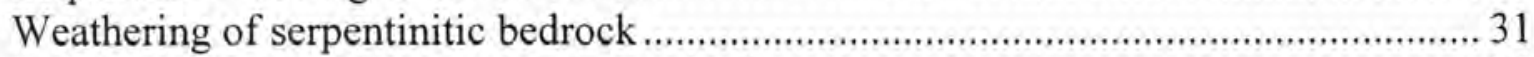

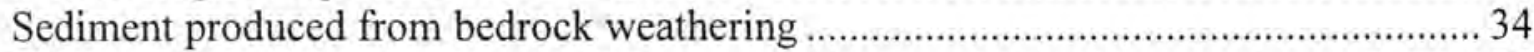

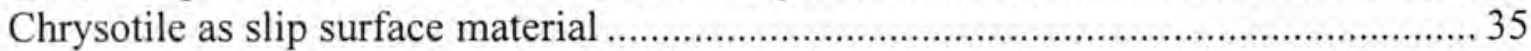

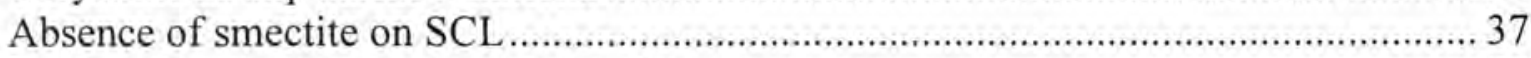

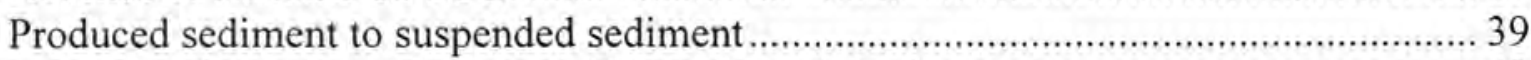

Relationship between discharge, SSC and precipitation.......................................... 42

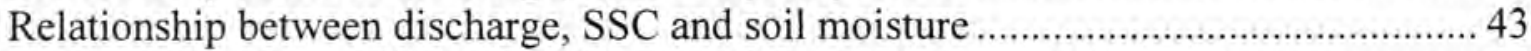

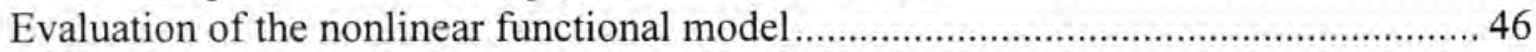

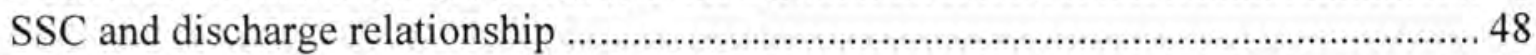

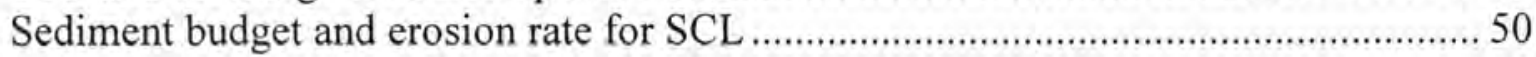

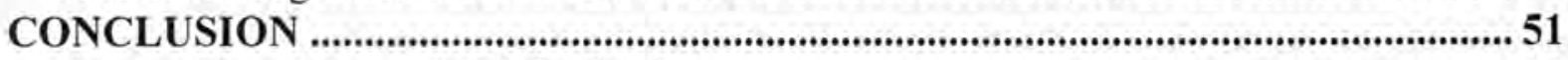

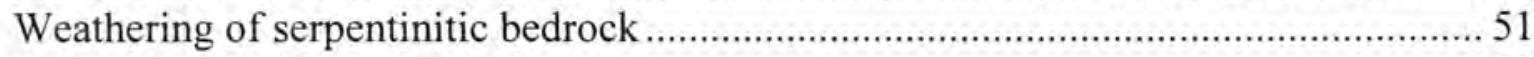

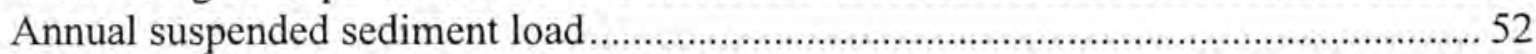

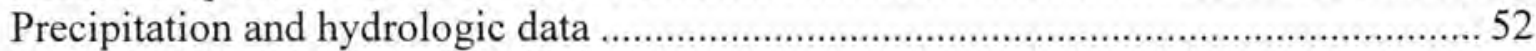

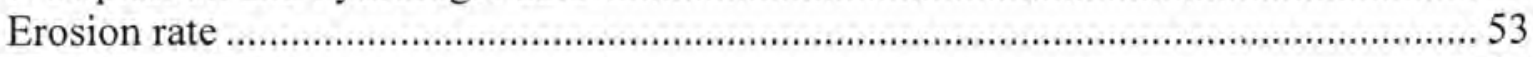

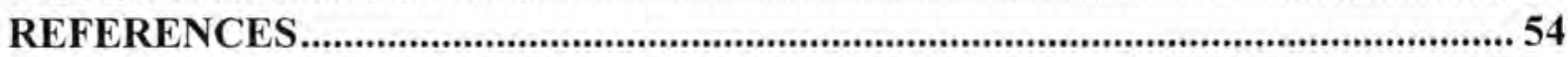




\section{APPENDICES}

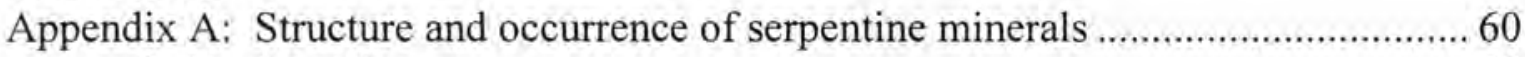

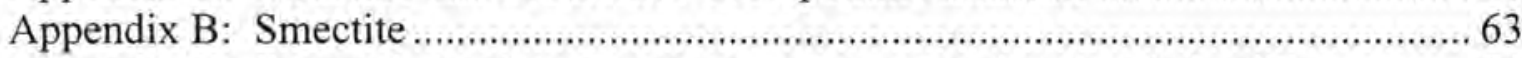

Appendix C: Suspended sediment concentration vs. total suspended solids .............. 64

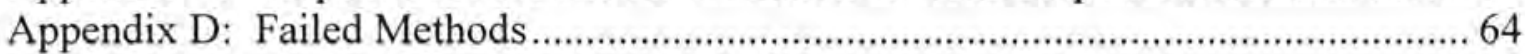

Appendix E: Nonlinear functional model (2D unit sediment graph),.......................66

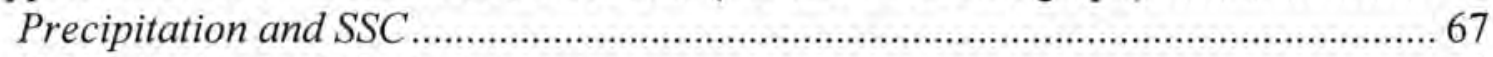

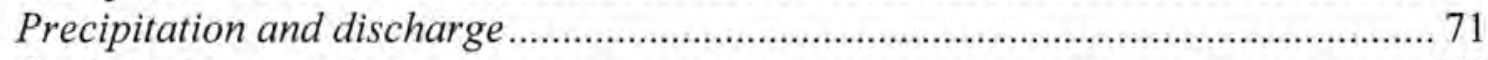

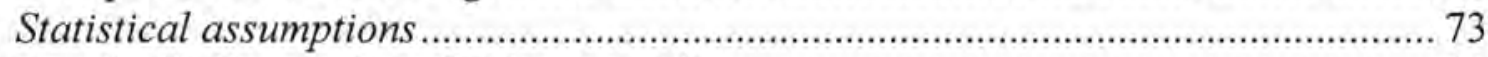

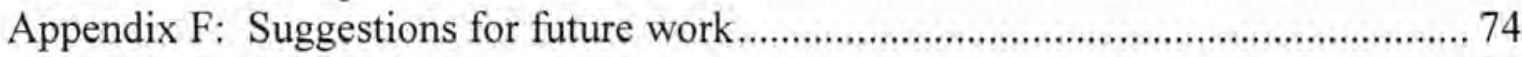

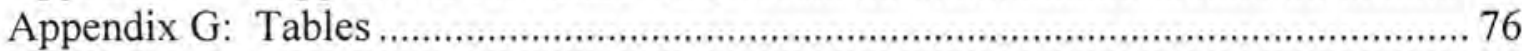

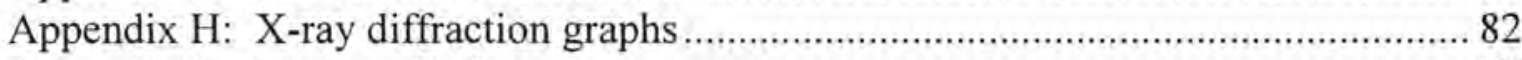

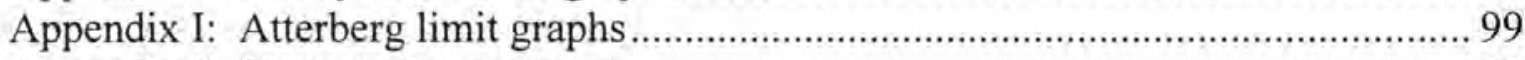

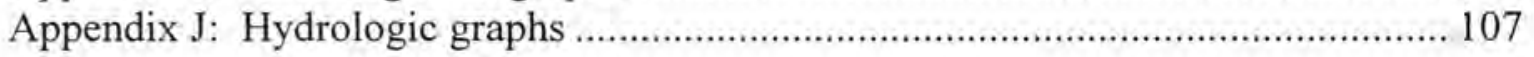




\section{LIST OF TABLES}

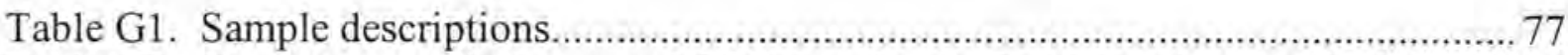

Table G2. Precipitation, discharge and SSC data for the Swift Creek watershed........... 78

Table G3. Nonlinear functional model statistics used to choose best model ....................80

Table G4. Nonlinear functional model equations used to generate continuous

SSC and discharge data 


\section{LIST OF FIGURES}

\section{IN TEXT}

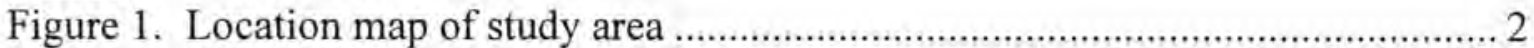

Figure 2. Picture of confluence between the north and south forks of Swift Creek ..... 4

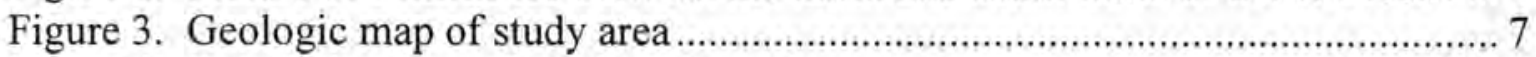

Figure 4. Sample locations for mineralogical analyses.............................................. 11

Figure 5. Graph of percent of monthly percipitation vs, percent of monthly

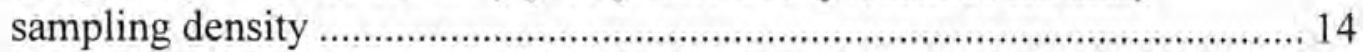

Figure 6. Cross correlation coefficients for SSC and discharge used in nonlinear

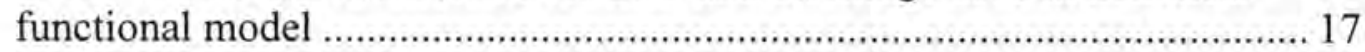

Figure 7. XRD pattern of serpentinitic whole rock

Figure 8. XRD pattern of green/white fractions of serpentinitic whole rock ..............2 21

Figure 9. Four categorical XRD patterns for clay samples.........................................23

Figure 10. SEM images of serpentine grain and clay; showing disaggregating

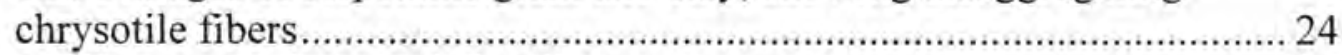

Figure 11. XRD pattern of suspended sediment ................................................26

Figure 12. Graph of precipitation, SSC and discharge for $8 / 28 / 05 \ldots \ldots \ldots \ldots \ldots \ldots \ldots \ldots \ldots . . .27$

Figure 13. Graphs of seasonal correlations between SSC and discharge ...................2 29

Figure 14. Picture of serpentinitic whole rock displaying in-situ disintegration ......... 32

Figure 15. Pictures of clay seeps on Swift Creek landslide; showing different

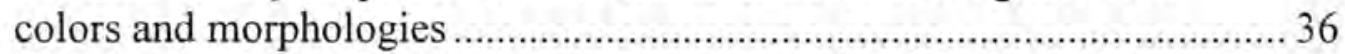

Figure 16. Graph of percent of the total sampled SSC values that fell within certain concentration ranges.

Figure 17. Graph of relationship between precipitation intensity, SSC and discharge during 2005-2006.

Figure 18. Graph of relationship between precipitation, SSC and soil moisture during 2005-2006.

Figure 19. Graph of observed data vs. data predicted by the nonlinear functional model for SSC and discharge during 2005-2006.

\section{IN APPENDICES}

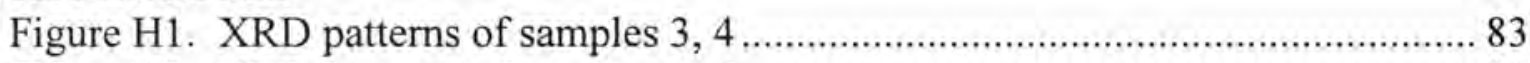

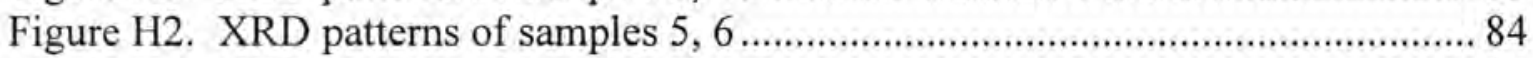

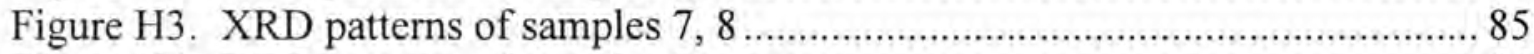

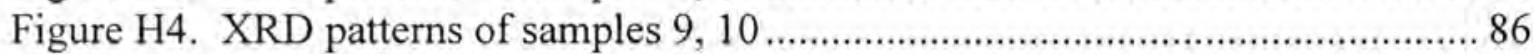

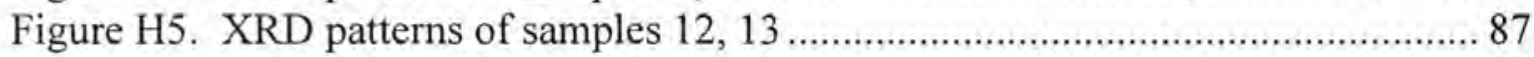

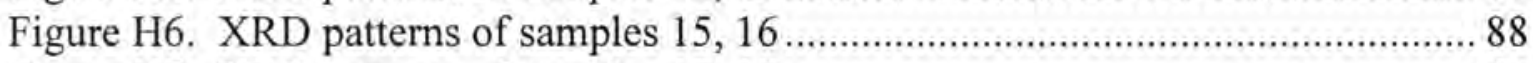

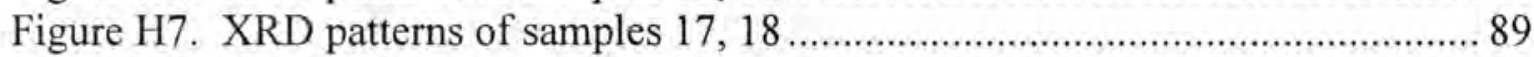

Figure H8. XRD patterns of samples 19,20 ................................................ 90

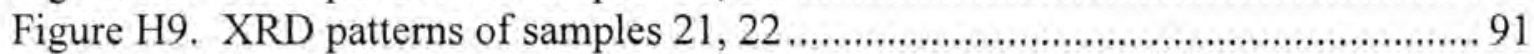

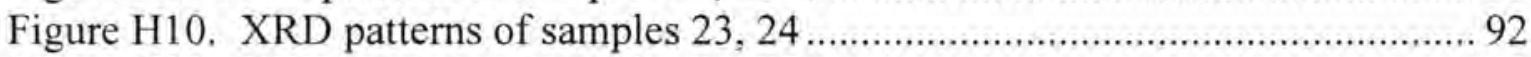

Figure H11. XRD patterns of samples 25, 27 .................................................... 93

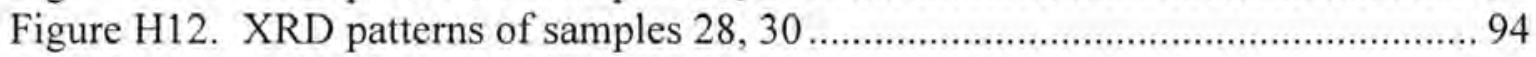




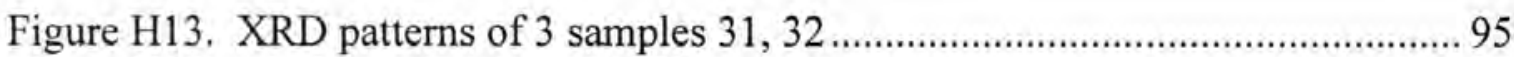

Figure H14. XRD pattern of sample 33 ……………..................................... 96

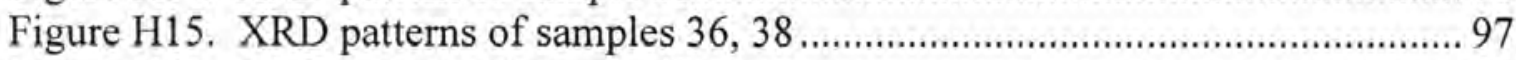

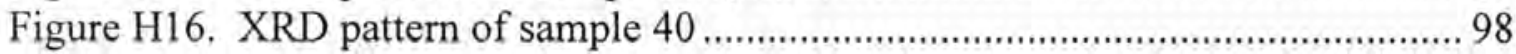

Figure I1. Liquid limit graph for sample 35 ....................................................... 100

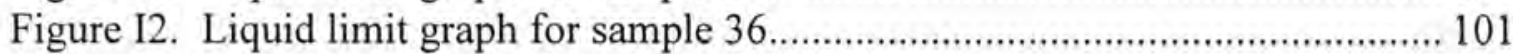

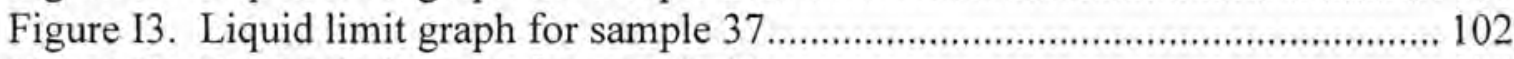

Figure I4. Liquid limit graph for sample 38................................................... 103

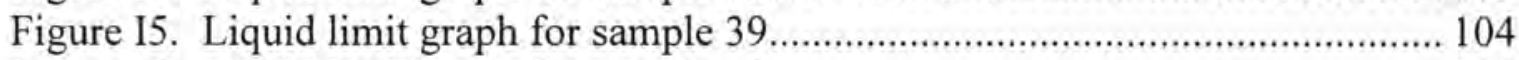

Figure I6. Liquid limit graph for sample 40.................................................. 105

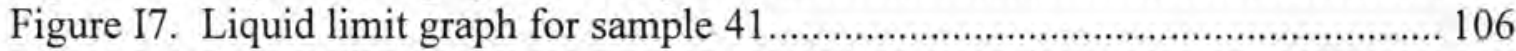

Figure J1. Graph of the percent of monthly precipitation occurring at night ........... 108

Figure J2, Graph of relationship between precipitation, discharge and SSC

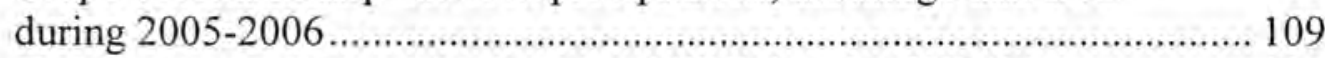

Figure J3. Graph of precipitation, discharge and SSC data for 1/11/06 .................. 110 


\section{EXTENDED INTRODUCTION}

Rivers function as major transporters of terrestrial material to the oceans and are studied to better understand the role they play in the global sediment budget. Small rivers are of particular interest due to their small watersheds and thus greater relative response to single events (i.e., precipitation and debris flows). Small rivers also greatly outnumber large rivers and therefore collectively deliver more sediment to the oceans (Farnsworth and Milliman, 2003).

A disproportionate amount of the material entering the oceans comes from small rivers that drain active mountains (Farnsworth and Milliman, 2003). Small mountainous rivers can be rivers that drain directly to the oceans or rivers that are tributaries, so long as they have a drainage basin of less than $10,000 \mathrm{~km}^{2}$ and drain mountainous terrain of at least 1000m in elevation (Milliman, 2005). Milliman and Syvitski (1992) further suggest that as much as half of the sediment reaching the oceans can be attributed to small, mountainous rivers, including those draining western North and South America, Oceania and parts of Europe. The Amazon River, for example, which drains an area about three times that of 460 small, mountainous rivers in the East Indies put together, has an estimated sediment load that is roughly only $1 / 4$ their amount (Farnsworth and Milliman, 2003).

Over the past 50 years, small rivers have been monitored by suspended-load sampling devices developed by U.S. government agencies (Leopold, 1994). However, sampling is often infrequent and not well distributed along the many rivers. Lack of funding has caused over 100 hydrologic stations with records of more than 30 years to be shut down annually in the United States since the early 1990s (Lanfear and Hirsch, 1999). While new 
stations have been activated, they are only useful for immediate needs, not for looking at long-term flow characteristics with acceptable uncertainty (Lanfear and Hirsch, 1999). Due to changes in the climate and land use, relying on such inadequate and outdated data could lead to unreliable estimates.

Because a major portion of the total suspended sediment is transported during large, infrequent runoff events (Walling et al., 1992), understanding or quantifying the global sediment budget necessitates regular, systematic sampling. In the Latnjavagge drainage basin in the northern Swedish Lapland, Beylich and Gintz (2004) found that, during the years 2000-2002, approximately $90 \%$ of the annual sediment yield was transported during high magnitude/low frequency rainfall-generated runoff peaks. According to Farnsworth and Milliman (2003), the Salinas River in California delivered half of its historical (70 years) sediment load in less than 5 weeks. Emmett (1975) similarly noted that, for the Salmon River in Idaho, over $90 \%$ of the average annual sediment yield was delivered in less than $10 \%$ of the time. Relying on an annual average of sediment discharged to the oceans may therefore ignore the single events that dominate the influx.

Sediment yield has not only been observed to increase during single high precipitation events but has also been noted to vary temporally. In Reynolds Creek, Idaho, sediment yields were negligible during periods of drought but increased by more than 10 times during wet periods (Slaughter and Pierson, 2000). Rainfall "aggressiveness", defined by the authors as the ratio of the square of maximum monthly rainfall amount to the annual rainfall amount in the area, was also shown to have a direct relationship on the annual sediment yield in submontane Punjab (Matharu et al., 2003). Months with high 
precipitation and frequent snow melting in the Baltic Sea drainage basin were shown to produce an increase in the suspended sediment yield (Lajczak and Jansson, 1993).

Sediment yield is often related to discharge as well, through the use of equations and rating curves (Walling et al., 1992). Jain et al. (2003) found a logarithmic relationship between sediment and discharge in rivers of the Himalayan region, expressed by the general formula:

$$
\log _{10}(\mathrm{~S})=\mathrm{x} * \log _{10}(\mathrm{Q})-\mathrm{y}
$$

Where $\mathrm{S}$ is sediment yield, $\mathrm{Q}$ is discharge and $\mathrm{x}$ and $\mathrm{y}$ are empirically derived constants. However, Gomi et al.(2005) and Moliere et al.(2004) observed that a direct relationship between sediment yield and discharge can be difficult to ascertain, because sediment yield often comes in pulses and is not necessarily coeval with the discharge peaks on the hydrograph. The remobilization of stored material within the creek bed, in conjunction with new sediment being delivered from external sources, can cause drastic fluctuations in the total suspended sediment within and between rain events, complicating the sediment response to the hydrograph. More sophisticated, physically based models have also been developed to estimate suspended-sediment concentrations. They are based on partial differential equations of flow and sediment flux and are usually highly sophisticated models that contain components that correspond to physical processes (Güldal and Müftüoglu, 2001). Theoretically, their complexity allows them to account for spatial variations in the watershed, such as the uneven distribution of precipitation. However, the present inability to measure the real distribution of precipitation makes those models no more advantageous 
over simpler, lumped models and may even offer practical disadvantages (Güldal and Müftüoglu, 2001).

In an attempt to overcome such inadequacies in sediment estimation models, Güldal and Müftüoglu (2001) proposed a black-box analysis that predicts the suspended-sediment concentration from the current and antecedent precipitation. It assumes that an analysis of the input and output data is sufficient to get an idea of the behavior of the system. Because the model looks at the overall behavior of the system, it is acceptable to consider the effective precipitation as a lumped input even though it is not evenly distributed over the catchment. Similarly, the suspended sediment concentration can be accepted as a lumped output, even though it is unevenly distributed over the river channel (Güldal and Müftüoglu, 2001). This nonlinear functional model put forth by Güldal and Müftüoglu (2001) will be used in this study to estimate the annual suspended sediment yield in a small river in NW Washington.

Swift Creek, located in western Washington $\left(48^{\circ} 55^{\prime} \mathrm{N}, 122^{\circ} 16^{\prime} \mathrm{W}\right)$ (Figure 1), is an event-driven, small river that varies substantially throughout the year in its sediment yield because it drains an active landslide, the Swift Creek landslide (SCL). The SCL acts as the major external source for the material entering Swift Creek. The serpentinitic bedrock, in which the Swift Creek landslide is apparently rooted (McKenzie-Johnson, 2004), is highly fractured and easily weathered. The produced sediment, resulting from the weathering of the bedrock, serves as a consistently available sediment source for Swift Creek. However, the weathering process of the serpentinite bedrock to the fine-grained material is insufficiently understood. 
Knowing the mineralogy of the landslide material may constrain the causes and timing of the fine-grained influx into Swift Creek. The mineralogy of the clay fraction is of particular interest because it plays an important role in dictating the soil's response to stress (Istok and Harward, 1982a) and in determining the cohesiveness and stability of a hill-slope (Ambers, 2001).

Knowing the weathering products of the serpentinitic bedrock also provides more accurate parameters to be used in hazard assessment landslide models. The Mohr-Coulomb equation is often used to predict when failure will occur and is expressed as:

$$
S=\left(\sigma_{n}-\mu\right) \tan \Phi
$$

Where $\mathrm{S}$ is the shear strength, $\sigma_{\mathrm{n}}$ is the total normal stress on the shear surface, $\mu$ is the pore water pressure and $\Phi$ is the apparent friction angle. The factor of safety (FS), which is the ratio of forces resisting failure to the forces promoting failure (Duncan, 1996), is therefore dependent on the shear strength calculated from materials with varying friction angles. For instance, serpentinite has an internal friction angle of $30^{\circ}$, while chlorite and montmorillonite have internal friction angles between $20^{\circ}$ and $10^{\circ}$ (Yokota et al., 2000), A slope containing serpentinite would have an FS significantly higher than one that contains primarily chlorite or montmorillonite.

The reduction in the shear strength of clays to residual values can occur as the clay minerals align during progressive shearing, a phenomenon that tends to be more pronounced in high plasticity clays (Stark and Eid, 1997). The determination of the plasticity of the clays located on the SCL, through the use of Atterberg limits, would give better insight into the sensitivity of the landslide to outside forces. 
The large bedload influx into Swift Creek necessitates mitigation projects downstream from the landslide. Annual dredging and temporary sediment control structures have been used in an attempt to reduce the risks of flooding and avulsion due to rapid channel aggradation and to limit the amount of sediment transported downstream to fishinhabited rivers. Optimizing sediment reservoirs requires an accurate estimation of the total transported load. An underestimation would result in an insufficient reservoir life, while an overestimation would result in an overcapacity reservoir (Güldal and Müftüoglu, 2001). Reservoir designs are usually based on historical records, or when these are unavailable, sediment data generated from precipitation data (Güldal and Müftüoglu, 2001). Prior to this study, only bedload estimates were available for Swift Creek. With precipitation data as well as suspended sediment load data collected as part of this study, better estimates of the total load in Swift Creek can be made, subsequently leading to better mitigation practices.

However, before estimations of future sediment influxes into Swift Creek can be used to design adequate mitigation plans, an understanding of the sediment production and corresponding erosion rates of the sediment source, the SCL, is necessary. Annual estimates of bedload in Swift Creek have been made based on the dredged material; however, estimates of the total transported load are unavailable because no attempts have been made to quantify the suspended sediment load. This paper will: (1) characterize the process of sediment production on the SCL, from the weathering of the bedrock to the formation of the fine-grained component that comprises the suspended sediment in Swift Creek; (2) quantify the annual suspended sediment load in Swift Creek through the collection of discrete suspended sediment samples taken during 2004-2006; (3) determine if measured 
precipitation in the Swift Creek watershed can be used as a predictor of suspended sediment concentrations by applying a nonlinear functional model to predict suspended sediment concentrations from current and antecedent precipitation; (4) establish an erosion rate for the SCL by combining calculated suspended sediment loads with the estimated bedload flux for Swift Creek and known rates of movement of the SCL. 


\section{INTRODUCTION}

Rivers function as major transporters of terrestrial material to the oceans and are studied to better understand the role they play in the global sediment budget. Small rivers are of particular interest due to their smaller watersheds and thus greater relative response to single events (i.e., precipitation and debris flows). A disproportionate amount of the material entering the oceans comes from small rivers that drain active mountain ranges. (Farnsworth and Milliman, 2003).

The western flank of Sumas Mountain, NW Washington (Figure 1), contains serpentinitic bedrock that is highly fractured and easily weathered. Mechanisms of sediment production include mass wasting and chemical and physical weathering as well as channel erosion. The produced sediment serves as a constant available sediment source to a small river, Swift Creek, which it enters through the means of an active landslide, the Swift Creek landslide.

The large bedload influx into Swift Creek necessitates mitigation projects downstream from the landslide. Local authorities attempt to reduce the risks of flooding due to rapid channel aggradation and to limit the amount of sediment transported downstream to fish-inhabited rivers through annual dredging and temporary sediment control structures. Optimizing sediment reservoirs requires an accurate estimation of the total transported load. An underestimation would result in an insufficient reservoir life, while an overestimation would result in an overcapacity reservoir (Güldal and Müftüoglu, 2001).

The development of adequate mitigation plans requires estimations of current and future sediment influxes into Swift Creek. However, before those estimates can be 


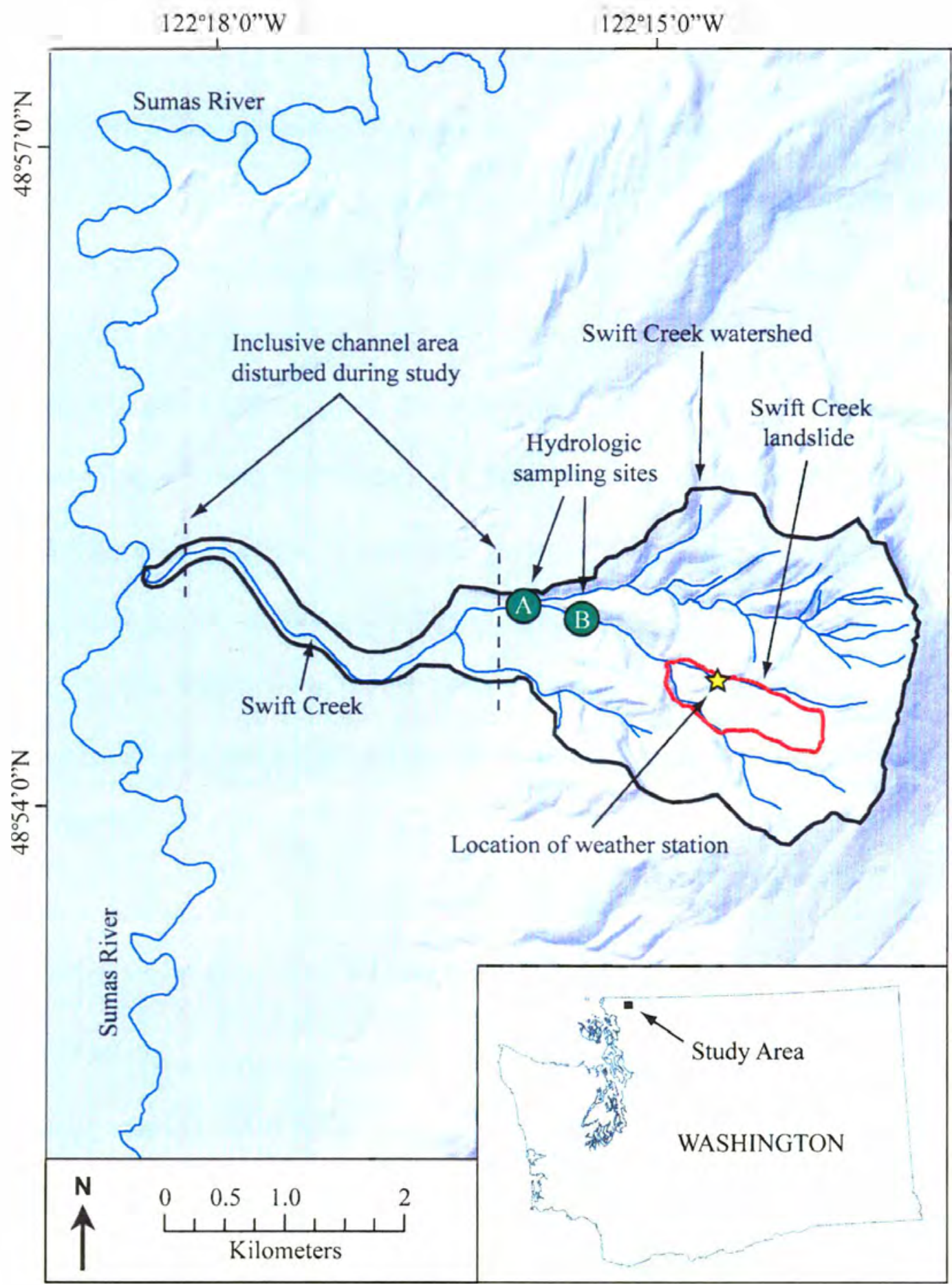

Figure 1. Location map of the Swift Creek watershed in NW Washington. The disturbed area refers to that which is affected by the gravel mine operation and channel dredging. 
made, an understanding of the sediment production and corresponding erosion rates of the sediment source, the Swift Creek landslide (SCL), is necessary. Annual estimates of bedload in Swift Creek have been made based on the dredged material; however, estimates of the total transported load are unavailable because no attempts have been made to quantify the suspended sediment load. This paper will: (1) characterize the process of sediment production on the SCL, from the weathering of the bedrock to the formation of the finegrained component that comprises the suspended sediment in Swift Creek; (2) quantify the annual suspended sediment load in Swift Creek through the collection of discrete suspended sediment samples taken during 2005-2006; (3) determine if measured precipitation in the Swift Creek watershed can be used as a predictor of suspended sediment concentrations by applying a nonlinear functional model to predict suspended sediment concentrations from current and antecedent precipitation; (4) establish an erosion rate for the SCL by combining calculated suspended sediment loads with the estimated bedload flux and known rates of movement of the SCL.

\section{STUDY AREA}

\section{Geomorphic setting}

The study area is located in the Cascades foothills in NW Washington $\left(48^{\circ} 55^{\prime} \mathrm{N}\right.$, $122^{\circ} 16^{\prime} \mathrm{W}$ ) (Figure 1). Swift Creek drains a portion of the western slope of Sumas Mountain and consists of two main forks. The northern fork runs through a densely wooded slope, while the southern fork runs through the Swift Creek landslide, gaining a high suspended sediment load as a result (Figure 2). Swift Creek, approximately $8 \mathrm{~km}$ 


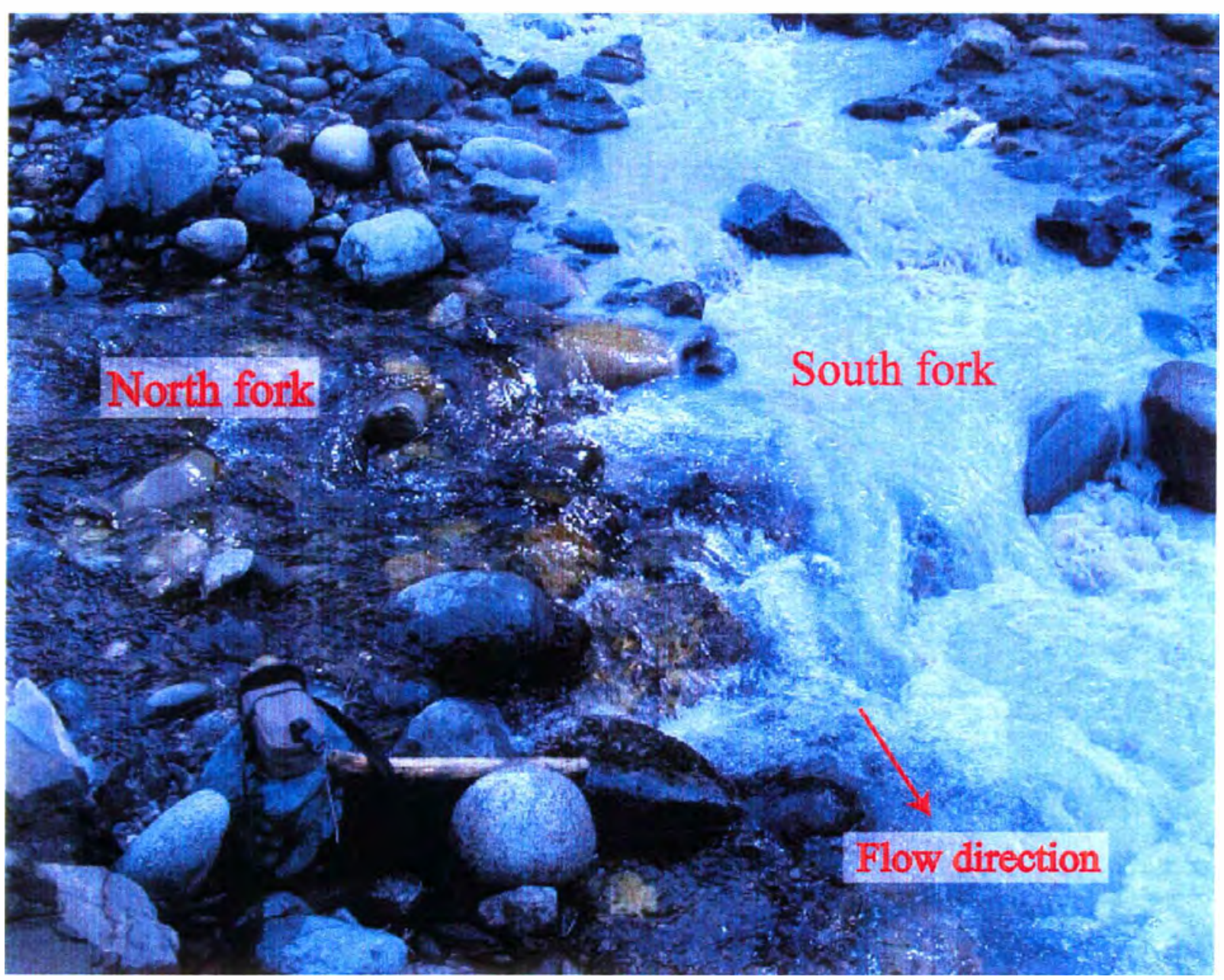

Figure 2. Confluence of the north and south forks of Swift Creek. The milky color of the south fork is due to the large sediment load that it picks up after draining the SCL. 
long, discharges into the Sumas River, which then flows into the Fraser River in British Columbia. The south fork, which has an average gradient of $23 \%$ over $3 \mathrm{~km}$ down to the fan, has a watershed area of $2.6 \mathrm{~km}^{2}$. The north fork, which has an average gradient of $25 \%$ over $3.6 \mathrm{~km}$ to where it meets the south fork, has a watershed area of $2.9 \mathrm{~km}^{2}$. The total watershed area of Swift Creek is about $7.1 \mathrm{~km}^{2}$ (Figure 1).

After flowing through the SCL, the south fork continues through a bedrockconstricted valley, where the width of the landslide changes from almost $275 \mathrm{~m}$ to less than $10 \mathrm{~m}$, over a distance of approximately $200 \mathrm{~m}$. Material from the SCL is currently blocking approximately $2 / 3$ of the valley and has the potential to create a natural dam on the southern tributary with subsequent outbreak floods. The south fork continues to be confined downstream for another $425 \mathrm{~m}$ as it flows through a bedrock canyon that is less than $10 \mathrm{~m}$ wide before discharging onto the Swift Creek fan. The Swift Creek fan is a composite fan of approximately $200 \mathrm{Ha}$ that has formed just downstream of the bedrock canyon, where Swift Creek quickly changes to a lower gradient stream and reaches the Sumas River floodplain. The gradient of Swift Creek decreases from approximately $17 \%$ just above the fan, to $8 \%$ at the apex of the fan, to $1 \%$ at mid-fan to about $0.2 \%$ at the Swift Creek-Sumas River confluence.

Downstream of the canyon, the Swift Creek channel is being disturbed (Figure 1). On the upper to middle reaches, a gravel mining operation removed bedload material during the study period and constructed several sediment traps. From the middle to the lower reaches of the creek, Whatcom County annually dredges the channel. 


\section{Geologic setting}

Bedrock units at the Swift Creek landslide include pre-Tertiary ultramafic rock overlain unconformably by late Eocene to Oligocene sandstone and conglomerate. Quaternary glacial deposits and landslide debris form the top layer (Dragovich et al., 1997) (Figure 3).

The pre-Tertiary ultramafic rock is a dark, shiny green to pale green serpentinite, originating from a plutonic dunite and pyroxene peridotite (Dragovich et al., 1997). The serpentinite varies from massive, smooth and cohesive, to highly fractured, weathered and friable. Many samples contain slickensides. Its contact with overlying conglomerate is highly weathered and oxidized. In many places on the landslide, mostly near the toe, clay seeps appear to emanate from the serpentinite (McKenzie-Johnson, 2004). The clay ranges in color from white and bluish-gray to brown, and in texture from cohesive to non- cohesive.

The late Eocene to Oligocene sandstone-conglomerate unit that overlies the preTertiary serpentinite is locally known as the Huntingdon Formation. According to Dragovich et al. (1997), the Huntingdon is composed of two main lithofacies. The alluvial fan facies, mapped near the head of the landslide, is massive, serpentinite-rich diamictite with $95-100 \%$ ultramafite clasts. It is moderately lithified, with gravel to sand size, subrounded clasts. Near the toe of the SCL Dragovich et al. (1997) identified a fluvial lithofacies that is poorly lithified and is composed of a massive conglomerate that contains lenses of sandstone. Clasts within the Huntingdon Formation include varieties of intrusive igneous, metamorphic and volcanic lithologies. Dragovich et al. (1997) estimate the thickness of the Huntingdon Formation to range from as thin as a few 


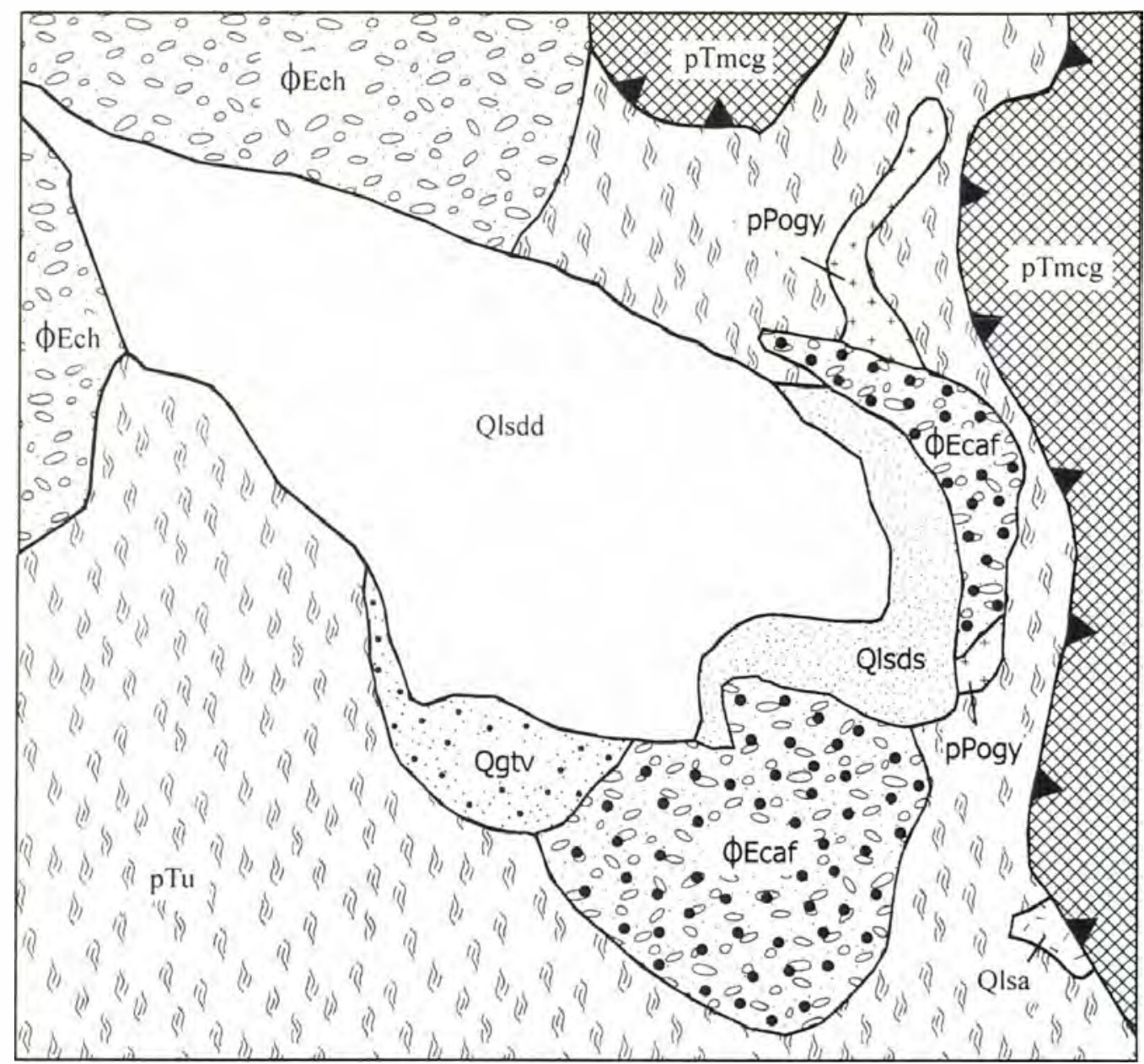

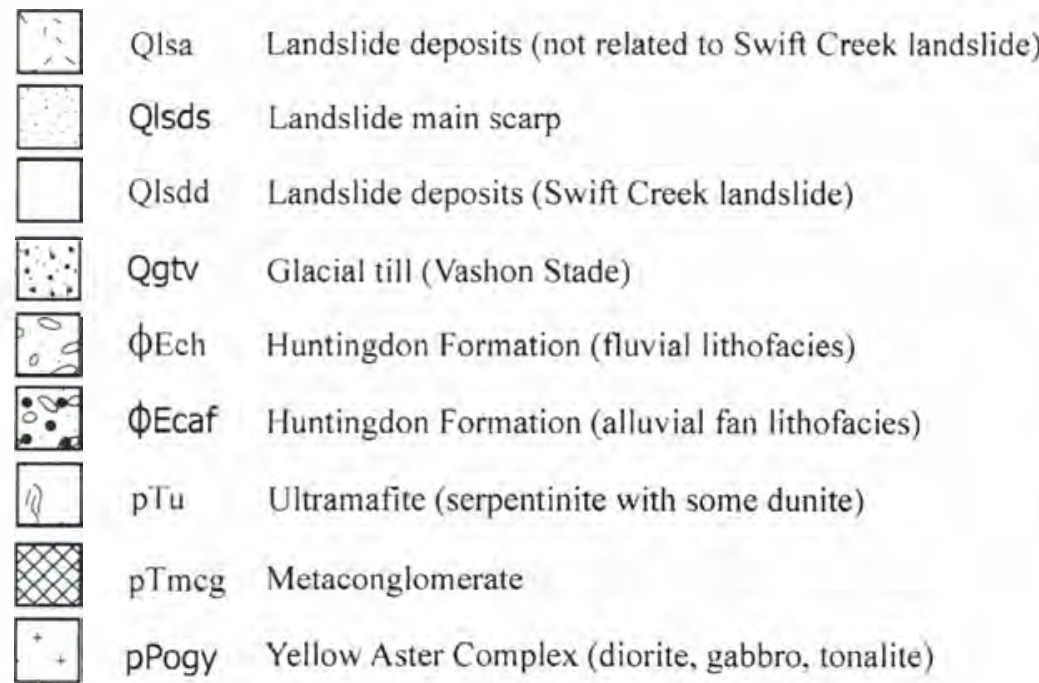
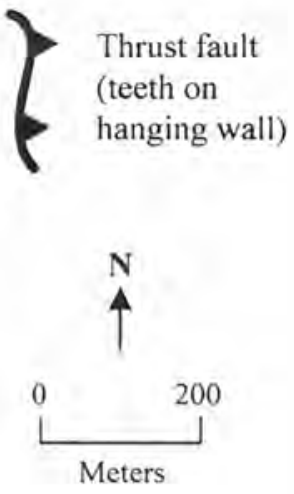

Figure 3. Geologic map of the Swift Creek landslide and surrounding area. Modified from Dragovich et al. (1997). 
centimeters to approximately 300 meters. Large, displaced blocks of the Huntingdon Formation conglomerate are located on the northern half of the SCL's unvegetated toe, while the southern part of the toe contains exclusively serpentinitic boulders.

Pleistocene glaciation deposited till within the study area (Dragovich et al., 1997). However, little glacial material can be seen in the landslide mass itself and is most abundant on the headscarp and below the modern composite fan.

Using GPS surveys, the annual rate of movement of the SCL between 2002 and 2003 was determined to be $4-5 \mathrm{~m} / \mathrm{yr}$ with shallow slumping and flowing on the toe in excess of 40 $\mathrm{m} / \mathrm{yr}$ (McKenzie-Johnson, 2004). The movement on the toe of the landslide also showed significant seasonal variation, with the greatest amount of movement occurring during the wettest months (McKenzie-Johnson, 2004).

On the landslide are numerous clay seeps, which are presumed to emanate from the underlying serpentinitic bedrock. A previous study (McKenzie-Johnson, 2004) assumed the clay from the SCL to be smectite based on the weathering of serpentinite at other landslides and on the observations that smectite is generally the initial weathering product of serpentinite (Egashira et al., 1992; Egashira et al., 2000; Rabenhorst and Foss, 1981). The soils of previously inundated fields in the Sumas River Basin, downstream from the SCL, were analyzed by Schreier et al. (1987) and found to contain halloysite, kaolinite and smectite clay. The occurrence of smectite in downstream soils, below the sediment/organic soil contact zone, suggested that it is the main weathering product of serpentinite and possibly originated in the SCL. 
Schreier et al. (1987) also found that about $15 \%$ of the fine grained material deposited on sites flooded by Swift Creek was in the form of asbestiform chrysotile with the average length of the fibers being about 1 to $3 \mu \mathrm{m}$. The serpentinitic soil samples also revealed high $\mathrm{Ni}, \mathrm{Cr}, \mathrm{Co}, \mathrm{Mn}$ and $\mathrm{Mg}$ concentrations.

\section{Regional setting}

The SCL is one of a number of bedrock-rooted, deep-seated landslides located in the Pacific Northwest. Highly weathered bedrock, steep slopes and heavy precipitation, found in the Pacific Northwest, are conditions that lead to slope failure (Duncan, 1996). More than 34 bedrock-rooted, deep-seated landslides have been found in the Chuckanut Formation of northwest WA alone (Schmidt and Montgomery, 1995, 1996). It is also estimated that approximately $10-30 \%$ of southwestern Oregon has been disturbed by slope failure, most noticeably in the Cascade and Coast Ranges (Swanston, 1988).

Sheared serpentinites are common on the west coast of North America, including the Coast Ranges of Oregon and California as well as the Klamath Mountains (Cowan and Mansfield, 1970; Page, 1968). The rugged relief and weakly consolidated, flaky serpentinite matrix are highly susceptible to mass wasting and are the causes of many landslides (Cowan and Mansfield, 1970; Lee et al., 2003). In areas of the Coast Range in Oregon that are affected by debris avalanches, the weathered serpentinitic bedrock is found to be overlain by smectite, chlorite and serpentine. Smectite, chlorite and halloysite are found on hillslopes experiencing large rotational slump and creep, and halloysite and chlorite are often found to be associated with earthflows (Istok and Harward, 1982a). 
The weathered bedrock and swelling clays make hillslopes much more susceptible to failure during precipitation events. Monitoring of landslides in the Baker Creek watershed, Klamath Mountains, Oregon, suggests that their rates and displacements are correlated to long-term rainfall rather than seasonal and annual rainfall (Swanston, 1988). However, the Six-Soldier slide, also located in the Klamath Mountains, Siskiyou National Forest, Oregon, is presumed to have failed as a result of high precipitation, with groundwater as the activating agent (Vandre, 1975).

\section{METHODS}

\section{Characterization of sediment production process}

Samples of the fine-grained material, occurring in clay seeps on the surface of the SCL, were chosen based on their differing colors and morphologies. A representative suite of 27 clay samples was collected on the landslide (Figure 4). No clay seeps were found towards the middle or top of the landslide, where soil and trees were prevalent. The mineralogical compositions of the clay seeps were determined by using a PhilipsR X-pert MPD theta-theta X-ray diffractometer with an energy dispersive Peltier cooled detector. It was run at $40 \mathrm{kV}$ and $30 \mathrm{~mA} \mathrm{Cu} \mathrm{K}$, with 1-degree divergence and anti-scatter slits and 0.2 $\mathrm{mm}$ receiving slit. Standard procedures for an oriented aggregate XRD slide, using the Millipore filter system transfer method, were followed (see Moore and Reynolds, 1997 p. 216). Each sample was analyzed three times, after it was: (1) air-dried; (2) exposed to ethalyne-glycol for one week; (3) heated to $250^{\circ} \mathrm{C}$ for two hours. 


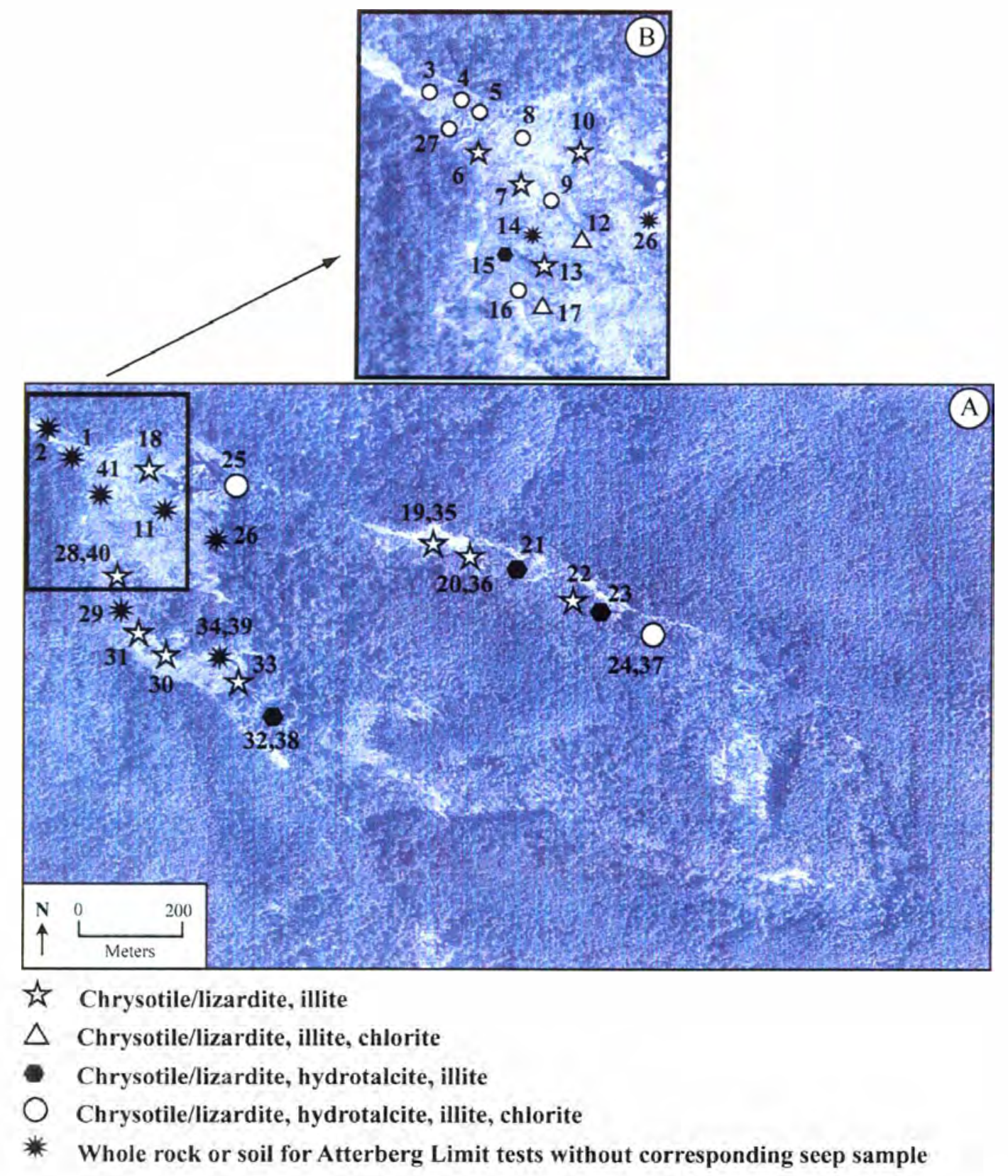

Figure 4. USGS orthophoto of the Swift Creek landslide (1998) showing sample locations collected for subsequent lab analyses. The numbers correspond to sample numbers while the symbols are based on mineral compositions determined using X-ray diffraction. Photograph (B) is an enlarged image of the toe of the landslide from photograph (A). Samples 3-10, 12, 13, 15-20, 22-25, 27, 28, 30-34 are of the $<2 \mu \mathrm{m}$ fraction found in seeps. Samples 1, 2, 11, 14, 21, 26, 29 are whole rock samples. Samples $35-41$ are bulk surface material samples taken for Atterberg Limit tests. 
The structural characteristics of the clay were determined at Western Washington University (WWU) using a Camscan Vega Scanning Electron Microscope, while the chemical composition was found using an EDAX energy dispersive X-ray spectrometer mounted on the SEM.

Whole rock analyses of the serpentinite were done at WWU using SEM-EDAX and a random powder mount on a Rigaku Geigerflex X-ray diffractometer (Moore and Reynolds, 1997). The samples were not sieved in preparation for the XRD analysis in order to ensure that the more easily weathered components were not unintentionally separated out.

Engineering properties were determined by performing Atterberg limit tests on the coarser grained material that made up the main surficial body of the landslide. The samples were chosen based on location and were taken close to several of the fine-grained sample locations (Figure 4). The liquid limit and plastic limit of 7 samples were done a total of 3 times on each sample, following the standard methodology (ASTM, 1998). The liquid and plastic limits reported for each sample are the average of the 3 trials.

\section{Discharge and suspended sediment sampling}

The suspended sediment sampling sites in Swift Creek were chosen based on accessibility, proximity to disturbances and stream channel morphology. In order to eliminate the collection of sediment produced and entrained as a result of the gravel mining and dredging operations, hydrologic measurements were taken upstream of the local creek mitigation projects (Figure 1). The sampling sites were also located where the channel was relatively straight to ensure the most accurate discharge measurements. Site A (Figure 1) 
was sampled during times of low flow when sampling and velocity measurements could be made by wading in the creek. At site B, a cable line was suspended across the width of the creek to allow measurements to be taken while suspended above the creek in a harness when high flow and large bedload prevented wading in Swift Creek.

Velocity and depth measurements were taken using the Marsh-McBirney Flowmate 2000, and discharge was calculated according to the standard USGS midsection method (US Department of the Interior Bureau of Reclamation, 2001). Suspended sediment samples were collected at two locations along the same transects as the velocity measurements. Vertically integrated samples were taken using the grab sample method (Edwards and Glysson, 1999). The shallowness of Swift Creek at both of the sampling sites prevented the use of any suspended-sediment sampler device designed by the Federal Inter-Agency Sedimentation Project. Therefore, each sample was collected using a $500 \mathrm{~mL}$ ISCO bottle. In order to ensure isokinetic sampling, a rubber stopper was placed in the bottle to cover half of the opening. During low flow, Swift Creek was not deep enough to leave an unsampled zone of 3 inches above the creek bed, as suggested by the method used. However, in order to avoid the sampling of bedload material, special care was taken not to touch the mouth of the bottle to the creek bed.

Knowing that the suspended sediment concentration increases with discharge and that a majority of the sediment is likely to be mobilized during low-frequency, highmagnitude precipitation events, sampling was increased during periods of higher precipitation (Figure 5). 


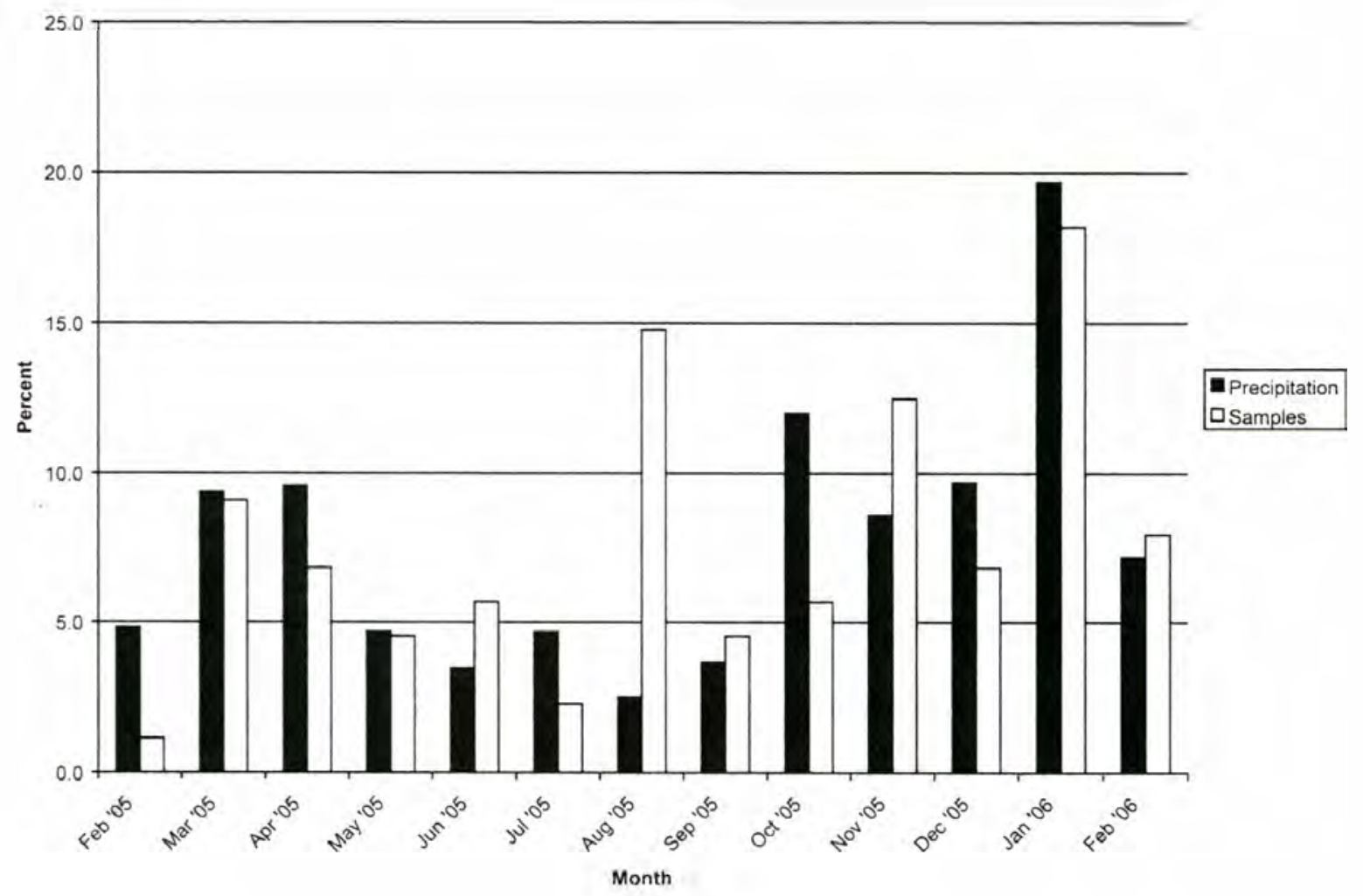

Figure 5. Comparison between percent of total precipitation that fell each month and percent of total sampling performed each month for 2005-2006. Eight out of 13 samples collected in August were on 8/28/05 in order to capture a single storm event. 


\section{Suspended sediment analysis}

The suspended sediment concentration (SSC) of each sample was determined at WWU using the standard suspended sediment concentration analytical filtration methodology (ASTM, 2000). The SSC at a given time was then taken to be the average of the two samples collected along the same transect. After the two samples yielded SSC values within $0.1 \mathrm{~g} / \mathrm{L}$ of each other for 25 of 29 separate sample sets, confidence was gained that subsequent analyses needed the collection of only one sample from Swift Creek. For quality control, replicate samples were taken along the same transect at least once out of every 10 field measurements.

The flocculating portions of the samples were analyzed using the SEM at WWU. The volumetric proportion of asbestiform chrysotile in the suspended sediment was estimated by doing a point count on three SEM images each taken at around 720 times magnification. The printed images were divided into a 19 by 25 grid consisting of approximate $1 \mathrm{~cm}^{2}$ boxes, resulting in a total of 475 intersections. Following the OSHA (2004) definition of asbestos fibers, only grains longer than $5 \mu \mathrm{m}$ and with an aspect ratio of 3:1 were counted as asbestiform chrysotile.

The Kendall's tau statistical test was applied to the collected discharge and SCC data to see if a correlation existed between the two variables. 


\section{Precipitation and SSC analysis}

A Campbell Scientific Instrument weather station with a CR510 basic datalogger was placed just above the toe of the SCL (Figure 1). Precipitation was recorded every ten minutes and ambient air temperature and soil moisture were recorded every hour.

The nonlinear functional model proposed by Güldal and Müftüoglu (2001) was modified for the limited amount of data collected during the study. It was used to predict continuous SSC for the 2005-2006 year from discrete SSC samples and a continuous precipitation record. The precipitation data downloaded from the weather station were used as the sole input into the lumped model. The memory period of the catchment was first based loosely on data analyses that suggested that there was a lag time of approximately 1 hour between peak precipitation and peak SSC and on field observations that suggested that precipitation had an effect on SSC lasting only a few hours. A cross-correlogram was then used to determine the exact memory period that would be used in the model. For this dataset, the total memory length was determined to be when the cross-correlation coefficient neared zero (Figure 6).

In order to determine the response function between SSC and precipitation, the model was applied with five different combinations of linear and nonlinear memory components for the three-hour memory period. The calibration of the model involved splitting the 88 collected SSC data points in half, where observations 1-44 were used for calibrating the model and observations 45-88 were used for testing the model. The calibration and verification periods were then reversed. 

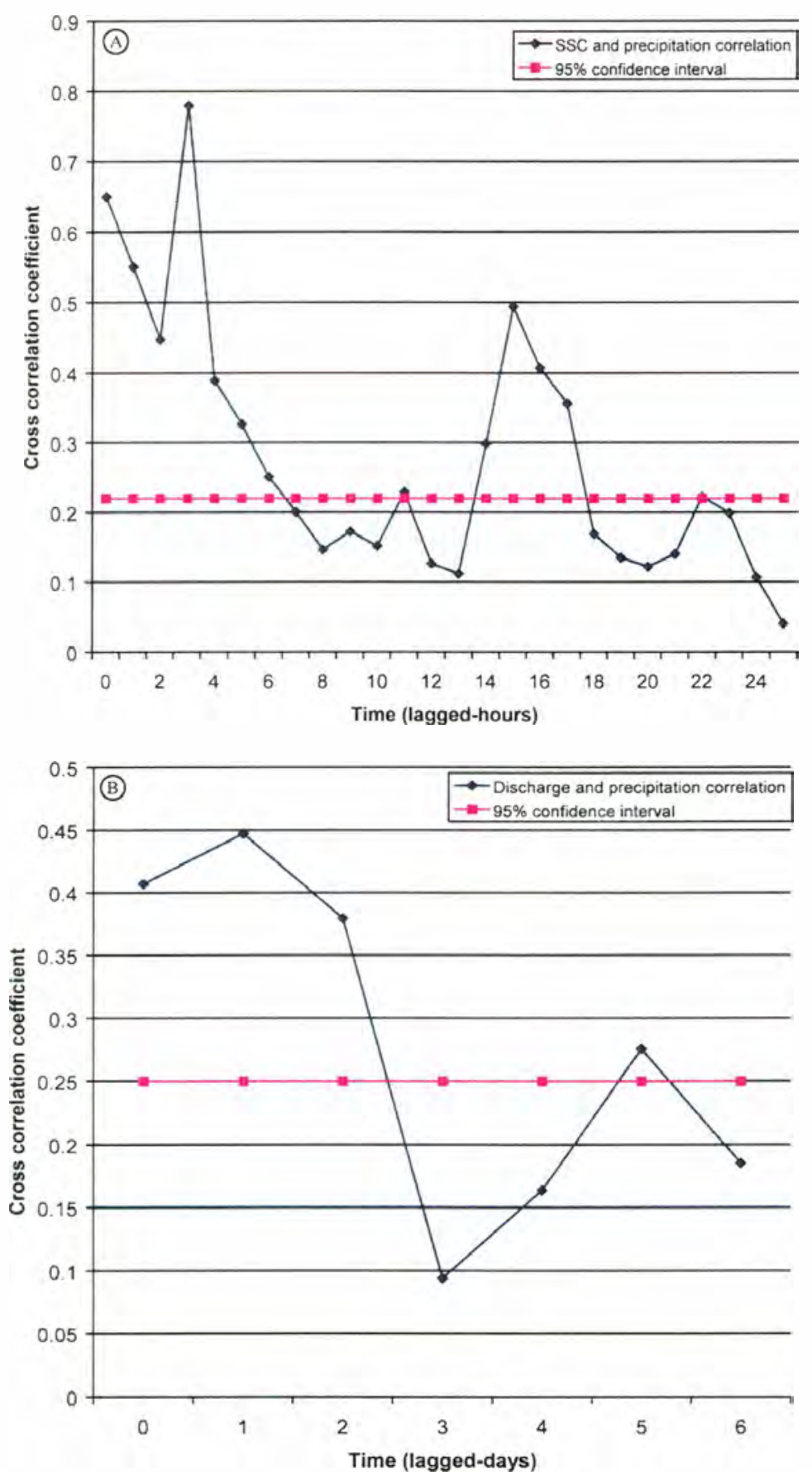

Figure 6. Correlation between (A) suspended sediment concentrations and precipitation (B) discharge and precipitation. Zero time on the $\mathrm{x}$-axis represents the current hour/day precipitation. 
The efficiency of the nonlinear functional model was evaluated based on the adjusted $\mathrm{R}^{2}$ value and on how well the descriptive statistics fit the observed data. The same procedure was used to predict continuous discharge data for the 2005-2006 year from 58 discrete discharge measurements and a continuous precipitation record. Only 58 discharge measurements were used out of the total 67 taken because the model was calibrated on daily discharge rather than hourly and could therefore only use one daily measurement for the input. If more than one discharge measurement was taken on one day, the average was used as the daily discharge.

\section{Sediment yield estimate}

An approximation of the bedload in Swift Creek for the 2005-2006 year was made by comparing channel surveys conducted by Whatcom County between the years 2003 and 2005 , and was made on estimates of material removed during dredging and construction (Kerr Wood Leidal Associates, 2004). The suspended yield was estimated from the continuous SSC and discharge predictions obtained through the application of the nonlinear functional model.

The estimates of the bedload, coupled with those of the suspended sediment, were used to determine an erosion rate for the SCL. The bulk density of the suspended material was calculated to be $1.67 \mathrm{~g} / \mathrm{L}$, assuming a porosity of $35 \%$ and a particle density of 2.58 (Gaines et al., 1997). 


\section{RESULTS}

\section{Composition of serpentinitic bedrock}

Serpentinitic whole rock samples analyzed using XRD were found to consist of chrysotile, lizardite and chlorite (Figure 7). Antigorite was dismissed as a possible constituent because of the lack of several identifying XRD peaks in the pattern (Joint Committee on Powder Diffraction Standards, 1980; Wicks and O'Hanley, 1988). Many of the d-spacings for chrysotile and lizardite overlap, making total distinction between the two serpentine minerals difficult (Joint Committee on Powder Diffraction Standards, 1980).

Elemental mapping using SEM and EDAX analyses of veined whole rock samples revealed that the veins were also made of serpentine minerals, most likely chrysotile.

Numerous rock samples collected on the landslide were found to have a green outer rim and a white inner core (Figure 8a), Through the use of XRD, the green rim was found to consist of chrysotile and lizardite (Figure $8 \mathrm{~b}$ ). The white inner core was found to be hydrogrossular garnet, chrysotile and/or lizardite, and chlorite (Figure 8c).

\section{Weathering products of serpentinite}

XRD patterns identify the clay-sized fraction found at the seeps on the SCL as being predominantly chrysotile/lizardite, with scant amounts of illite and chlorite and occasionally hydrotalcite $\left[\mathrm{Mg}_{6} \mathrm{Al}_{2}\left(\mathrm{CO}_{3}\right)(\mathrm{OH})_{16} \cdot 4 \mathrm{H}_{2} \mathrm{O}\right]$. Based on the occurrences of the 4 aforementioned minerals, the 27 clay samples taken from the surface of the landslide 


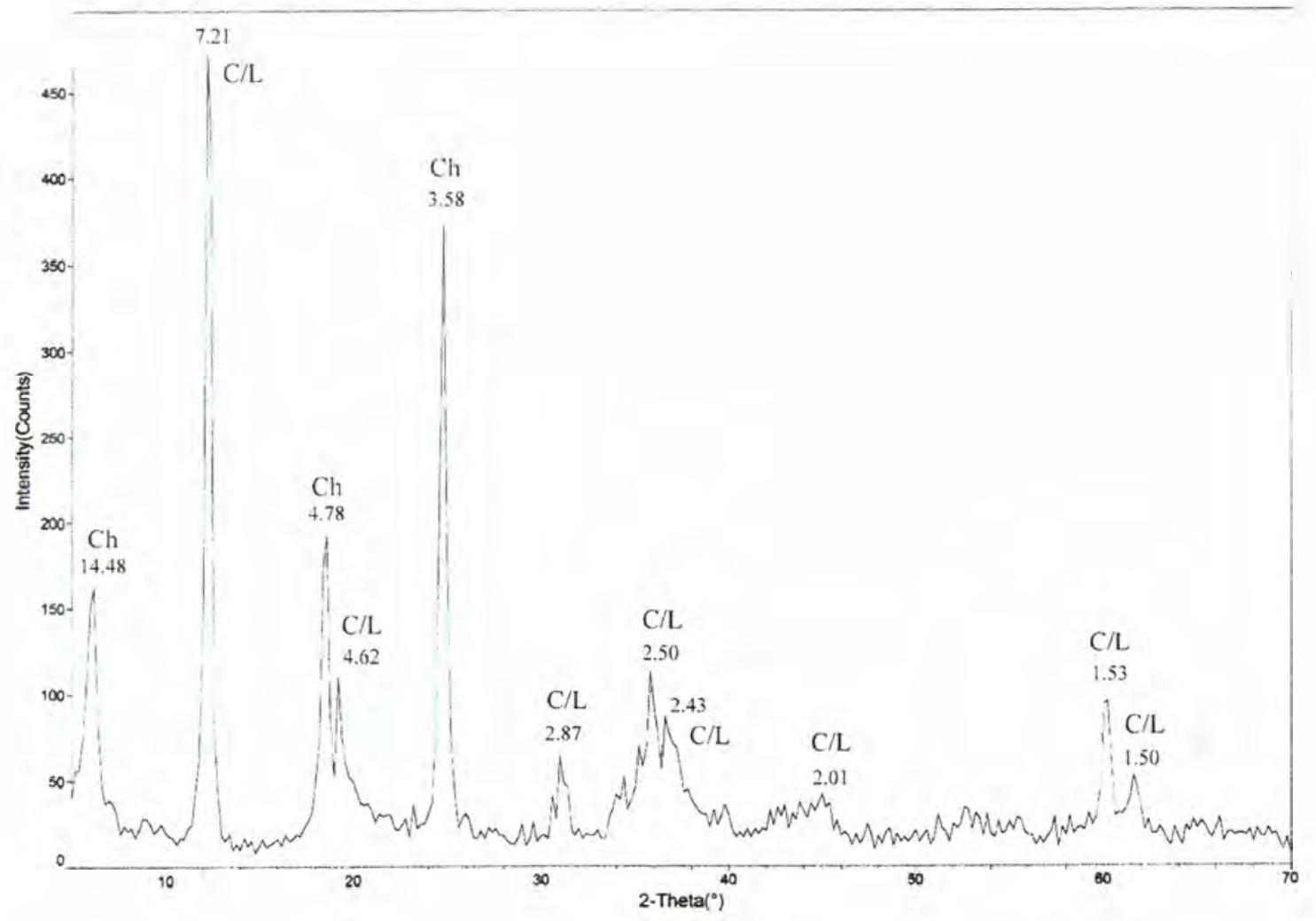

Figure 7. XRD pattern of a serpentinitic whole-rock sample found on the Swift Creek landslide. The individual peaks are labeled with their d-spacing and mineral name. $\mathrm{Ch}=$ chlorite $\mathrm{C} / \mathrm{L}=$ chrysotile/lizardite 

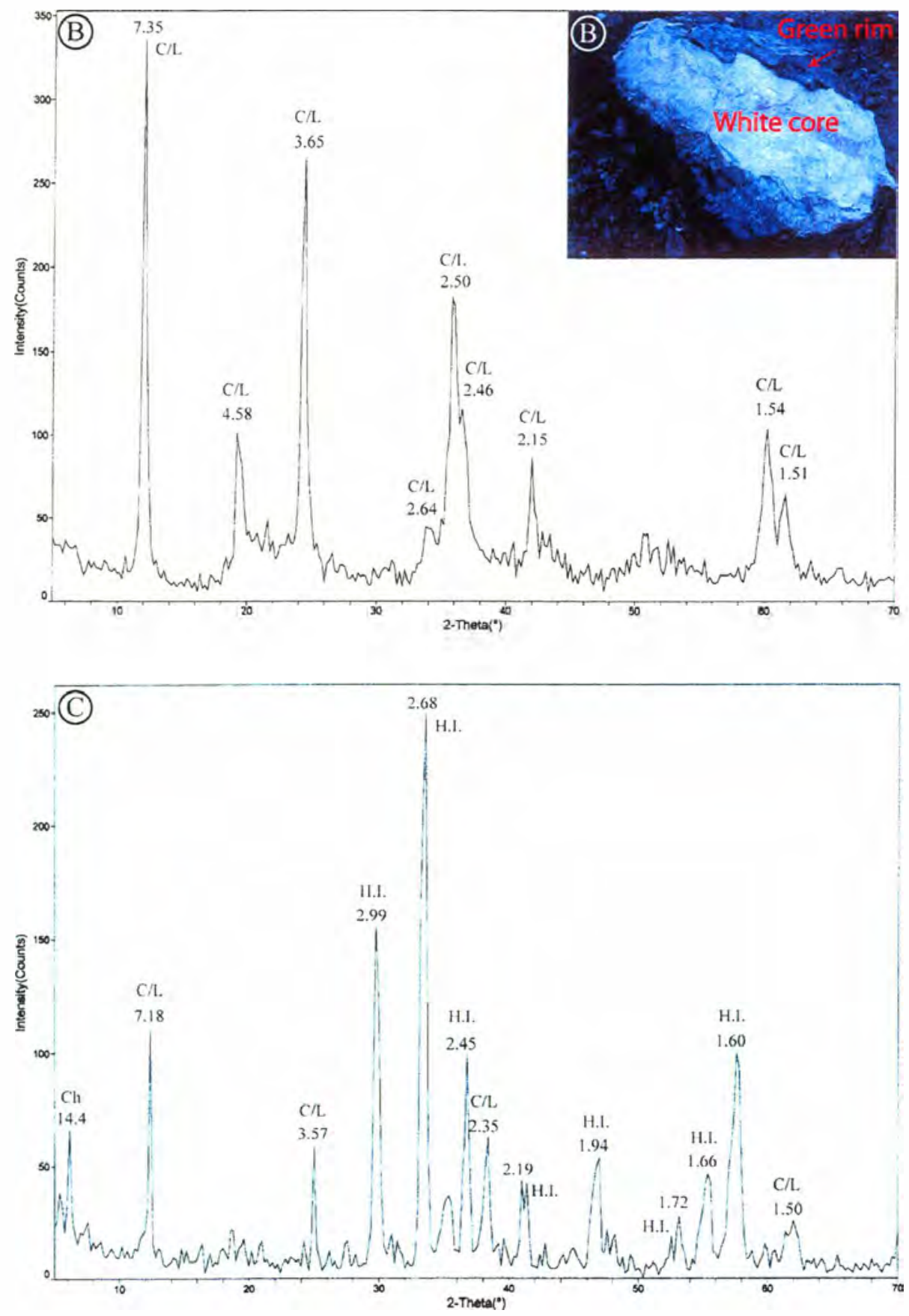

Figure 8. (A) The inset is a picture of a single serpentinitic whole-rock sample that is marked by a green outer rim and a white inner core. The two fractions were analyzed separately using XRD. (B) XRD pattern for the green outer rim. (C) XRD pattern for the white inner core. The individual peaks are labeled with their $\mathrm{d}$-spacing and mineral name. $\mathrm{C} / \mathrm{L}=$ chrysotile/lizardite; $\mathrm{Ch}=$ chlorite; H.I. = hydrogrossular intermediate garnet. 
can be separated into 4 general categories. The first XRD group contains chrysotile/lizardite and illite and characterizes samples 6, 7, 10, 13, 18, 19, 20, 22, 28, 30, 31, 33) (Figure 9a). The second group contains chrysotile/lizardite, illite and chlorite (samples 12 and 17) (Figure 9b). The third group contains chrysotile/lizardite, hydrotalcite and illite (samples 15, 21,23 and 32) (Figure 9c). The fourth group contains chrysotile/lizardite, hydrotalcite, illite and chlorite (samples $3,4,5,8,9,16,24,25,27$ ) (Figure 9d). While the XRD patterns were similar for all the inclusive samples in a particular category, there were variances in the peak heights.

SEM examination of the sand-sized fractions of the samples revealed serpentine grains splintering apart, with individual fibers of chrysotile breaking off (Figure 10a).

The term "clay" can refer to either a particle grain size of less then $2 \mu \mathrm{m}$, regardless of composition, or to a group of aluminous silicate minerals that have layered, sheet-like crystal lattices. Under the SEM, the fine-grained samples were observed to be predominantly fibrous in habit rather than platy. Individual fibers had an average length of about $2 \mu \mathrm{m}$ (Figure 10b). In comparison, the very few platy minerals observed were assumed to be lizardite or chlorite based on their platy structure and the XRD patterns. Therefore, SEM observations made of the fine-grained samples taken from the landslide revealed that while the grains are clay-sized, overall, they do not possess clay mineralogy.

The XRD patterns of the main surface material, samples 36,38 and 40 contained not only chrysotile/lizardite \pm illite, but also the mineral sjogrenite $\left[\mathrm{Mg}_{6} \mathrm{Fe}_{2} \mathrm{CO}_{3}(\mathrm{OH})_{16} \cdot 4 \mathrm{H}_{2} \mathrm{O}\right]$, which is a dimorph of pyroaurite. 

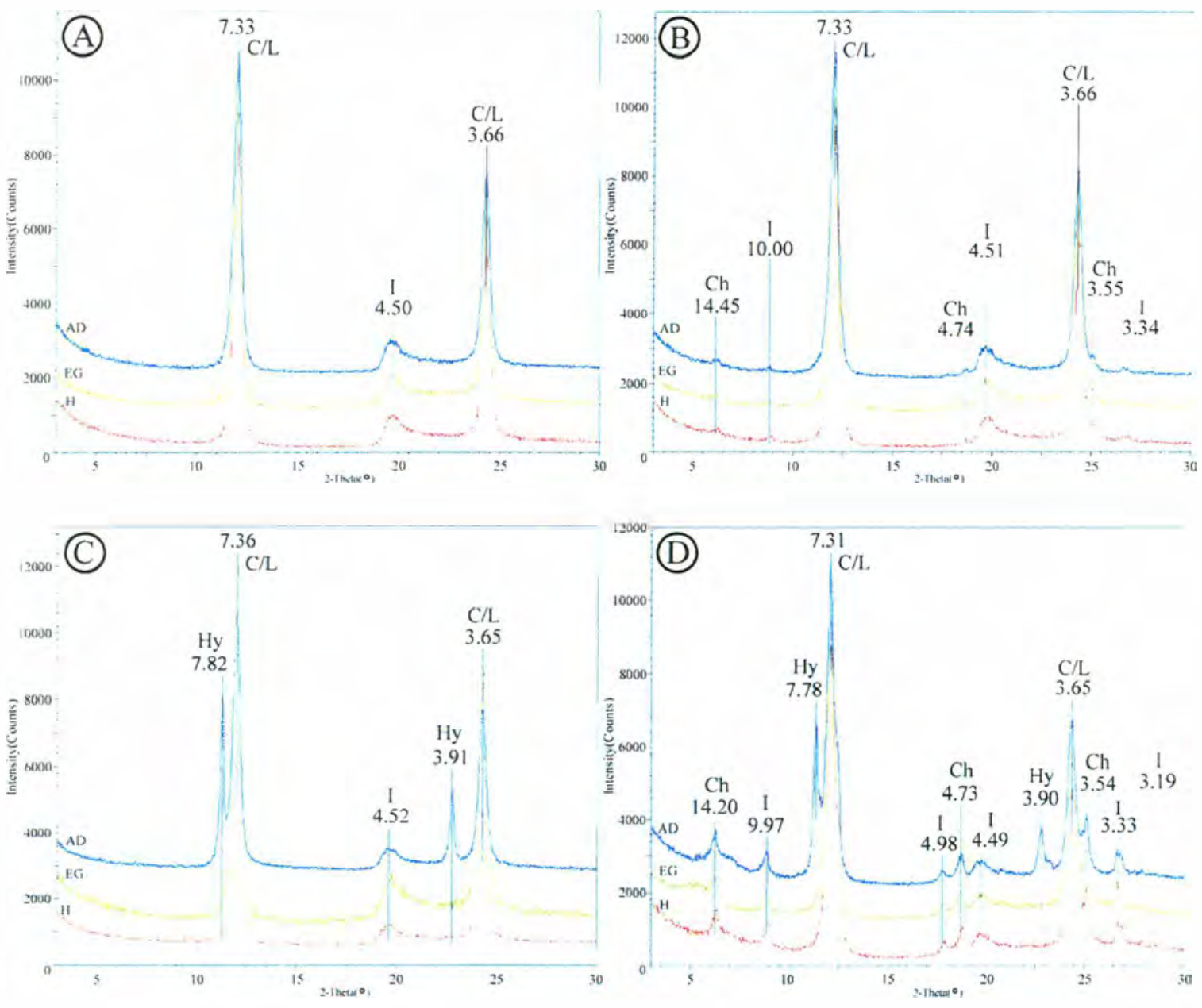

Figure 9. XRD patterns showing the four categories of mineral compositions that could be used to explain each of the 27 fine-grained samples $(<2 \mu \mathrm{m}$ fraction). The individual peaks are labeled with their $\mathrm{d}$-spacing and mineral name. $\mathrm{C} / \mathrm{L}=$ chrysotile/lizardite; $\mathrm{I}=$ illite; $\mathrm{Ch}=$ chlorite; Hy = hydrotalcite. Each graph (A,B,C,D) has 3 superimposed patterns for the same sample in order to show the 3 different stages that each sample underwent during the analysis. $\mathrm{AD}=$ air dried; $\mathrm{EG}=$ ethylene-glycol; $\mathrm{H}=$ heated. 

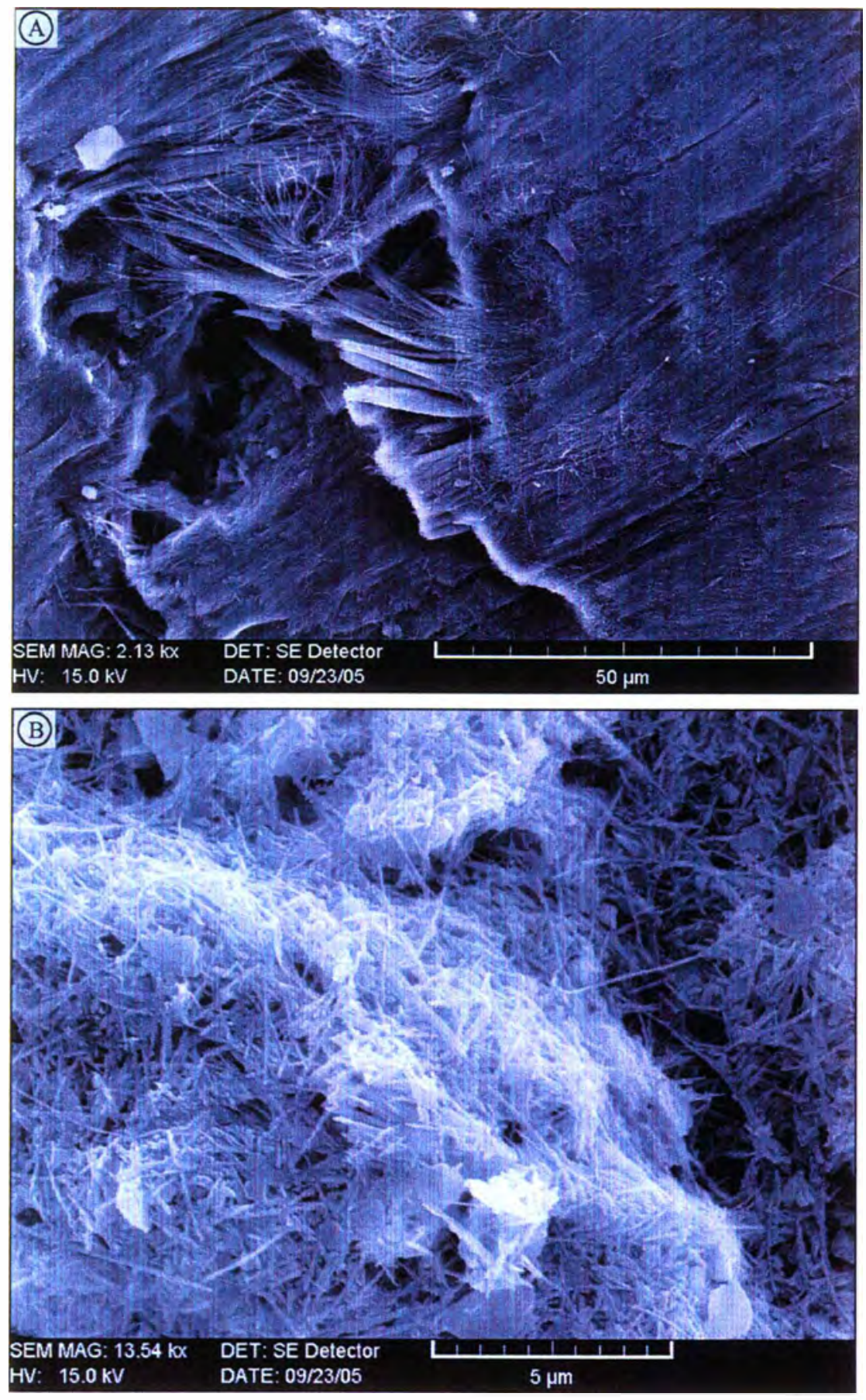

Figure 10. (A) SEM image of a serpentine grain from sample 4, found as a seep on the SCL. Notice the individual chrysotile fibers disaggregating from the serpentine grain. (B) SEM image of sample 3 found as a seep on the SCL. Notice the abundance of elongated fibers (chrysotile) and the few platy minerals (lizardite and/or chlorite). 


\section{Engineering properties of SCL material}

Atterberg Limit tests performed on the main mass material on the surface of the landslide resulted in a plastic limit (PL) range of $26 \%$ to $36 \%$, a liquid limit (LL) range of $26 \%$ to $43 \%$ and a plastic index (PI) range of $0 \%$ to $16 \%$. Sample 36 was deemed to be nonplastic because the PI was negative.

\section{Suspended Sediment Concentration}

$\mathrm{XRD}$ analyses of the suspended sediment in Swift Creek show that it is composed primarily of serpentine minerals (Figure 11). Point counts performed on SEM images of suspended sediment samples demonstrate that at least $50 \%$ of the suspended sediment is asbestoform chrysotile.

\section{Relationship between SSC, discharge and precipitation}

The highest suspended sediment concentration was not coeval with the highest discharge based on several discharge and SSC measurements taken on 8/28/05 (Figure 12). Rather, the peak concentrations occurred approximately one hour before the peak discharges. On $1 / 11 / 06$, when an identical sampling strategy was employed, the peak concentration was found to occur at least 1.5 hours prior to the maximum discharge. An absolute lag time is unknown between the two variables for that day, because the lack of daylight prevented the continuation of sampling to the point where a decline was observed in the discharge curve. 


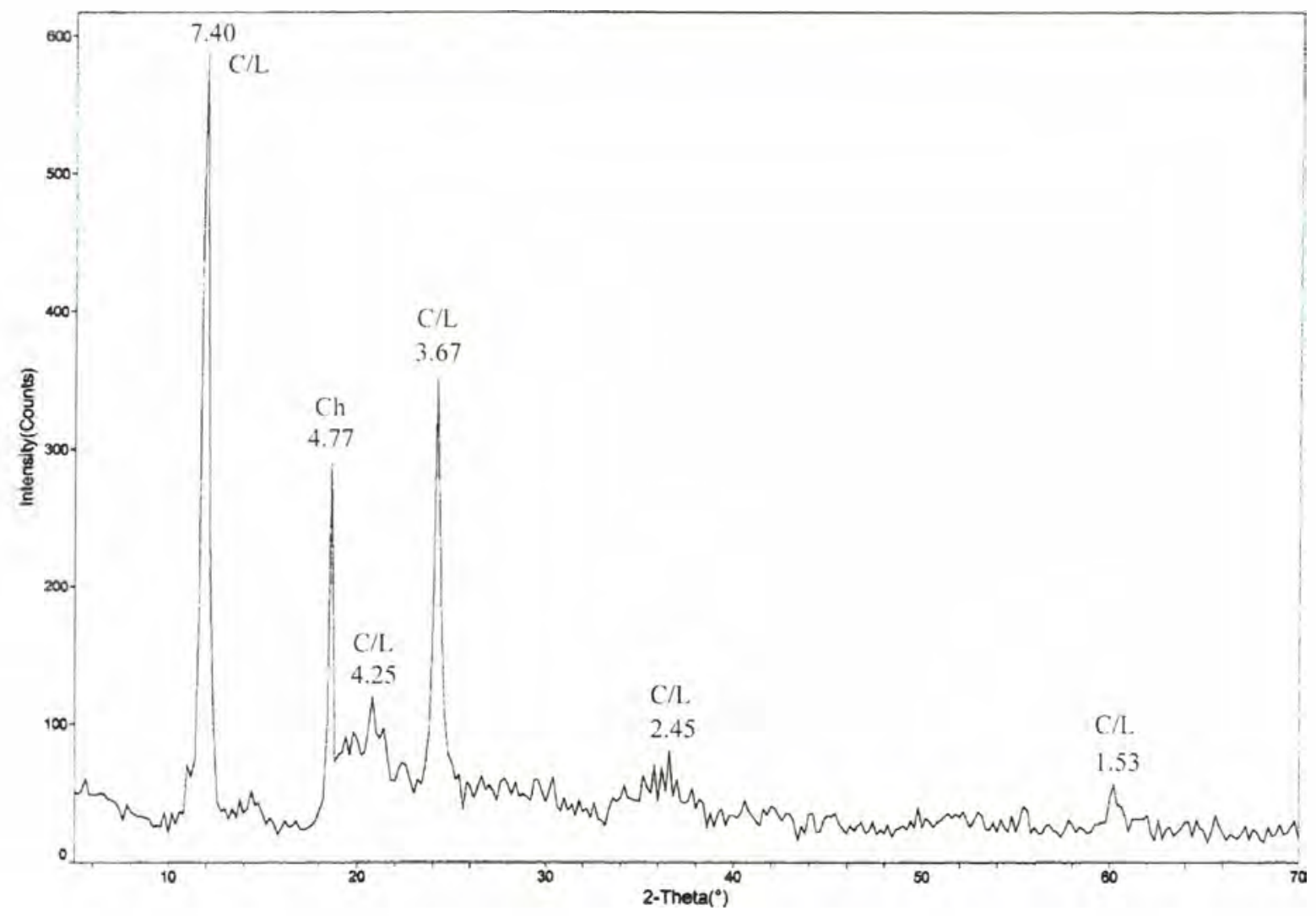

Figure 11. XRD pattern of suspended sediment from Swift Creek. The individual peaks are labeled with their $\mathrm{d}$-spacing and mineral name. $\mathrm{C} / \mathrm{L}=$ chrysotile/lizardite. 

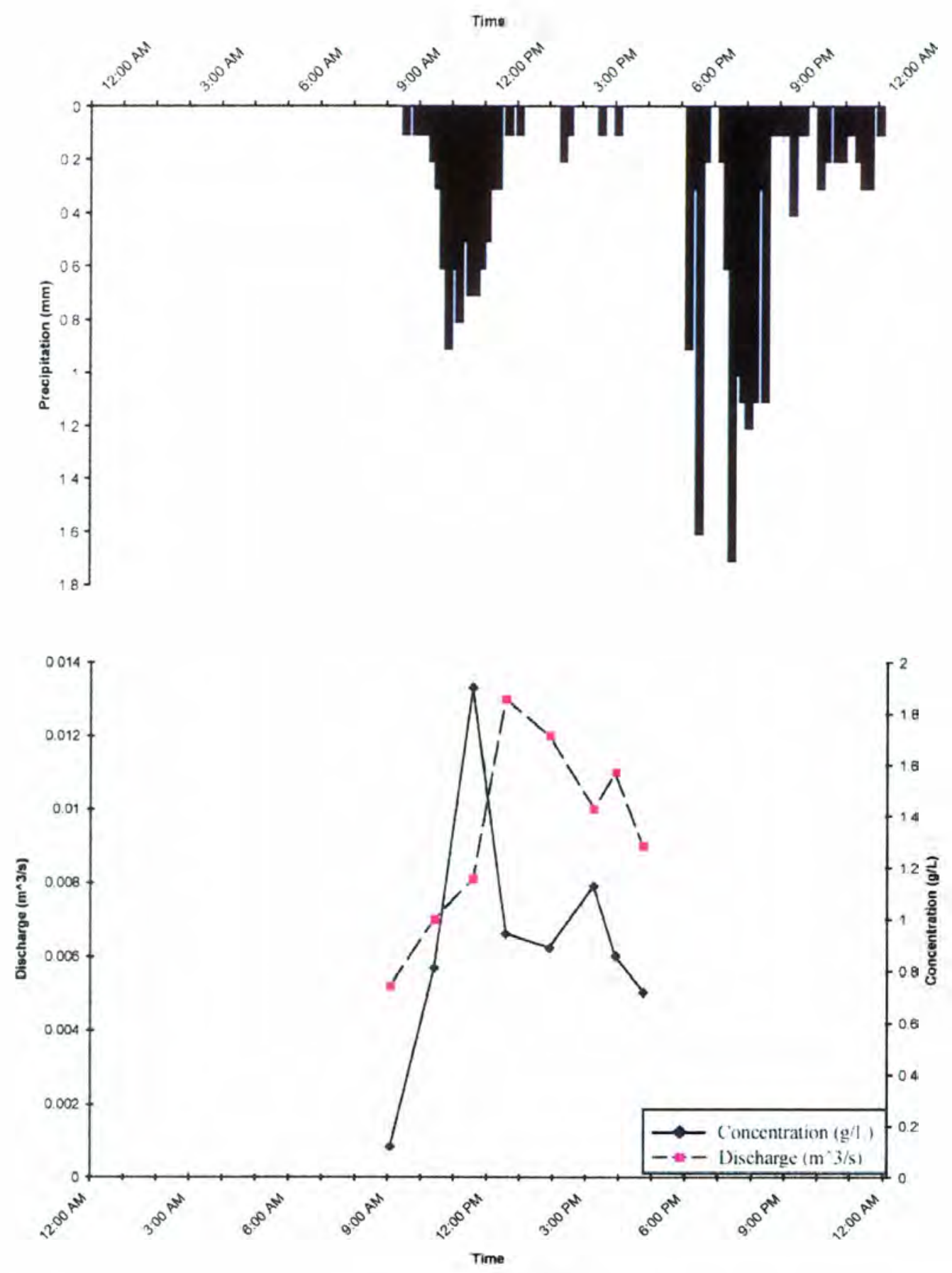

Figure 12. Relationship between precipitation, suspended sediment concentration and discharge for 8-28-05. The eight discrete discharge and SSC measurements are connected with lines to help visualize the data, not to suggest continuity. 
The peak discharge measurement was also found to have a lag time of a little less than two hours in relation to the precipitation (Figure 12).

Kendall's tau statistical test was applied to the discharge and corresponding SSC values to see if there was a correlation between the two variables. By applying the test to all of the values collected during 2005-2006, it was found that overall, the tau correlation was 0.44 and the p-value was $1.87 \times 10^{-7}$. Testing for seasonality led to a tau correlation of 0.63 and a p-value $3.18 \times 10^{-3}$ for the winter; a tau correlation of 0.66 and p-value of $2.61 \times 10^{-4}$ for spring; a tau correlation of $6.06 \times 10^{-3}$ and p-value of 0.97 for summer; and a tau correlation of 0.33 and a p-value of 0.02 for fall (Figure 13). With the summer values excluded from the dataset because of no correlation between the discharge and SSC values, the resulting tau correlation was 0.51 and a p-value of $8.94 \times 10^{-8}$.

During the sampled time between 2005-2006, the total precipitation collected by the Campbell Scientific weather station was $182.4 \mathrm{~cm}$. Approximately $57 \%$ of that precipitation fell during nighttime hours when sampling was deemed to be unsafe and was not conducted.

\section{Sediment yield and erosion rate}

Using the predicted continuous SSC and discharge values for 2005-2006 generated by the model, the total suspended sediment yield was estimated to be approximately 910 $\mathrm{t} / \mathrm{km}^{2} / \mathrm{yr}$. That number, coupled with the estimated bedload, 17,600 $\mathrm{t} / \mathrm{km}^{2} / \mathrm{yr}$ (Kerr Wood Leidal Associates, 2004), resulted in an estimated total yield of $18,530 \mathrm{t} / \mathrm{km}^{2} / \mathrm{yr}$. The erosion rate for the whole Swift Creek watershed was calculated to be $11 \mathrm{~mm} / \mathrm{yr}$. On the 

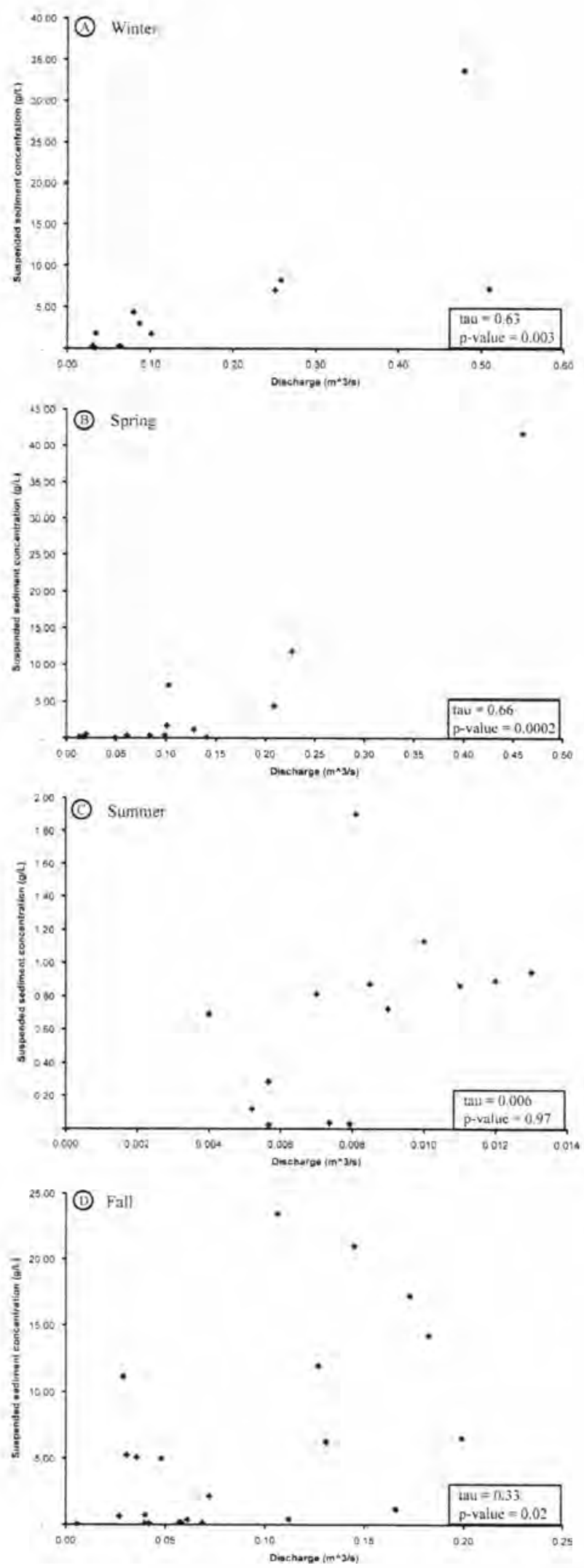

Figure 13. Correlation between SSC and discharge during the different seasons.

(A) winter (B) spring (C) summer (D) fall 
SCL alone, the erosion rate is approximately $158 \mathrm{~mm} / \mathrm{yr}$ and just on the unvegetated toe of the SCL it is $950 \mathrm{~mm} / \mathrm{yr}$.

\section{DISCUSSION}

\section{Serpentinite - rodingite}

Boulders containing a green serpentine outer rim and a white inner core composed mainly of hydrogrossular intermediate garnet have been found on the SCL and downstream on the composite fan. Hydrogrossular intermediate garnet $\left[\mathrm{Ca}_{3} \mathrm{Al}_{2} \mathrm{Si}_{2} \mathrm{O}_{8}(\mathrm{OH})_{4}\right]$ is a Ca-rich silicate that is often found in association with rodingites. Rodingites are calcium-rich rocks that form through metasomatism during the process of serpentinization. They can form from numerous types of rocks, such as basalt, gabbro or graywacke, that have come into contact with an ultramafic rock by means of deposition, intrusion or faulting ( $\mathrm{O}^{\prime}$ Hanley, 1997). During serpentinization, $\mathrm{Ca}$ is leached out of the ultramafic rock because the newly formed serpentine minerals are not able to incorporate the $\mathrm{Ca}$ into their structures. The $\mathrm{Ca}$ is therefore concentrated in the fluid where it can be added to the rodingite protolith through metasomatism (O'Hanley, 1997). One possible rodingite protolith is the gabbro of the Yellow Aster Complex, which is in contact with the pre-Cretaceous serpentinite just northeast and east of the SCL (Figure 3). The presence of rodingite in the serpentinite of Sumas Mountain is consistent with the discovery by Norgard (1970). 


\section{Weathering of serpentinitic bedrock}

The landslide debris derived from the serpentinitic bedrock is composed predominantly of highly weathered and sheared serpentine. Serpentinitic boulders several meters in diameter, located on the southern part of the toe of SCL, can easily have layers stripped and whole sections broken apart by hand. Rocks ranging in size from a few centimeters to nearly 0.5 meter in diameter crumble in place under the slightest applied pressure (Figure 14). An explanation for the rapid in-situ rock disintegration, which also takes place in the New Idria Formation near Coalinga, CA, is put forth by Mumpton and Thompson (1966) and Yokota et al. (2000). Brucite, $\left[(\mathrm{Fe}, \mathrm{Mg})(\mathrm{OH})_{2}\right]$, is a common accessory mineral in serpentinite and forms primarily as a by-product of serpentinization. During serpentinization, ultramafic rocks react with ocean water and olivine is hydrated during an exothermic process giving rise to serpentine minerals according to the following reactions (Moore et al, , 2001):

$$
\begin{aligned}
& 2 \mathrm{Mg}_{2} \mathrm{SiO}_{4}+3 \mathrm{H}_{2} \mathrm{O}=\mathrm{Mg}_{3} \mathrm{Si}_{2} \mathrm{O}_{5}(\mathrm{OH})_{4}+\mathrm{Mg}(\mathrm{OH})_{2} \\
& \text { Mg-olivine chrysotile/lizardite brucite } \\
& 34 \mathrm{Mg}_{2} \mathrm{SiO}_{4}+51 \mathrm{H}_{2} \mathrm{O}=\mathrm{Mg}_{48} \mathrm{Si}_{34} \mathrm{O}_{85}(\mathrm{OH})_{62}+20 \mathrm{Mg}(\mathrm{OH})_{2} \\
& \text { Mg-olivine antigorite brucite }
\end{aligned}
$$

Mumpton and Thompson (1966) found that brucite, which is a major constituent of the New Idria serpentinite, is present in the fresh, unweathered serpentinite but is absent from the weathered uppermost $10 \mathrm{~m}$. The absence of brucite from the weathered serpentinite 


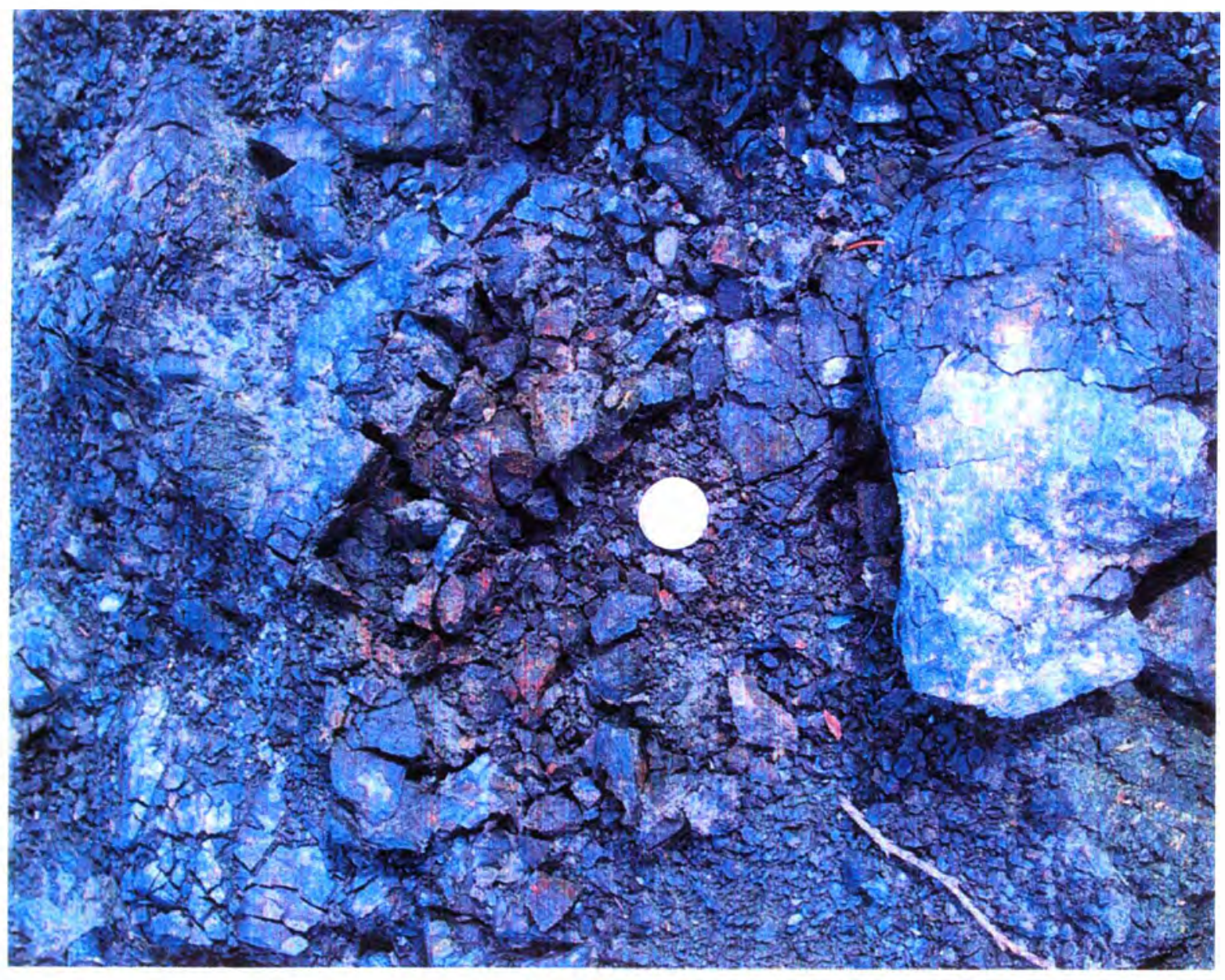

Figure 14. Serpentinitic boulder displaying in-situ disintegration. 
is explained by its instability in air and its reaction with carbon dioxide-rich ground water, which dissolves the brucite and leaves behind coalingite $\left[\mathrm{Mg}_{10} \mathrm{Fe}_{2} \mathrm{CO}_{3}(\mathrm{OH})_{24} \cdot 2 \mathrm{H}_{2} \mathrm{O}\right]$ and other dark-brown amorphous iron oxides (Mumpton and Thompson, 1966). The oxidation and dissolution reaction of iron-rich brucite to coalingite under dry conditions can be shown by:

$\begin{array}{cccc}\left(\mathrm{Mg}_{10} \mathrm{Fe}_{2}\right)(\mathrm{OH})_{24} & \underset{\text { Brucite }}{\stackrel{\mathrm{O}_{2}+\mathrm{CO}_{2}}{\longrightarrow}} \stackrel{\left(\mathrm{Mg}_{10} \mathrm{Fe}_{2}\right) \mathrm{CO}_{3}(\mathrm{OH})_{24} \cdot 2 \mathrm{H}_{2} \mathrm{O}+\text { or } \mathrm{Mg}_{6} \mathrm{Fe}_{2} \mathrm{CO}_{3}(\mathrm{OH})_{16} \cdot 4 \mathrm{H}_{2} \mathrm{O}}{\mathrm{C}_{2} \mathrm{O}} \quad \text { Coalingite } & \text { Pyroaurite }\end{array}$

In wet conditions, both coalingite and brucite dissolve resulting in the formation of hydromagnesite $\left[\mathrm{Mg}_{4}\left(\mathrm{CO}_{3}\right)_{3}(\mathrm{OH})_{2} \cdot 3 \mathrm{H}_{2} \mathrm{O}\right]$ and iron oxides, which are precipitated from ground waters. The serpentine rocks therefore are easily weathered and break into pieces due to the dissolution of brucite, which can comprise up to $20 \%$ of natural serpentinites (Moore et al., 2001).

The cause for the disintegrating rocks on the SCL is inconclusive. There is no direct evidence to support reactions (1) or (2) ever taking place at the SCL. However, the presence of iron oxides, which could have formed from the dissolution of brucite and coalingite, might suggest the presence of brucite in the Sumas Mountain serpentinite. Even if brucite was present, it would most likely be found in very small quantities due to the expected volumetric relationship between brucite and chrysotile, and the amount of chrysotile found.

The presence of the iron-oxides in the SCL samples could be due to the iron-oxide impurities that are common in serpentinites (Istok and Harward, 1982b). The SCL rocks are 
also heavily fractured and veined with chrysotile, which could provide conduits for water, expediting the weathering and disintegration processes.

\section{Sediment produced from bedrock weathering}

In the unvegetated portions of the landslide, where the landslide debris derived from the serpentinitic bedrock is exposed, the serpentine is flaky and unconsolidated. SEM examinations show that a large portion of that material is composed of chrysotile. Chrysotile originating from serpentinitic bedrock is common on the west coast of North America. It is found primarily in the ultramafic rocks of the Sierra Nevada foothills, the Coastal Range, from Santa Barbara to the Oregon border, the Klamath Mountains of northwest California and in the mountains of north-central California (Bales et al., 1984; Hayward, 1984). It is the dominant serpentine mineral in a sheared serpentinite lens in the Franciscan Formation on the Tiburon Peninsula, California (Page, 1968) and forms the greatest commercial chrysotile deposits located in the New Idria Formation near Coalinga, California (Bales et al., 1984). Hayward (1984) discovered that every water sample taken from a drainage basin containing serpentinitic bedrock in California contained chrysotile asbestos. The only known source in all of those cases was the natural erosion of the serpentinite.

$\mathrm{XRD}$ analyses have confirmed that the clay-sized fraction on the SCL contains chrysotile/lizardite, chlorite, illite and hydrotalcite in various combinations. SEM images show that the chrysotile is a direct weathering product of the serpentinite (Figure 10a). Due to the weak van der Waals bonds holding the chrysotile fibers together, they are easily 
separated into fibrils (Ross and Nolan, 2003) which then disaggregate from the highly sheared serpentinitic bedrock and form a major component of the landslide material. Previous work done on clay fractions of soils derived from serpentinite has unanimously concluded that the clay-fraction serpentine is inherited from the parent material (Graham et al., 1990). The clay seeps sampled on the landslide are almost exclusively composed of $<$ $2 \mu \mathrm{m}$ chrysotile, suggesting that the clay seeps originate from the weathered serpentinite.

\section{Chrysotile as slip surface material}

The failure surface of the SCL was modeled using Janbu's Method of Slices and determined to be located $80-120 \mathrm{~m}$ deep in weathered serpentinite (McKenzie-Johnson, 2004). That supposition remains unconfirmed because the SCL cannot be cored. However, the idea that it is rooted in weathered serpentine is reasonable considering that serpentine clay is the result of faulting and weathering and forms the slip surface of other landslides rooted in serpentinite (Yokota et al., 2000). Regardless, the failure surface can act as a conduit for water. The hydraulic head of the serpentine clay slurry at the failure surface is sufficient to make it rise through fractures in the bedrock, resulting in the many seeps found on the surface of the landslide (Figure 15). Knowing the mineralogical makeup of the seeps could give insight into the failure mechanism of the SCL.

The seeps, as shown by XRD, are composed almost entirely of chrysotile.

Chrysotile has a very low coefficient of friction $(\mu)$. Experiments conducted by Moore et al. (2001) showed that at $10 \mathrm{MPa}$ fluid pressure and $11 \mathrm{MPa}$ normal stress, chrysotile had a $\mu$ of 0.2 ; while brucite, lizardite and antigorite had $0.3 \mu, 0.42 \mu$ and 0.43 respectively, 

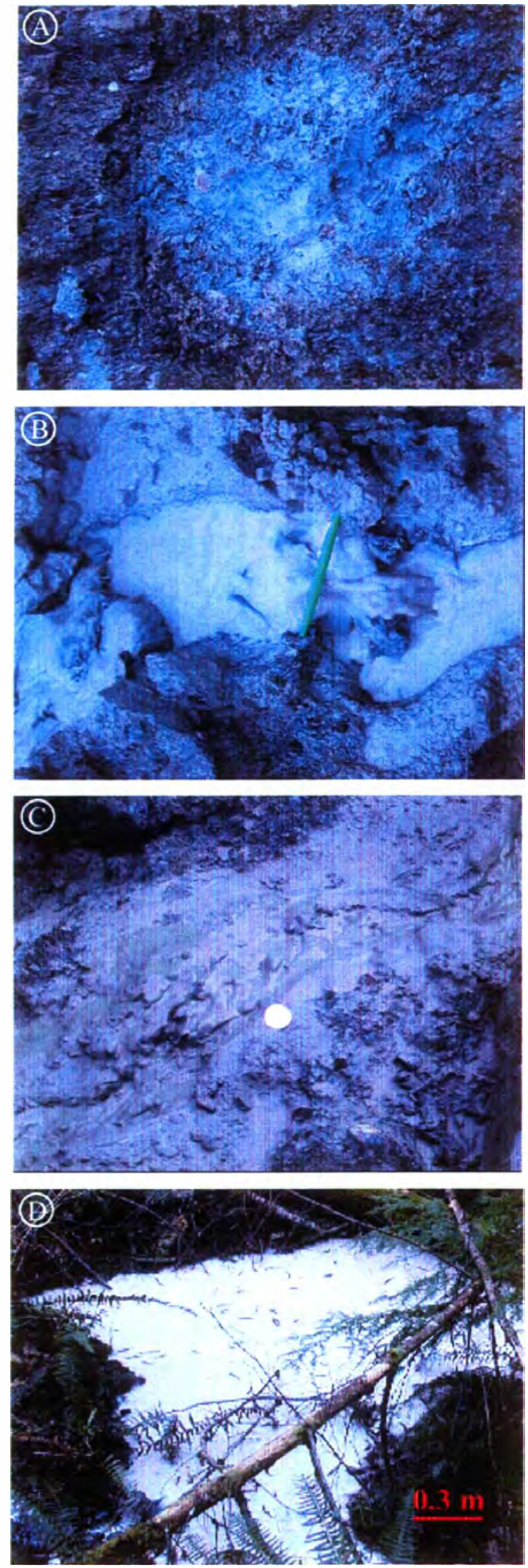

Figure 15. Examples of different clay colors and morphologies that occur as seeps on the SCL. In A and C, quarters are used for scale.

(A) Blue-gray clay, can be rolled into a "snake"

(B) Gray clay, smooth texture

(C) Brown clay, gritty texture

(D) White clay, with the consistency of "stirred yogurt", found as pools up to approximately one foot in depth 
Chrysotile and lizardite are also velocity weakening, meaning that with an increase in the velocity of the sliding rate, $\mu$ decreases even more (Moore et al., 1997).

Sheet-silicate minerals usually exhibit low frictional strength for one of several reasons: because of the presence of interlayer water, as in the swelling clays; the presence of adsorbed water which occurs with chrysotile; or the weakness of the interlayer bonds, such as with brucite (Moore et al.,2001). Chrysotile is able to adsorb unusually large amounts of water, increasing its volume by several percent and decreasing its coefficient of friction by at least a factor of three (Moore et al.,1997). The adsorbed water could create a thin film on the crystal surfaces, reducing the stress needed during shearing to slide one grain past another. The frictional strength is thus affected much in the same way as with interlayer water (Moore et al., 2001).

The seep composition, coupled with the adsorbtion capability of chrysotile and its low coefficient of friction, contributes to the plausibility that the slip surface of the SCL is made up of chrysotile as the weathering product of the serpentinitic bedrock, and not smectite as previously thought.

\section{Absence of smectite on SCL}

Schreier et al. (1987) conducted a study on three soil profiles from agricultural fields inundated in 1975 by Swift Creek. They noted that the soil profiles were covered by asbestos-rich sediments from the 1975 flood and estimated that approximately $15 \%$ of the surface sediments were chrysotile asbestos with an average length of $1-3 \mu \mathrm{m}$. They also discovered the presence of smectite and possibly chlorite below the sediment/organic soil 
contact zone and suggested that they were the weathering products of the chrysotile that was initially there,

Lee et al. (2003) and Yokota et al. (2000) observed that smectite is generally the most abundant constituent of the clay-sized fraction in serpentinitic soils and can be derived from chlorite transformation or from serpentine weathering. In a study on the weathering of ultramafic rocks at Mt. Prinzera, Italy, Venturelli (1997) found that the saprolite overlying the serpentinite contained among other mineral assemblages, lizardite, chrysotile, clays and chlorite. He concluded that the lizardite, chlorite and chrysotile were relics of the serpentinite and that the clays, identified by XRD to be smectite or a mixed layer of smectite-chlorite, were a result of chemical weathering.

Serpentine minerals are not stable in acidic environments and the exposure to such conditions results in the alteration of serpentine to other minerals. During the weathering process of serpentine minerals, $\mathrm{Mg}$ is leached out of the silicate structure (Schreier et al., 1987). Smectite clays are formed when $\mathrm{Mg}$ and $\mathrm{Si}$ are leached out of the easily-weathered serpentinite as dissolution products of serpentine weathering or from the solid-state transformation of chlorite (Lee et al, 2003).

The XRD patterns show that there is no smectite clay present on the surface of the landslide. Atterberg Limit tests suggest that there was no smectite present in the bulk surface material on the landslide either. According to Rahn (1996), soils with a small plasticity index (PI), around $5 \%$, are very sensitive to moisture and will change from a semisolid to a liquid with a slight increase in moisture content. Soils with a very high PI, > $35 \%$, can accommodate a large amount of water and therefore would have a high swell 
capacity. Having such a high PI would indicate that smectite was present. On the SCL, the PI averaged about $6 \%$, which places it among the sensitive soils.

Istok and Harward (1982b) noted that smectite was a weathering product of serpentinite but found that smectite, chlorite and serpentine were present within poorly drained soils of toeslopes and only serpentine and chlorite were found in well-drained upland soils of ridgetops and sideslopes. They explain this distribution by postulating that the dissolution products of the serpentine, which are highly mobile, are removed from upland positions and concentrated in lower landscape positions.

$\mathrm{XRD}$ analyses showed that there is no smectite present in the clay-sized fractions on the surface of the SCL; however the studies conducted by Schreier et al. (1987) found smectite downstream of the SCL. Therefore, if the same drainage conditions observed by Istok and Harward (1982b) existed in the study area, then the SCL is well drained. Field observations of the SCL during the summer months have shown that what little rain falls during that time is quickly absorbed into the landslide material. However, the true drainage capacity of the SCL is unknown.

The absence of smectite on the SCL could also be due to the lack of acidic conditions necessary for smectite formation on the SCL, which are present in the downstream soils.

\section{Produced sediment to suspended sediment}

Water samples collected in this study show that chrysotile makes up at least $50 \%$, by volume, of the suspended load in Swift Creek. During periods when the stream's velocity is 
insufficient to transport the chrysotile fibers downstream, the particles settle out and form a thin $(1-5 \mathrm{~mm})$ surficial layer on the stream's banks immediately adjacent to the current waterline. Channel sections exposed due to downward channel erosion have revealed a few small, discontinuous lenses of fine-grained material suggesting that the chrysotile is mostly stored temporarily in the channel, until re-suspended by rising water.

High values of SSC occurred infrequently (Figure 16). Fifty-seven percent of the time, the south fork of Swift Creek had a SSC less than $1.0 \mathrm{~g} / \mathrm{L}$. Only $1 \%$ of the time did it contain its highest SSC of $41.64 \mathrm{~g} / \mathrm{L}$. A major portion of the total suspended sediment in Swift Creek is transported during large, infrequent runoff events, similar to results found for other rivers (Beylich and Gintz, 2004; Emmett, 1975; Farnsworth and Milliman, 2003; Walling et al, 1992).

During the sampled time in 2005-2006, Swift Creek (drainage basin of $7.1 \mathrm{~km}^{2}$ ) had SSC values ranging from $0.0 \mathrm{~g} / \mathrm{L}$ to $41.64 \mathrm{~g} / \mathrm{L}$ with an average predicted SSC of $1.91 \mathrm{~g} / \mathrm{L}$. For comparison, during the 1996-1998 water years, the Skokomish River near Potlatch, WA (drainage basin of $588 \mathrm{~km}^{2}$ ) and the Nooksack River at North Cedarville, WA (drainage basin of $1,525 \mathrm{~km}^{2}$ ) had SSC values ranging from 0.085 to $0.44 \mathrm{~g} / \mathrm{L}$ (Embrey and Frans, 2003). During storm events, the Skokomish had a maximum SSC of $1.5 \mathrm{~g} / \mathrm{L}$ and the Nooksack had a maximum SSC of $3.2 \mathrm{~g} / \mathrm{L}$.

The Eel River, which drains the Coast Range of northwest California, gains a high sediment load as a result of numerous streamside landslides (Lisle, 1990). The Eel River has an average SSC of $3 \mathrm{~g} / \mathrm{L}$ (Lisle, 1990) and was observed to have an average SSC of 28 $\mathrm{g} / \mathrm{L}$ for 3-days as a result of a storm event (Farnsworth and Milliman, 2003). The amount of 


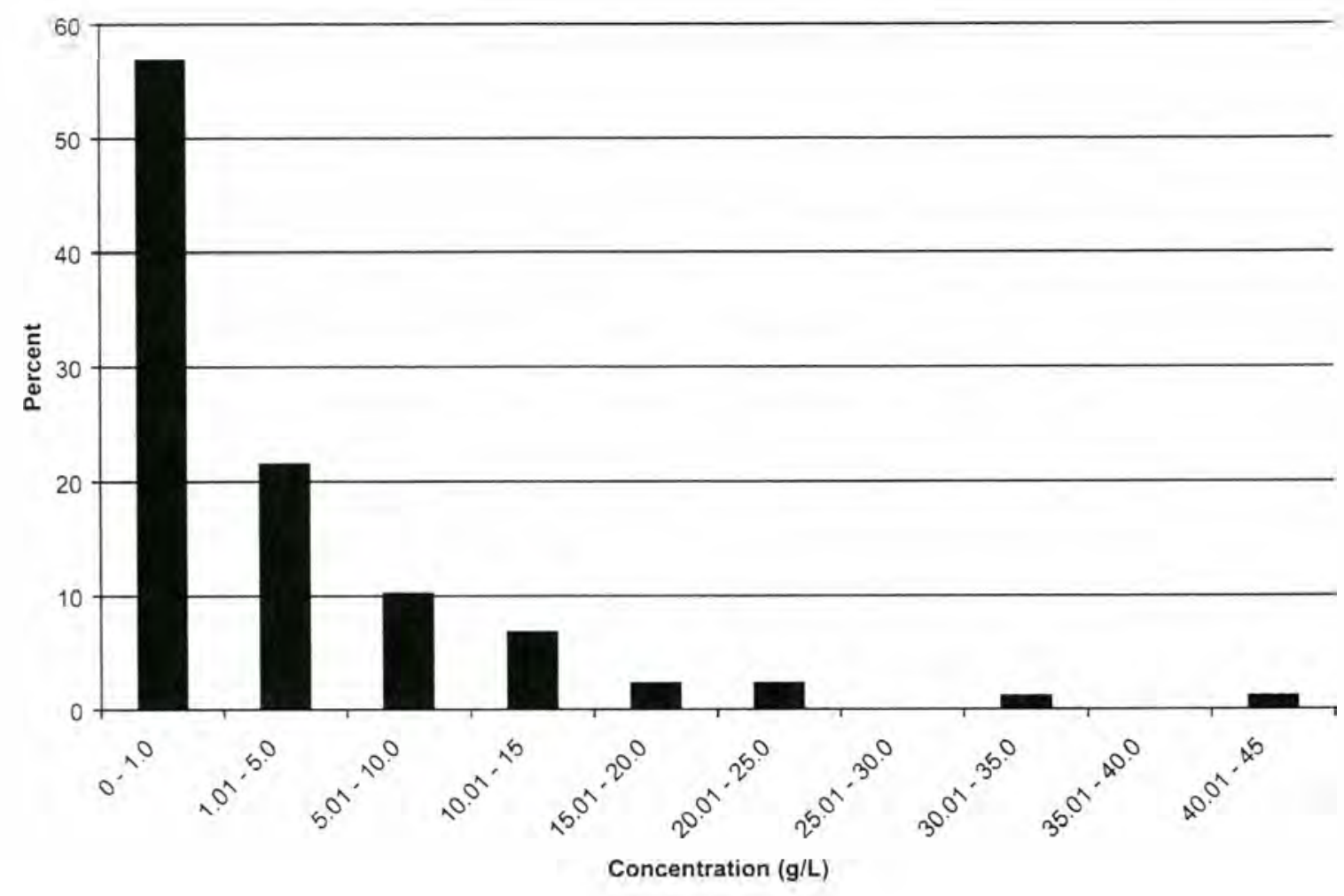

Figure 16. Percentage of the total sampled SSC values that fell within certain concentration ranges 
precipitation and the intensity of that storm event were not reported. Among comparably sized rivers (drainage basin of $9,390 \mathrm{~km}^{2}$ ), the Eel River has the highest recorded average suspended sediment yield per drainage area $\left(1,720 \mathrm{t} / \mathrm{km}^{2} / \mathrm{yr}\right)$ in the conterminous United States; not affected by volcanic eruptions or glaciers (Lisle, 1990). That is almost twice the $910 \mathrm{t} / \mathrm{km}^{2} / \mathrm{yr}$ predicted for Swift Creek.

\section{Relationship between discharge, SSC and precipitation}

The total precipitation for the SC watershed, as measured by the Campbell Scientific Instrument weather station from $2 / 28 / 05$ to $2 / 28 / 06$ was $182.4 \mathrm{~cm}$. That is $21 \%$ higher than the $143.5 \mathrm{~cm}$ reported by the Clearbrook Weather Station during the same time period, which in turn, is higher than the 75 -year annual average precipitation of $117.2 \mathrm{~cm}$. The Clearbrook Weather Station is a National Climatic Data Center that is located about $9 \mathrm{~km}$ to the northwest of the SCL at an elevation of around $20 \mathrm{~m}$. The elevation of the weather station on the SCL is approximately $120 \mathrm{~m}$. The precipitation lapse rate is therefore $39 \mathrm{~cm}$ of rain per $100 \mathrm{~m}$ of elevation. The difference in measured precipitation between the two weather stations suggests a significant orographic effect in the study area.

Both SSC and discharge showed seasonality in their relationships to precipitation intensity (Figure 17). During the summer months, both values remained close to zero despite the $16-22 \mathrm{~mm} /$ day rain events. With very little precipitation occurring during the summer, Swift Creek becomes an intermittent stream at the lower reaches. What little suspended sediment is transported in Swift Creek during this time is most likely the result of re-suspension of sediment in the channel and raindrop impacts on the exposed landslide toe. 
During the fall, winter and spring months, the greatest increases in discharge and SSC were observed to occur during high-intensity, low-duration rain events (Figure 17).

\section{Relationship between discharge, SSC and soil moisture}

During the summer months, not only do portions of Swift Creek become dry, but the SCL material becomes relatively dry as well (Figure 18), capable of absorbing water before reaching its saturation point. Therefore, due to the increased infiltration capabilities in the catchment, relatively large precipitation events can occur without causing a drastic change in the SSC. For instance, similar measurements of precipitation were observed on August $28^{\text {th }}, 2005$ and November $25^{\text {th }}, 2005$ of $22.4 \mathrm{~mm}$ and $25.8 \mathrm{~mm}$, respectively (Figure 18). However, during the August storm event, the SSC remained under $1.0 \mathrm{~g} / \mathrm{L}$, while during the November storm event, the SSC was $21.0 \mathrm{~g} / \mathrm{L}$. That high value could be a reflection of the increased infiltration capabilities of the SCL in the summer or simply that Swift Creek was transport limited during the summer.

During the wetter months, between late September and early June, the base-flow in Swift Creek increases as a result of ground-saturation (Figure 18) and increased runoff. The observation that the greatest increases in discharge and SSC occurred during high-intensity, low-duration rain events (Figure 17), could be because during high intensity storms, much of the precipitation turns into overland flow. It is the sheet and rill erosion resulting from the overland flow that is the major agent in the production of suspended sediment. 

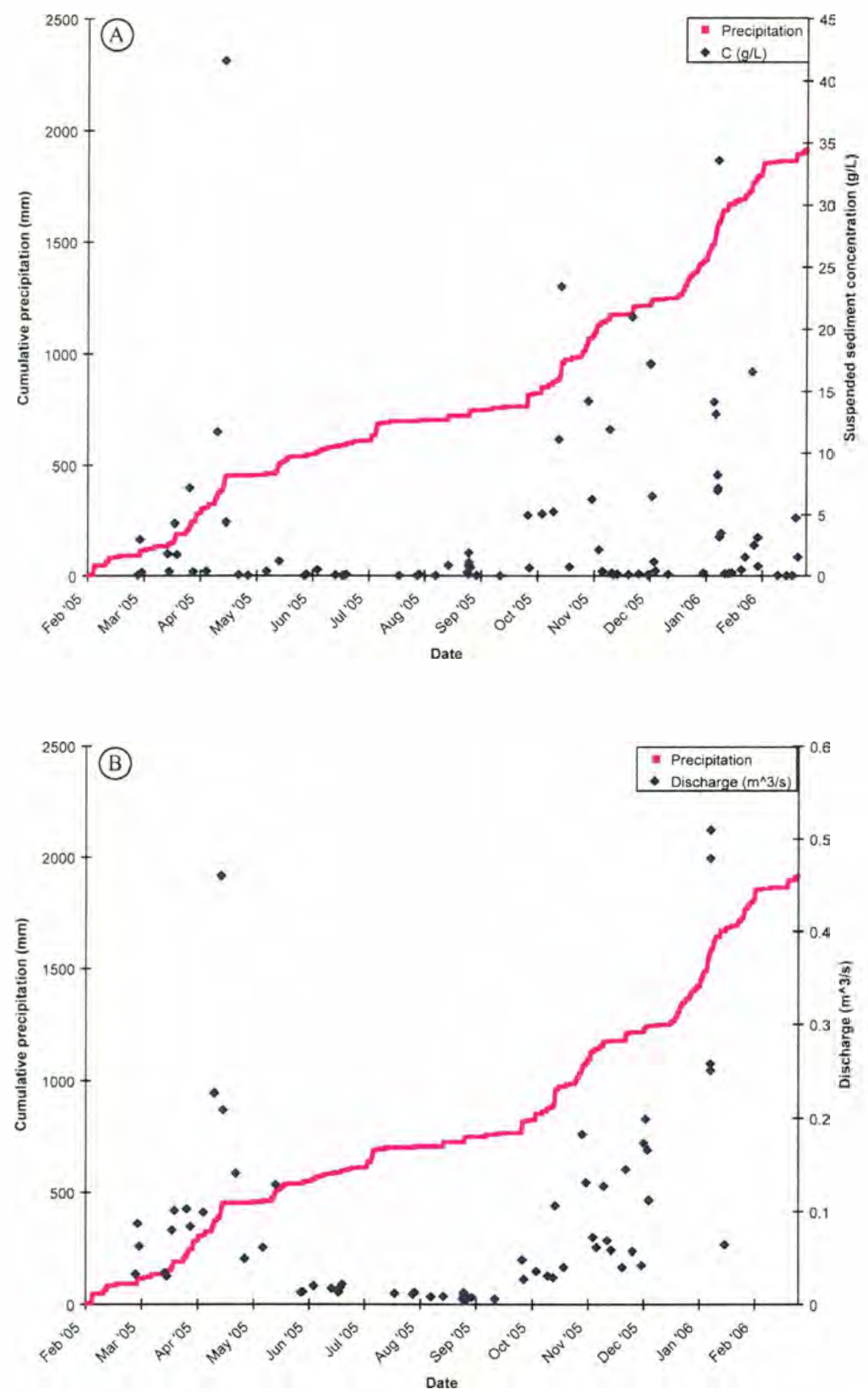

Figure 17. Relationship between precipitation and (A) discharge and (B) SSC during 20052006. Note that the precipitation is cumulative hourly precipitation. The slope of the line represents rainfall intensity. 
(A)
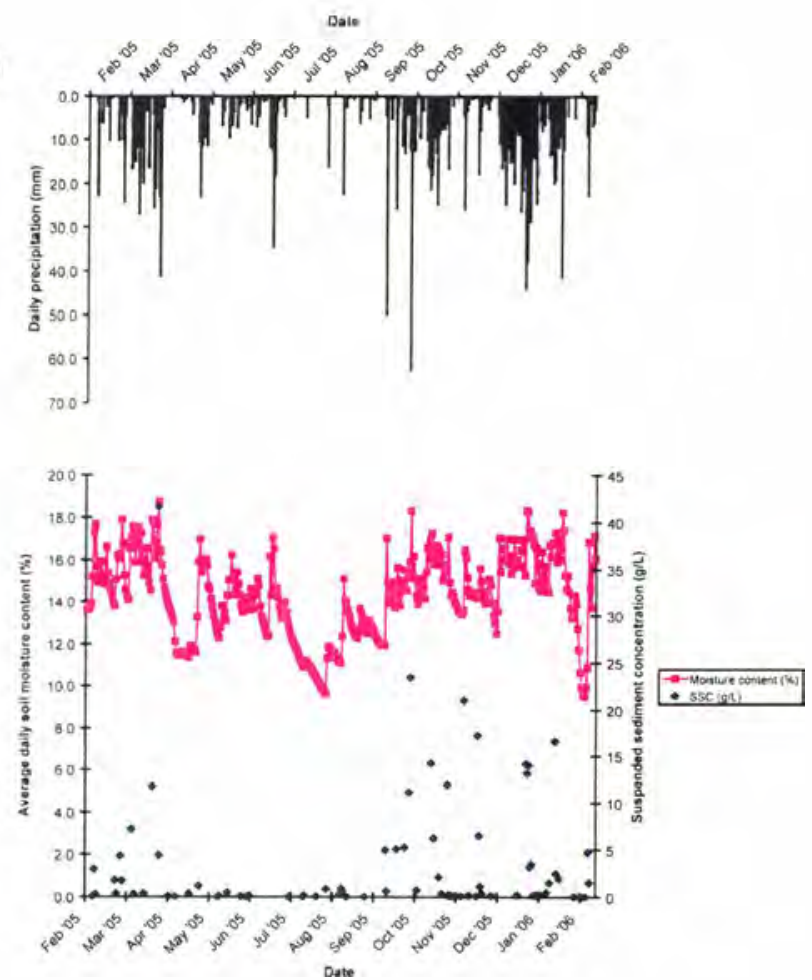

(B)
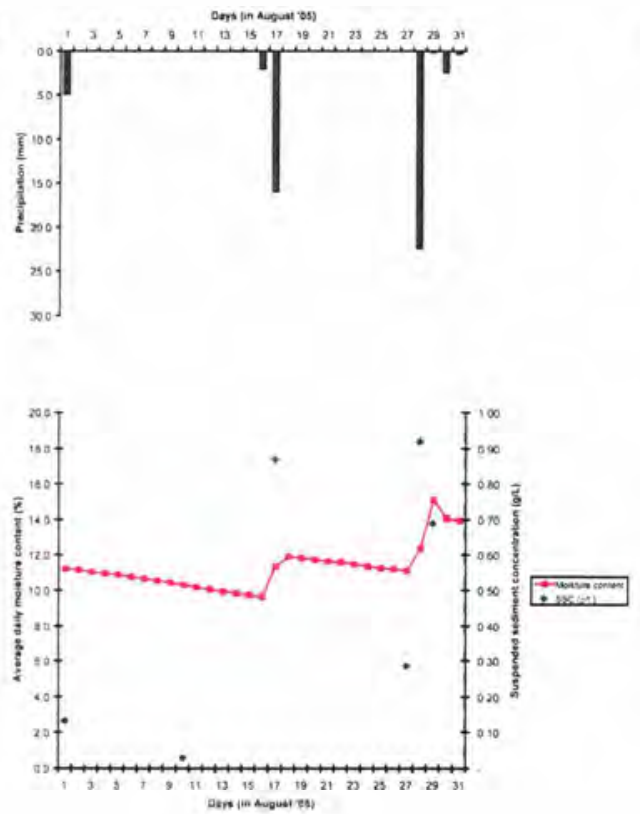

(C)
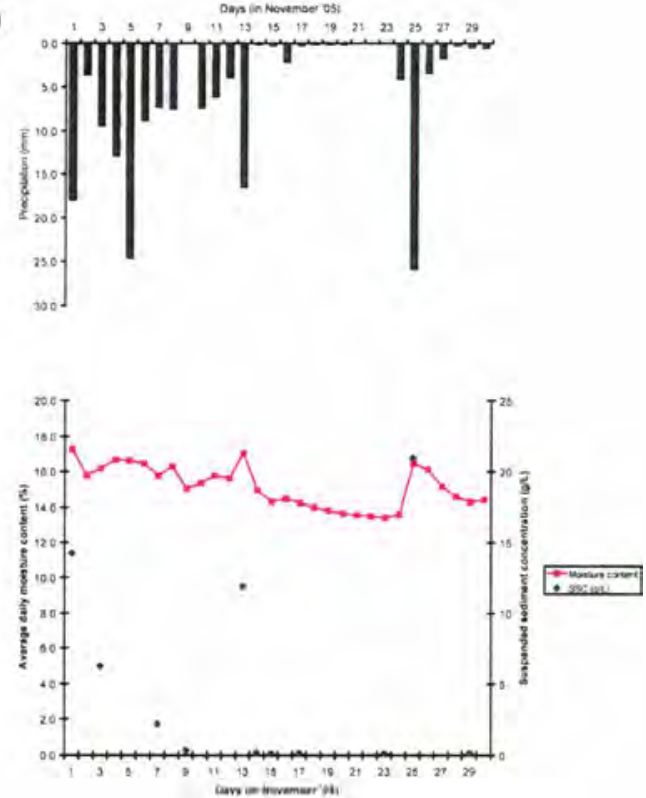

Figure 18. Relationship between SSC, soil moisture and precipitation for (A) 2005-2006 (B) August, 2005 (C) November, 2005. B and C are details of A. 


\section{Evaluation of the nonlinear functional model}

The nonlinear functional model was not a good predictor of SSC or discharge (Figure 19). It over-predicted both the SSC and discharge, by as much as $4.6 \mathrm{~g} / \mathrm{L}$ and 0.1 $\mathrm{m}^{3} / \mathrm{s}$ respectively, during the summer of 2005 because that is when the intermittent creek is transport-limited and recharges directly to the groundwater. The model assumes a constant base-flow.

The major divergence between the predicted and observed values for the SSC occurred during times of relatively higher suspended sediment concentrations, where the model significantly under-estimated the values. It under-estimated the SSC during the fall and winter months by an average of $9.5 \mathrm{~g} / \mathrm{L}$ and as much as $30.1 \mathrm{~g} / \mathrm{L}$ on April 16 , 2005. Perhaps a sudden sediment influx from the SCL (i.e., debris flow) caused a drastic increase in the SSC that the nonlinear functional model had no means of predicting based on previous patterns. For discharge, the model under-predicted at most $0.1 \mathrm{~m}^{3} / \mathrm{s}$ during the fall of 2005 and over-predicted by an average of $0.02 \mathrm{~m}^{3} / \mathrm{s}$ during the winter of 2005 .

One reason that the model failed to accurately predict discharge and SCC was the low sampling density. The dataset was divided in half in order to both calibrate and test the model. With relatively few data points to begin with, the model was limited in its predicting capabilities.

Another explanation is that the model is based on the assumptions of time invariance of the catchment and uniform spatial distribution of precipitation (Güldal and Müftüoglu, 2001). It is reasonable to assume that the latter assumption was not violated because the Swift Creek catchment is small, with an area of only $7.1 \mathrm{~km}^{2}$. Therefore, it is unlikely that 

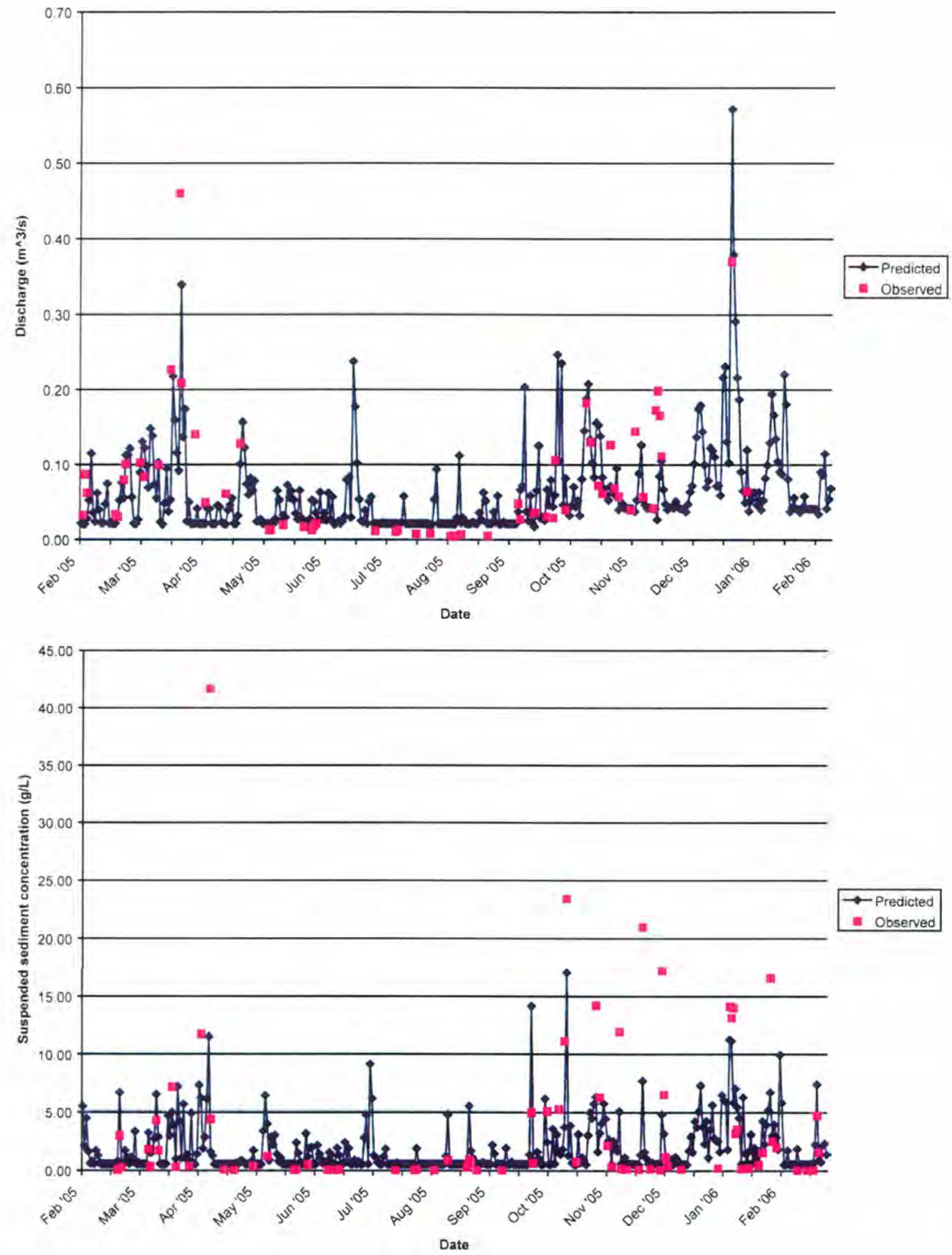

Figure 19. Observed data vs. data predicted by the nonlinear functional model for (A) SCC and (B) discharge during 2005-2006. 
precipitation varied significantly within the catchment. However, the assumption of time invariance of the catchment was violated. There was significant seasonal variation in the precipitation (Figure 5). The model requires re-calibration if an abrupt or seasonal change occurs. However, there were not enough data in the collected dataset to recalibrate for seasonality. Either a higher sampling density or multiple years of collected data are necessary.

A more continuous discharge and SSC data set for the catchment might improve the overall prediction capabilities of the model. However, the temporal variability in landslide activity, as well as infrequent phenomena such as debris flows, creates complications in the natural system that the model cannot account for.

\section{SSC and discharge relationship}

When material from the SCL is supplied to the channel by means of landslide movement or as a result of precipitation, the sediment is available for transport until carried away by Swift Creek. As observed in Taiwan by Fuller (2003), during the channel-clearing period the sediment discharge is transport limited, meaning that the amount of sediment transported is limited by the creek's carrying capacity. However, between landslide events, when the channel is relatively cleared of sediment, the discharge is supply limited, implying the lack of available sediment for transport.

During the sampled time of 2005-2006, there appears to be a seasonal effect on the correlation between suspended sediment concentration and water discharge (Figure 13). Times of correlation would imply that Swift Creek was transport limited. At other times the 
water discharge increased but the SSC remained close to zero, implying that the creek was supply limited.

The SCL remains a continuous presence in the watershed. It continues to move during the dry summer months, but the rate of movement of the unvegetated toe increases during the wet winter months (McKenzie-Johnson, 2004). The SCL supplies suspended sediment as a result of seeps and small debris flows occurring on the saturated, exposed toe.

Therefore, the seasons with the greatest tau correlations were winter and spring, with values of 0.63 and 0.66 , respectively (Figure 13 ). That could be because the ground is saturated during those times and Swift Creek is continuously flowing. Therefore, the precipitation that is dislodging the sediment on the SCL to be transported is also going directly to increase the discharge, causing simultaneous increases in the SSC and discharge. During the summer and early part of fall, Swift Creek is barely flowing in the upper reaches and turns intermittent in the lower reaches. Therefore, the precipitation that is dislodging the sediment to be transported is going to recharge the groundwater before increasing the discharge, causing times of higher SSC at lower discharges and resulting in lower tau correlations.

The fact that the SSC peaked before the discharge matches the findings of (Gomi et al., 2005) in other small streams of the Pacific Northwest. They reasoned that the peak offsets occurred because the available sediment supply is often exhausted during the rising limb of the flow hydrograph. In this case, however, the SCL serves as a constant available sediment source. The lag time could be due to the immediate re-suspension of sediment along with sediment released by raindrop impact. 


\section{Sediment budget and erosion rate for SCL}

The estimated suspended sediment yield of around $910 \mathrm{t} / \mathrm{km}^{2} / \mathrm{yr}$ for the Swift Creek catchment is comparable to other small catchments in the Pacific Northwest. (Gomi et al., 2005) summarize the sediment yields found by numerous authors in various catchments. The suspended sediment yields of 4.5 to $4,300 \mathrm{t} / \mathrm{km}^{2} / \mathrm{yr}$, that were observed in small $(<5$ $\mathrm{km}^{2}$ ) coastal catchments in Oregon and California, were generally greater than yields reported from elsewhere in the United States. Other western U.S. states reported suspended sediment yields ranging from 2.3 to $117 \mathrm{t} / \mathrm{km}^{2} / \mathrm{yr}$.

Studies comparing the percent of bedload to suspended load have shown that suspended loads comprise a significant amount of the total sediment load. The Tyne River in England was monitored and found to have an average annual bedload equal to only about $11 \%$ of the average annual suspended sediment load (Muir, 1970). Jowett and Hicks (1981) observed that the bedload in the Clutha River system in New Zealand made up between 10$30 \%$ of the total sediment load of a river. Duck and McManus (1994) found a higher percentage of bedload from the Pinmacher catchment, being about $46 \%$ of the total load, while Pal (2000) found similar estimates of $36-53 \%$ in the Ghatgad, Gungad and Kolani catchments in the Lesser Himalaya. Leopold (1994) found the same trends within the Tanana River, Alaska, and Little Granite Creek, Wyoming. At the same discharge, the suspended sediment load was greater than the corresponding bedload.

As a result of this study, the annual suspended sediment load in Swift Creek was found to be only $5 \%$ of the total annual load. Assuming that the majority of the annual sediment yield is delivered during a small percentage of the time (Figure 16), the sampling 
frequency was increased during periods of higher precipitation (Figure 5). However, during $2005-2006,57 \%$ of the rain fell during nighttime hours, when manual sampling was not possible. Therefore, the maximum SSC concentrations that occurred may not have been sampled. Also of note is that while, according to the Clearbrook weather station there was above average precipitation during the sampling year, negligible snow accumulation was observed in the study area. With no rain on snow events, significant sediment mobilization may not have even occurred during the sampling time. Consequently, the estimated suspended sediment yield of $910 \mathrm{t} / \mathrm{km}^{2} / \mathrm{yr}$ is probably an underestimation.

In this study, the erosion rate of $158 \mathrm{~mm} / \mathrm{yr}$ for the whole $\mathrm{SCL}$, was calculated based on the total estimated sediment and bed load. That rate is approximately four times less than the $660 \mathrm{~mm} / \mathrm{yr}$ erosion rate suggested by McKenzie-Johnson (2004), which was based on volume losses estimated by 30 -year topographic comparisons. The difference between the two calculated erosion rates could be due to the underestimation of continuous SSC by the nonlinear functional model, which in turn would lead to a lower annual suspended sediment yield and erosion rate.

\section{CONCLUSION}

\section{Weathering of serpentinitic bedrock}

The fine-grained component of the SCL is predominantly chrysotile with scant amounts of lizardite, illite, chlorite and occasionally hydrotalcite. The asbestiform chrysotile is a direct weathering product of the serpentinitic bedrock and can be found in both the main landslide material and the clay seeps, which are presumed to emanate from 
the failure surface. No smectite was found on the SCL. The absence of smectite, coupled with the chrysotile composition of the seeps, suggests that it is the chrysotile forming the slip surface and not smectite as assumed by previous studies.

The findings of Mumpton and Thompson (1966) and Yokota et al. (2000) that the insitu serpentinitic rock disintegration is due to the dissolution of brucite were not absolutely substantiated by this study, as no brucite or coalingite were ever found in the fresh boulders. However, the presence of iron oxides, which could have formed from the dissolution of brucite and coalingite, might suggest the presence of brucite in the Sumas Mountain serpentinite.

\section{Annual suspended sediment load}

The annual suspended sediment yield estimated to be approximately $910 \mathrm{t} / \mathrm{km}^{2} / \mathrm{yr}$, is only about $5 \%$ of the bedload estimate. The suspended sediment yield is probably an underestimation due to the inability to sample during several of the large rain events and the subsequent poor predictability of the model.

\section{Precipitation and hydrologic data}

According to the Kendall's tau statistical test, the overall correlation between the SSC and discharge during the sampling time was 0.44 . Therefore, discharge alone would not be a reliable predictor for SSC.

Using the nonlinear functional model, the SSC was found to be correlated to current and antecedent precipitation within three days of the sample being taken. However, 88 
discrete measurements proved to be insufficient to adequately calibrate and test the model. Therefore, the predicted SSC and discharge values produced by the model did not fit the observed data well. In order to improve upon the predicting capabilities of the model, either a higher sampling density or multiple years of collected data are necessary. Complications would still exist due to the presence of the SCL in the watershed and its variability in sediment influxes into Swift Creek.

Approximately $57 \%$ of the rain events, some of which were high-intensity, lowduration events, occurred during the nighttime, when sampling was deemed to be unsafe. In order to ensure the capture of those infrequent events, when a majority of the suspended load is suspected to be transported, a continuous sampling methodology must be employed.

Despite the shortcomings of this study, the annual estimated suspended sediment yield does provide a basis for comparison between the annual suspended load and the bedload in the Swift Creek watershed.

\section{Erosion rate}

The weathering of the serpentinitic bedrock produces the sediment that is transported in Swift Creek. The erosion rate of the SCL was estimated to be $158 \mathrm{~mm} / \mathrm{yr}$, while the erosion rate of just the unvegetated toe, where most of the suspended sediment is presumed to originate, is approximately $950 \mathrm{~mm} / \mathrm{yr}$. 


\section{REFERENCES}

Ambers R. 2001. Relationships between clay and mineralogy, hydrothermal metamorphism, and topography in a western Cascases watershed, Oregon, USA. Geomorphology 38(1-2): 47-61.

ASTM. 1998. Standard test methods for liquid limit, plastic limit, and plasticity index of soils. American Society for Testing and Materials D 4318-98: 546-556.

ASTM. 2000. Standard test methods for determining sediment concentration in water samples. D 3977-9711.02 Water (II): 395-400.

Bales RC, Newkirk DD, Hayward SB. 1984. Chrysotile asbestos in California surface waters: from upstream rivers through water treatment. American Water Works Association 76(5): 66-74.

Beylich AA, Gintz D. 2004. Effects of high-magnitude/low-frequency flucial events generated by intense snowmelt or heavy rainfall in arctic periglacial environments in northern Swedish Lapland and northern Siberia. Geografiska Annaler 86A(1): 11-29.

Chernosky JVJ, Berman RG, Bryndzia LT. 1988. Stability, phase relations, and thermodynamic properties of chlorite and serpentine group minerals. Reviews in mineralogy 19: 295-346.

Cowan DS, Mansfield CF. 1970. Serpentinite flows on Joaquin Ridge, southern Coast Ranges, California. Geological Society of America Bulletin 81: 2615-2628.

Dragovich JD, Norman DK, Haugerud RA, Pringle PT. 1997. Geologic map and interpreted geologic history of the Kendall and Deming 7.5 minute Quadrangles, Western Whatcom County, Washington. Washington Division of Geology and Earth Resources Open File Report 97-2.

Duck RW, McManus J. 1994. A long-term estimate of bedload and suspended sediment yield derived from reservoir deposits. Journal of Hydrology 159(1-4): 365-373.

Duncan J. 1996. Soil slope stability analysis. In Landslides: Investigation and Mitigation, Special Report 247, Turner A, and Schuster R (eds). Transportation Research Board, National Research Council: 675.

Edwards TK, Glysson GD. 1999. Field methods for measurement of fluvial sediment. U.S. Geological Survey Techniques of Water-Resources Investigations, Book 3. Chapter C2: 89 . 
Egashira K, Gibo S, Sasaki K. 1992. Swelling chlorite as a possible alteration product of serpentinization, relating to the formation of a slip-surface in the Tochinoki landslide, Kochi. Clay Science 8; 221-232.

Egashira K, Matsuo K, Gibo S, Nakamura S, Zhou Y, Inoue H, Sasaki K. 2000. Clay mineralogical approach to the slip-surface formation in the O'dokoro landslide, Niigata, central Japan. Clay Science 11: 107-113.

Embrey SS, Frans LM. 2003. Surface-water quality of the Skokomish, Nooksack, and GreenDuwamish Rivers and Thornton Creek, Puget Sound Basin, Washington, 1995-98. Water-Resources Investigations, USGS Report WRI 02-4190.

Emmett W. 1975. The channels and waters of the upper Salmon River area, Idaho. Geological Survey Professional Paper 870-A.

Farnsworth K, Milliman J. 2003. Effects of climatic and anthropogenic change on small mountainous rivers: the Salinas River example. Global and Planetary Change 39: 53-64.

Gaines RV, Skinner H, Foord EE, Mason B, Rosenzweig A. 1997. Dana's new mineralogy. John Wiley \& Sons, Inc.: New York; 1819.

Gomi T, Moore RD, Hassan MA. 2005. Suspended sediment dynamics in small forest streams of the Pacific northwest. Journal of the American Water Resources Association 41(4): 877-898.

Graham RC, Diallo MM, Lund LJ. 1990. Soils and mineral weathering on phyllite colluvium and serpentinite in northwestern California. Soil Science Society of America 54: 1682-1690.

Gray JR, Glysson GD, Turcios LM, Schwartz GE. 2000, Comparability of suspendedsediment concentration and total suspended solids data. Water-Resources Investigations, USGS Report WRI 00-4191: 1-14.

Güldal V, Müftüoglu RF, 2001. 2D unit sediment graph theory. Journal of hydrologic engineering 6(2): 132-140.

Hayward SB. 1984. Field monitoring of chrysotile asbestos in California waters. American Water Works Association 76(3): 66-73.

Istok JD, Harward ME. 1982a. Clay mineralogy in relation to landscape instability in the Coast Range of Oregon. Soil Science Society of America 46: 1326-1331. 
Istok JD, Harward ME. 1982b. Influence of soil moisture on smectite formation in soils derived from serpentinite. Soil Science Society of America 46; 1106-1108.

Jain SK, Singh P, Saraf AK, Seth SM. 2003. Estimation of sediment yield for a rain, snow and glacier fed river in the Western Himalyan region. Water Resources Management 17(5): 377-393.

Joint Committee on Powder Diffraction Standards. 1980. Mineral powder diffraction file data book. International centre for diffraction data: Swarthmore, PA; 1168.

Jowett IG, Hicks DM. 1981. Surface, suspended and bedload sediment; Clutha River system. Journal of Hydrology 20(2): 121-130.

Kerr Wood Leidal Associates. 2004. Swift Creek management plan: draft report. Swift Creek management plan: draft report.

Lajczak A, Jansson M. 1993. Seasonal variations in suspended sediment yield in the Baltic Sea drainage basin. Nordic hydrology 24(1): 53-64.

Lanfear KJ, Hirsch R. 1999. USGS study reveals a decline in long-record streamgages, Eos 80(50): 605-607.

Lee BD, Sears SK, Graham RC, Amrhein C, Vali H. 2003. Secondary mineral genesis from chlorite and serpentine in an ultramafic soil toposequence. Soil Science Society of America 67: 1309-1317.

Leopold L. 1994. A view of the river. President and Fellows of Harvard College: 298.

Lisle TE. 1990. The Eel River, northwestern California; high sediment yields from a dynamic landscape. In Surface Water Hydrology, Wolman MG, and Riggs HC (eds). Volume 0-1:The Geology of North America, Geological Society of America: 311314.

Matharu GS, Kukal SS, Bawa SS. 2003. Soil erosion in relation to rain characteristics in submontane Punjab. Journal of the Indian Society of Soil Science 51(3): 288-290.

McKenzie-Johnson A, 2004, Dynamics of the Swift Creek landslide, Northwest Washington [Masters thesis]: Bellingham, Western Washington University.

Milliman JD, Syvitski J. 1992. Geomorphic/tectonic control of sediment discharge to the ocean: the importance of small mountainous rivers, The Journal of Geology 100: 525-544. 
Moliere DR, Evans KG, Saynor MJ, Erskine WD. 2004. Estimation of suspended sediment loads in a seasonal stream in the wet-dry tropics, Northern Territory, Australia. Hydrological Processes 18(3): 531-544.

Moore DE, Lockner DA, Iwata K, Tanaka H, Byerlee JD. 2001. How brucite may affect the frictional properties of serpetinite. U.S. Geologic Survey Open-File Report 01-320.

Moore DE, Lockner DA, Shengli M, Summers R, Byerlee JD. 1997. Strengths of serpentinite gouges at elevated temperatures. Journal of Geophysical Research 102(7): $14,787-14,801$.

Moore DM, Reynolds RC, Jr. 1997. X-ray diffraction and the identification and analysis of clay minerals. Oxford University Press: 378.

Muir TC. 1970. Bedload discharge of the River Tyne, England. Bulletin of the International Association of Scientific Hydrology 15(3): 35-39.

Mumpton FA, Thompson CS. 1966. The stability of brucite in the weathering zone of the New Idria serpentinite. Clays and Clay Minerals: 249-257.

Nesse WD. 2000. Introduction to mineralogy. Oxford University Press, Inc.: New York; 442.

Norgard GT, 1970, Ultramafic rocks of Mt. Pendleton, Cassiar District, British Columbia and Sumas Mountain, northern Washington [Bachelor's thesis]: Vancouver, University of British Columbia.

Normand C, Williams-Jones AE, Martin RF, Vali H. 2002. Hydrothermal alteration of olivine in a flow-through autoclave: nucleation and growth of serpentine phases. American Mineralogist 87: 1699-1709.

O'Hanley DS. 1997. Serpentinites and rodingites as records of metasomatism and fluid history, Oxford monographs on geology and geophysics 35: 164-175.

OSHA, 2004. Asbestos. - 1910.1001(b). http://www.osha.gov/pls/oshaweb/owadisp.show_document?p_table=STANDARDS $\&$ p_id $=9995$

Page NJ. 1968. Serpentinization in a sheared serpentinite lens, Tiburon Peninsula, California. U.S. Geologic Survey Professional Paper 600-B.

Pal PK. 2000. Evaluation of water discharge and sediment budget in the Lesser Himalaya. Photonirvachak (Dehra Dun) 28(1): 33-46. 
Rabenhorst MC, Foss JE. 1981. Soil and geologic mapping over mafic and ultramafic parent materials in Maryland. Soil Science Society of America 45: 1156-1160.

Rahn P. 1996. Engineering geology: an environmental approach. Prentice Hall, Inc.: Upper Saddle River, NJ; 127-131.

Ross M. 1978. The "asbestos" minerals: definitions, descriptions, modes of formation, physical and chemical properties, and health risk to the mining community. U.S. Geologic Survey Special Publication 506.

Ross M, Nolan RP. 2003. History of asbestos discovery and use and asbestos-related disease in context with the occurrence of asbestos within ophiolite complexes. Geological Society of America special paper 373.

Schmidt KM, Montgomery DR, 1995. Limits to relief. Science 270: 617-620.

Schmidt KM, Montgomery DR. 1996. Rock mass strength assessment for bedrock landsliding. Environmental and Engineering Geoscience 2(3): 325-338.

Schreier H, Omueti JA, Lavkulich LM. 1987. Weathering processes of asbestos-rich serpentinitic sediments. Soil Science of America 51: 993-999.

Slaughter CW, Pierson FB. 2000. Sediment yield and hydrology in northwestern rangelands. International journal of sediment research 15(2): 253-259.

Stark TD, Eid HT. 1997. Slope stability analyses in stiff fissured clays. Journal of Geotechnical and Geoenvironmental Engineering 123(4): 335-343.

Swanston DN. 1988. Timber harvest and progressive deformation of slopes in southwestern Oregon. Association of Engineering Geologists 25(3): 371-381.

US Department of the Interior Bureau of Reclamation. 2001. Water measurement manual. http://www.usbr.gov/pmts/hydraulics_lab/pubs/wmm/index.htm

Vandre B. 1975. A case history of a landslide caused by confined groundwater. Association of Engineering Geologists 12(4): 261-273.

Venturelli G, Contini S, Bonazzi A. 1997. Weathering of ultramafic rocks and element mobility at Mt. Prinzera, nothern Apennines, Italy. Mineralogical Magazine 61(6): 765-778.

Walling DE, Webb BW, Woodward JC. 1992. Some sampling considerations in the design of effective strategies for monitoring sediment-associated transport. IAHS 210: 279 288. 
Wicks FJ, O'Hanley DS. 1988. Serpentine minerals: structure and petrology. Reviews in mineralogy 19: 91-167.

Yokota K, Yatabe R, Yagi N, Bhandray NP. 2000. Shear strength of landslide clay soil containing weathered serpentinite. Journal of Nepal Geological Society 22: 147-154. 


\section{APPENDIX A \\ Structure and occurrence of serpentine minerals}

Serpentine minerals, which share the ideal end member $\mathrm{Mg}_{3}\left(\mathrm{SiO}_{5}\right)(\mathrm{OH})_{4}$ are hydrous magnesium phyllosilicates, or sheet silicates. Being phyllosilicates, their basic structure consists of two types of sheets, the octahedral sheet $(\mathrm{O})$ and the tetrahedral sheet $(\mathrm{T})$ (Nesse, 2000). The Octahedral sheets have two planes of $\mathrm{OH}^{-}$, with cations in between. Depending on the type of cations that occupy the octahedral sites in between the planes of $\mathrm{OH}-$, the resulting sheets will be either trioctahedral or dioctahedral: trioctahedral if the cations are divalent (i.e., $\mathrm{Fe}^{2+}$ or $\mathrm{Mg}^{2+}$ ); dioctahedral if the cations are trivalent (i.e., $\mathrm{Al}^{3+}$ or $\mathrm{Fe}^{3+}$ ). Unlike the octahedral sheets, the tetrahedral sheets consist of Si tetrahedra that are arranged in 6-fold rings, with three $\mathrm{O}^{2-}$ on each tetrahedron shared with an adjacent tetrahedron. When a tetrahedral sheet bonds to an octahedral sheet, the apical oxygens of the tetrahedral replace two of every three $\mathrm{OH}^{-}$on the octahedral sheet. Adjacent octahehral and tetrahedral layers are bonded by weak hydrogen and Van der Waals bonds.

Phyllosilicates are distinguished based on the ratio of octahedral sheets bonding to tetrahedral sheets. If one octahedral sheet is combined with one tetrahedral sheet, then it is referred to as a "TO" mineral, or "1:1". Such a unit structure has repeating TO layers. If, on the other hand, an octahedral sheet is bonded to tetrahedral sheets on both sides, then it is referred to as a "TOT" mineral, or "2:1". This unit structure has repeating TOT layers. Chlorite is unique in that it has a TOT structure with an interlayer octahedral sheet. 
Structurally, the serpentine minerals are similar in that they are all trioctahedral phyllosilicates based on a 1:1 layer structure. However, the lateral dimensions of the octahedral sheets are slightly different those of the tetrahedral sheets, with the b unit cell dimensions being $9.3 \AA$ and $8.7 \AA$, respectively. It is this misfit between the sheets that leads to the structural variations among the serpentine minerals. Lizardite has enough $\mathrm{Al}^{+3}$ in the tetrahedral sheet to increase its dimensions so that the misfit between the sheets can be accommodated within the normal 1:1 layer structure. Both antigorite and chrysotile need to adjust the smaller tetrahedral sheet by curling it parallel to the (001) plane so that the oxygens can match the anion sites on the octahedral sheet. Antigorite accommodates the misfit by periodically reversing the way the tetrahedral and octahedral are combined; forming undulations. Chrysotile accommodates the misfit by curling into tubes (Moore and Reynolds, 1997).

The formation of a specific serpentine mineral over another is dependent upon the crystallization temperature, fluid pressure and the molality of the aqueous silica (Ross, 1978; Wicks and O'Hanley, 1988). Antigorite is stable at much higher temperatures and pressures (up to $500^{\circ} \mathrm{C}$ at $2 \mathrm{kbars)}$ than both chrysotile and lizardite and occurs most commonly in prograde serpentinites (O'Hanley, 1997). At 2 kbars of pressure, chrysotile is stable at temperatures lower than $250^{\circ} \mathrm{C}$ (Chernosky et al., 1988) and is mostly found in veins of prograde mildly metamorphosed serpentinites (Wicks and O'Hanley, 1988). Lizardite, if stable, is probably stable at lower temperatures than chrysotile (Chernosky et al., 1988) and occurs most commonly in retrograde serpentinites. Depending on the aqueous silica concentration, forsterite (Mg-rich olivine) can react to form antigorite or chrysotile with a 
decrease in temperature. One possible reaction put forth by Ross (1978) and Moore (2001) is:

$$
\begin{array}{ccc}
2 \mathrm{Mg}_{2} \mathrm{SiO}_{4}+3 \mathrm{H}_{2} \mathrm{O} & \rightarrow \mathrm{Mg}_{3} \mathrm{Si}_{2} \mathrm{O}_{5}(\mathrm{OH})_{4}+\mathrm{Mg}(\mathrm{OH})_{2} \\
\text { forsterite } & \text { chrysotile brucite }
\end{array}
$$

The stability of the serpentine minerals is also dependent upon the concentration of $\mathrm{CO}_{2}$ in $\mathrm{CO}_{2}-\mathrm{H}_{2} \mathrm{O}$ fluids (O'Hanley, 1997). Antigorite is stable in fluids with less than a 5 $\mathrm{mol} \% \mathrm{CO}_{2}$ at $400^{\circ} \mathrm{C}$ and $1 \mathrm{kbar}$. Its stability decreases to lower values of $\mathrm{mol} \%$ with a decrease in temperature. Chrysotile and lizardite can both be considered to be unstable in the presence of $\mathrm{CO}_{2}$. At temperatures less than $260^{\circ} \mathrm{C}$ and at $2 \mathrm{kbars}$, neither can withstand fluids with $2 \mathrm{~mol} \% \mathrm{CO}_{2}$ or greater (O'Hanley, 1997).

It has been recognized that lizardite and chrysotile can co-precipitate without the presence of antigorite (Normand, 2002; O'Hanley, 1998), as the data from this study confirms. However, the extensive research done on the serpentine minerals has failed to provide explanations as to how and why the co-crystallization of lizardite and chrysotile occurs (Normand et al., 2002). 


\section{APPENDIX B}

\section{Smectite}

Smectite clays have a TOT layer structure and can be either dioctahedral or trioctahedral. The net charge of the TOT layers determines whether or not the smecite is considered to be a low-charge clay or a high-charge clay. Because the cations only occupy about a third of the interlayer sites in low-charge smectites, water is allowed to easily move into the interlayers, resulting in the expansion of the structure. The water can move in and out of the structure, at room temperatures, in response to the changing moisture content of the soil; resulting in the ability to shrink and swell.

Smectite can be identified by comparing the air-dried and ethylene-glycol solvated diffraction patterns. The air-dried faction will have a strong 001 reflection at about $15 \AA$. When treated with ethylene-glycol, the crystal lattice will expand as the glycol occupies the interlayer sites and the 001 reflection will shift to $16.9 \AA$. Subsequently, when heated to $250^{\circ} \mathrm{C}$, the structure collapses and the peak shifts to $10 \AA$, producing a diffraction pattern similar to illite. The fact that there are no shifts in any of the diffraction patterns suggests that there is no smectite present. 


\section{APPENDIX C \\ Suspended sediment concentration vs. total suspended solids}

According to (Gray et al., 2000) suspended sediment concentration (SSC) and total suspended solids (TSS) are two analytical methods designed to quantify the suspended material in surface water. While they are often used interchangeably, they entail different methodology and produce different uncertainties.

SSC measures all of the sediment from a known volume of a water-sediment mixture. TSS measures an aliquot of the original sample by agitating the sample before obtaining a subsample.

Due to settling rates governed by Stokes' Law, the removal of an aliquot for subsequent analysis according to the TSS method might produce results that are substantially different from the original sample. Therefore, the SSC method is more reliable for the analysis of natural-water samples.

\section{APPENDIX D}

\section{Failed Methods}

Early methodology used in this study attempted to obtain continuous discharge and SSC data. The discarded methods were as follows: 
1. A 3700 Portable Isco sampler, coupled with a 4150 Flow Logger was used to take timecalibrated measurements; three samples every day. With the Isco sampler equipped with 24 $500-\mathrm{mL}$ bottles, that would require changing the bottles every eight days. A pressuresensitive meter was calibrated on site and used to record the depth of the stream, while a Doppler velocity sensor attached to the 4150 Flow Logger measured the average stream velocity.

The location of the setup was decided based on channel morphology and was initially placed at the Oak Coles Bridge because the cross-sectional area would remain relatively constant. The shape of the channel under the Oak Coles Bridge was determined to be close to rectangular and was therefore considered rectangular for purposes of simplifying volume calculations. The length of the stream at the surface was then measured and entered into the Flowlink 4 program in order to calculate the area of the stream. The banks there were high and formed a constrained channel, making it hard for Swift Creek to jump its bank and run a new course at that location. Based on personal observations, there was also little to no risk of large bedloads damaging the equipment. The sensors were attached to the bridge using rebar and ties and were fixed at a certain height above the creek bottom.

A couple of problems surfaced. (1) Continuous deposition caused the sensors, which were set at a fixed height above the creek bottom, to become buried. (2) In November of 2004, the creek froze. A rain-on-snow event resulted in high flow and blocks of ice floating downstream. The ice dislodged the rebar structure that attached the sensors to the bridge and caused it to be buried under several feet of sand.

The collected data were unreliable and the setup was destroyed. 
2. The 3700 Portable Isco sampler, coupled with a 4150 Flow Logger was once again used to take time-calibrated measurements; three samples every day. However, the location was moved upstream, to where the current sampling site B is located (refer back to Figure 1), The channel there is bedrock constrained, thus minimizing the amount of scouring to the streambed. The gradient is also about $8 \%$ at this location, which based on personal observations, is high enough to ensure minimal aggradation. The problem at this location was larger bedload. During higher flows, large rocks knocked the sensors free from their setup.

Once again, the collected data were unreliable and the setup was destroyed.

\section{APPENDIX E \\ Nonlinear functional model (2D unit sediment graph)}

This black-box analysis predicts the suspended-sediment concentration from discrete SSC data and the current and antecedent precipitation. It assumes that an analysis of the input and output data is sufficient to get an idea of the behavior of the system. The erodibility of the landslide material as a result of the moisture state of the catchment, raindrop impacts and overland flow, is considered to be a function of precipitation. Because the model looks at the overall behavior of the system, it is acceptable to look at the precipitation as a lumped input even though it is not evenly distributed over the catchment 
and the sediment concentration as a lumped output, even though it is unevenly distributed over the river channel.

Precipitation data was used rather than effective precipitation because vegetation is lacking at the toe of the SCL. Therefore, the assumption was made that little to no evapotranspiration was taking place.

The model, which determines a mathematical relationship between the inputs and outputs, is calibrated on historical data. The historical data for Swift Creek consisted of the 88 discrete suspended sediment samples analyzed, 66 discrete discharge measurements and the precipitation data collected every 10 minutes during 2005-2006.

Suspended sediment concentrations and discharge are dependent upon rainfall occurring within a certain time frame, meaning that the system's response has a memory period.

All of the computations and analyses were done using the program Eviews.

\section{Precipitation and SSC}

The memory period for the Swift Creek watershed was determined by trial and error using field observations and a cross-correlation coefficient between precipitation and SSC as a starting point. Field observations as well as an analysis of the discrete data suggested that there was a lag time of approximately 1 hour between peak precipitation and peak SSC. The cross-correlation coefficient showed that the most significant correlation between the two variables existed up to three hours prior to the sediment sampling time (Figure 6). For this dataset, the most significant memory length was determined to be when the cross-correlation 
coefficient neared zero rather than when it crossed zero, as suggested by Güldal and Müftüoglu (2001). That was done because the coefficient didn't cross zero until after 26 hours. Including that many independent variables would decrease the degrees of freedom to the point where there was not a significant correlation between the independent and dependent variables.

In order to determine the response function, the model was applied with five different combinations of linear and nonlinear memory components for the three-hour memory period. The different combinations used are as follows:

A. Precipitation up to a three-hour lag*. This model assumes a linear relationship between precipitation and SSC.

B. Precipitation during the hour sampled and the sum of the precipitation up to a tenhour lag. This model assumes that each lag hour did not itself have a significant impact on the SSC, but that they might have had a cumulative impact.

C. Precipitation up to a three-hour lag and the square terms of each of each of the lags. This model was used to check for a nonlinear relationship between precipitation and SSC.

D. Precipitation up to a three-hour lag and interactive terms. The interactive terms multiplied variables from different time periods, once again testing for a nonlinear relationship [i.e., (current precipitation) x (1-hour lag precipitation)].

E. Precipitation up to a one-hour lag and the sum of the precipitation up to a ten-hour lag, as well as the current precipitation and interactive terms up to a one-hour lag.

\footnotetext{
* lag - the number of hours preceding the current hour of precipitation
} 
This model combined linear terms and nonlinear terms and was used to test a combination of all the above models.

The calibration of the model involved splitting the 88 collected data points in half, where observations 1-44 were used for calibrating the model and observations 45-88 were used for testing the model. The calibration and validation periods were then reversed so that the model was calibrated on observations $45-88$ and tested on observations 1-44. That procedure was repeated for each of the five different combinations entered into the model.

The efficiency of the model was evaluated based on the adjusted $\mathrm{R}^{2}$ value, the root mean square error (RMSE) and how well the descriptive statistics fit the observed data. The adjusted $R^{2}$ value was used instead of the $R^{2}$ value because, while both statistics describe the percent of $\mathrm{Y}$-variance that is accounted for by the predictors, a limitation of the $\mathrm{R}^{2}$ value is that it does not take the degrees of freedom into account, while the adjusted $\mathrm{R}^{2}$ value does.

For the estimation of the SSC, the models were accepted or rejected for two main reasons: (1) the size of the predicting errors; (2) the predicted negative SCC values. (The reader is referred to Table G3). More specifically, the models were accepted/rejected for the following reasons: 


\begin{tabular}{|c|c|l|}
\hline Model \# & Accepted/rejected? & \multicolumn{1}{c|}{ Reasons } \\
\hline $\mathrm{A}$ & Rejected & $\begin{array}{l}\text { Predicted a negative minimum concentration } \\
(-21.99 \mathrm{~g} / \mathrm{L}) \text { when the actual minimum was } \\
0.02 \mathrm{~g} / \mathrm{L}\end{array}$ \\
\hline $\mathrm{B}$ & Accepted & $\begin{array}{l}\text { Predicted lowest negative concentration } \\
(-0.19 \mathrm{~g} / \mathrm{L}) \text { when the actual minimum was } \\
0.02 \mathrm{~g} / \mathrm{L}\end{array}$ \\
& & $\begin{array}{l}\text { Lowest RMSE values on the test periods } \\
(5.85 \text { and } 6.12)\end{array}$ \\
\hline C & Rejected & $\begin{array}{l}\text { Predicted a negative minimum concentration } \\
(-45.5 \mathrm{~g} / \mathrm{L}) \text { when the actual minimum was }\end{array}$ \\
& & $\begin{array}{l}0.02 \mathrm{~g} / \mathrm{L} \\
\text { High } \mathrm{RMSE} \text { values on the test periods }(12.18 \\
\text { and } 7.81)\end{array}$ \\
\hline D & Rejected & $\begin{array}{l}\text { Predicted a negative minimum concentration } \\
(-295.13 \mathrm{~g} / \mathrm{L}) \text { when the actual minimum was } \\
0.02 \mathrm{~g} / \mathrm{L}\end{array}$ \\
& & $\begin{array}{l}\text { High } \mathrm{RMSE} \text { values on the test periods }(7.65 \\
\text { and } 23.32)\end{array}$ \\
\hline E & Rejected & $\begin{array}{l}\text { Predicted a negative minimum concentration } \\
(-30.3 \mathrm{~g} / \mathrm{L}) \text { when the actual minimum was } \\
0.02 \mathrm{~g} / \mathrm{L}\end{array}$ \\
\hline
\end{tabular}

By looking at the adjusted $R^{2}$ values and RMSE values (Table G3), the models with the higher adjusted $R^{2}$ values also had higher RMSE values. Since the adjusted $R^{2}$ value corresponds to the calibration period, the predicted data fit the calibrated period better, but the model did a poorer job of predicting during the test period. Therefore, model B was accepted, regardless of its low adjusted $R^{2}$ value $(0.37)$, because it predicted the lowest negative concentrations and best predicted the data during the test period.

Similarly, each model appears to better predict during one of its calibration periods as compared to its second period (i.e., Model D predicted a minimum concentration of -16.7 $\mathrm{g} / \mathrm{L}$ when the first half of the data was used to calibrate the model and the second half was used to test. However, it predicted a minimum concentration of $-295.13 \mathrm{~g} / \mathrm{L}$ when the 
procedure was reversed and the second half of the data was used to calibrate while the first half was used to test). Such a phenomenon could suggest seasonality in the data. However, there were not enough data to recalibrate the model to account for the temporal effects.

\section{Precipitation and discharge}

The same general procedure outlined above was used to predict continuous discharge data for the 2005-2006 year from 66 discrete discharge measurements and a continuous precipitation record. However, the model used daily discharge rather than hourly, because the length of the memory period would have necessitated too many independent variables. Therefore, if multiple discharge measurements were taken on the same day, the average was used as that day's discharge. As a result, the model was calibrated and tested on a total of 58 discharge measurements rather than 66 .

Using the cross-correlation coefficient (Figure 6), the memory length was determined to be two days, because the $3^{\text {rd }}$ day falls below the $95 \%$ confidence interval and was deemed to be insignificant.

In order to determine the response function, the model was applied with three different combinations of linear and nonlinear memory components for the two-day memory period. The different combinations used are as follows:

A. Precipitation up to a three-day lag. This model assumes a linear relationship between precipitation and discharge. 
B. Precipitation up to a two-day lag and interactive terms [(current precipitation) $\times(1-$ day lag precipitation)]. This model was used to check for a nonlinear relationship between precipitation and discharge.

C. Precipitation up to a two-day lag and interactive terms. This model once again tests for a nonlinear relationship.

The calibration of the model involved splitting the 58 daily discharge measurements in half, where observations $1-29$ were used for calibrating the model and the observations $30-58$ were used for testing the model. The calibration and validation periods were then reversed so that the model was calibrated using observations $30-58$ and tested using observations 1-29. That procedure was repeated for each of the three different combinations entered into the model.

The efficiency of the model was evaluated based on the adjusted $R^{2}$ value, the root mean square error (RMSE) and how well the descriptive statistics fit the observed data. (The reader is referred to Table G3). The models were accepted/rejected for the following reasons: 


\begin{tabular}{|c|c|c|}
\hline Model \# & Accepted/rejected? & Reasons \\
\hline A & Rejected & $\begin{array}{l}\text { - } \text { Highest RMSE values } \\
\text { - Lowest adjusted } \mathrm{R}^{2} \text { values } \\
\text { - Severely underestimated actual maximum } \\
\text { discharge }\end{array}$ \\
\hline B & Rejected & $\begin{array}{l}\text { - Low RMSE values } \\
\text { - } \text { Highest adjusted } \mathrm{R}^{2} \text { values } \\
\text { - } \text { Does not include that day's precipitation }\end{array}$ \\
\hline $\mathrm{C}$ & Accepted & $\begin{array}{l}\text { - Low RMSE values } \\
\text { - High adjusted } \mathrm{R}^{2} \text { values } \\
\text { - Includes that day's precipitation (field } \\
\text { observations show increases in discharge on } \\
\text { the day of precipitation) }\end{array}$ \\
\hline
\end{tabular}

Models B and $\mathrm{C}$ were similar in their efficiency, however, model B did not include that day's precipitation. Field observations showed that discharge increased on the day that precipitation fell. Therefore, it is unlikely that the current precipitation had no impact on the discharge, as suggested by Model B.

\section{Statistical assumptions}

The data for both SSC and discharge were tested to see if they exhibited autocorrelation and/or heteroskedasticity. Autocorrelation is a violation of the classical assumption, which assumes uncorrelated observations of the error terms (i.e., when you have autocorrelation, one error influences the next). Having autocorrelation does not bias the coefficients, but causes the ordinary least squares to underestimate the standard errors of the coefficients. If they are too small, then the variable could be assumed to be significant, when in fact it is not. 
Most commonly, corrections are based on finding the pattern in the error terms of the lagged data. However, the dataset does not include continuous lagged data, so if autocorrelation exists, it could not be corrected for.

Another assumption that is made in statistics when using ordinary least squares is that the error terms have constant variance. Heteroskedasticity is a violation of that assumption. A large error variance can result in inaccurate estimations as well as low tstatistics. All of the regressions were corrected for heteroskedasticity using White's correction procedure. The White's test looks to see if heteroskedasticity exists because of one or more of the variables in X.

\section{APPENDIX F}

\section{Suggestions for future work}

1. Serpentinitic whole rocks are highly sheared and exhibit complex veined cross-cutting relationships. Some samples have also been identified as rodingites. How do the serpentinic bedrock and rodingites fit into a regional structural context?

2. The SCL material becomes extremely dry in the summer months, capable of absorbing large amounts of water before becoming saturated. How well-drained is the SCL? Is it well-drained enough to explain the lack of smectite on the landslide? 
3. A geochemical analysis of different candidates for the suspended sediment in Swift Creek could allow for fingerprinting the source of the sediment. How much comes from bedrock weathering? How much comes from chrysotile veins?

4. The current bedload estimates come from the amount of dredged material; they do not account for the bedload that moves through the system. A continuous bedload sampling program would allow for bedload estimates to be made that included both the bedload that moved through the system and the bedload stored on the fan. 


\section{APPENDIX G}

Tables 


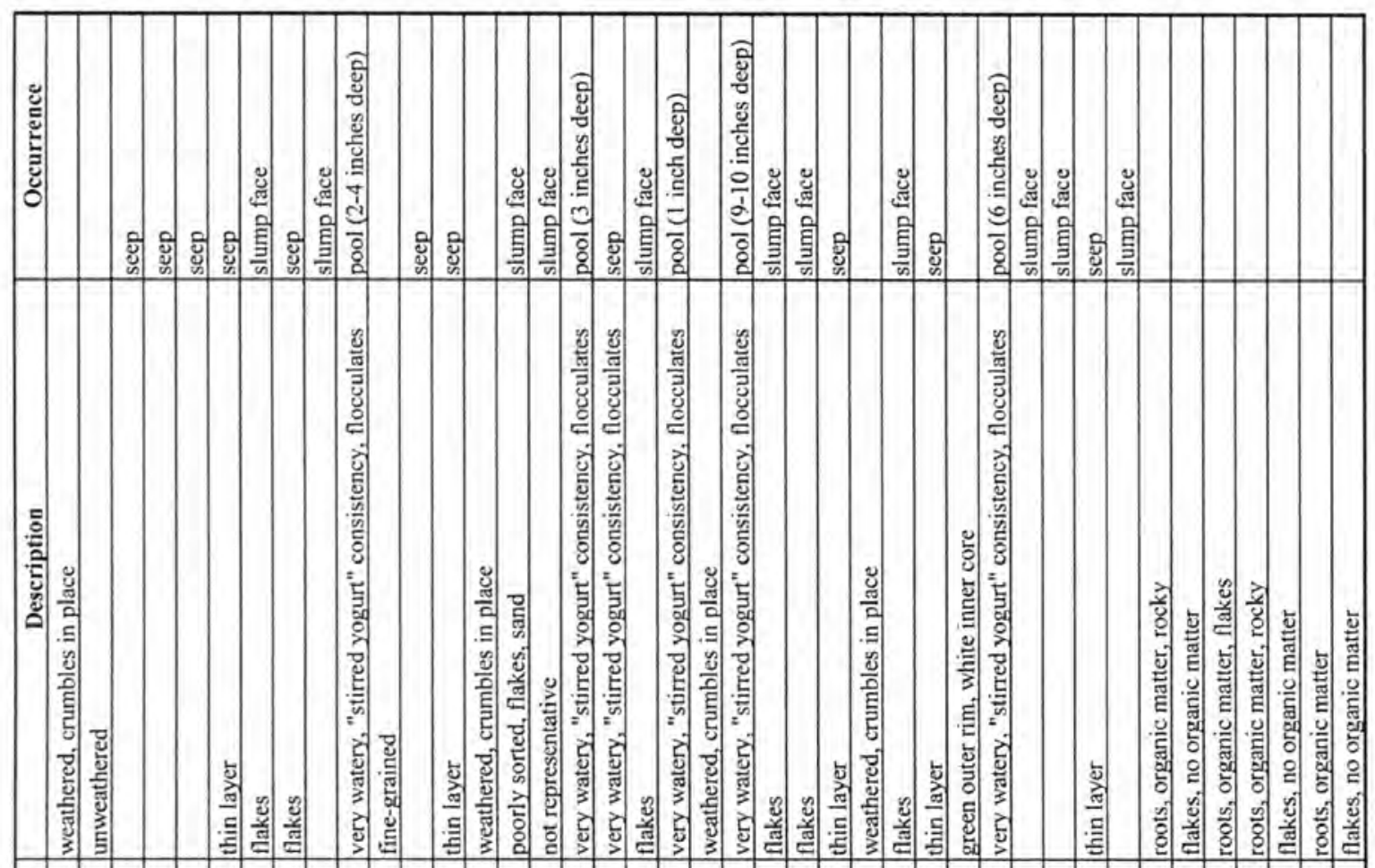

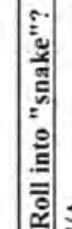

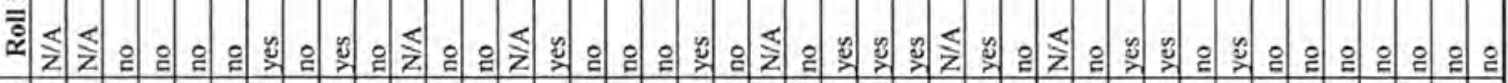

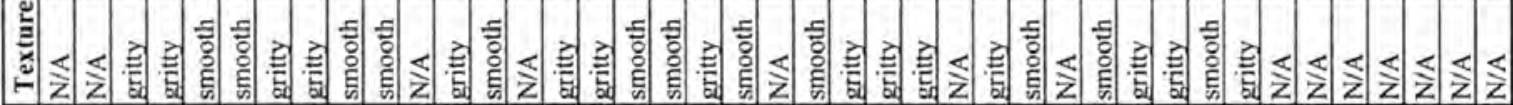

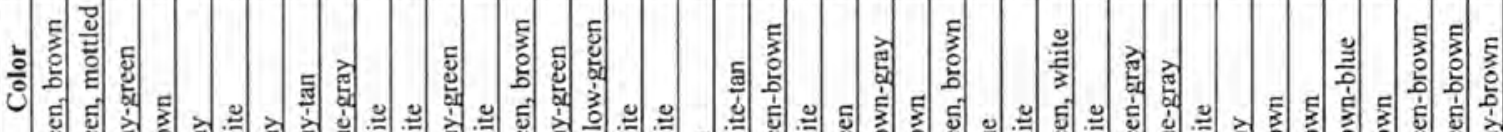

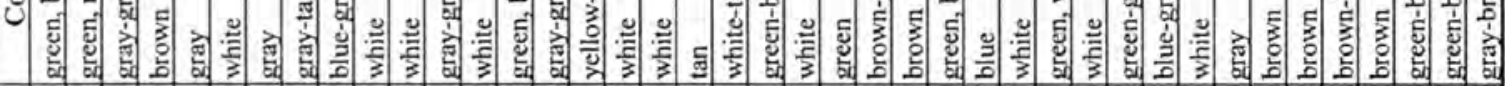

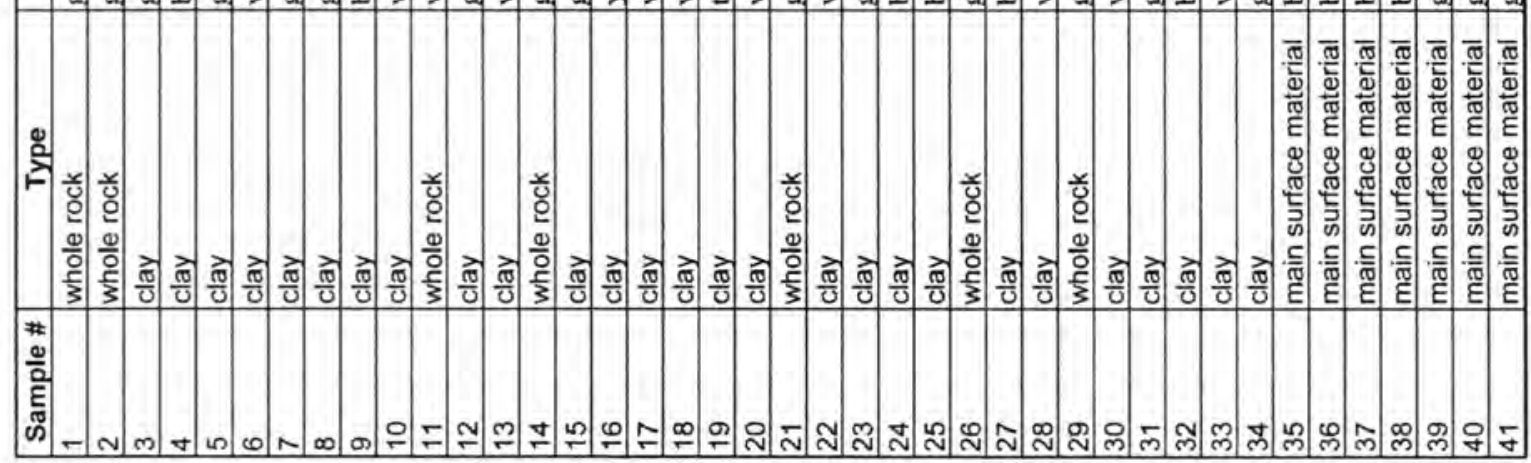




\begin{tabular}{|c|c|c|c|c|c|c|c|c|c|}
\hline Month & Day & Year & $\begin{array}{c}\text { Hour of sampling } \\
(0-2400 \mathrm{hrs})\end{array}$ & \begin{tabular}{|c|}
$\begin{array}{c}\text { Precipitation } \\
(\mathrm{mm})\end{array}$ \\
\end{tabular} & $\begin{array}{c}Q \\
\left(\mathrm{~m}^{3} / \mathrm{s}\right)\end{array}$ & $\begin{array}{c}C_{1} \\
(g / L)\end{array}$ & $\begin{array}{l}\mathrm{C}_{2}^{* \star} \\
(\mathrm{g} / \mathrm{L})\end{array}$ & $\begin{array}{c}\text { Avg C } \\
(g / L) \\
\end{array}$ & $\begin{array}{c}C_{1} \cdot C_{2}{ }^{* \star * *} \\
(g / L)\end{array}$ \\
\hline Feb & 28 & 2005 & 1000 & 0 & 0.03 & 0.06 & 0.09 & 0.08 & 0.03 \\
\hline Mar & 1 & 2005 & 1100 & 0.2 & 0.09 & 2.97 & 3.01 & 2.99 & 0.04 \\
\hline Mar & 2 & 2005 & 1000 & 0 & 0.06 & 0.26 & 0.30 & 0.28 & 0.04 \\
\hline Mar & 16 & 2005 & 1300 & 0.6 & 0.03 & 1.74 & 1.83 & 1.79 & 0.09 \\
\hline Mar & 17 & 2005 & 1200 & 0 & 0.03 & 0.35 & 0.33 & 0.34 & 0.02 \\
\hline Mar & 20 & 2005 & 900 & 0.6 & 0.08 & 4.37 & 4.23 & 4.30 & 0.14 \\
\hline Mar & 21 & 2005 & 1400 & 0 & 0.10 & 1.69 & 1.78 & 1.74 & 0.09 \\
\hline Mar & 28 & 2005 & 1100 & 0.1 & 0.10 & 7.20 & 7.18 & 7.19 & 0.02 \\
\hline Mar & 30 & 2005 & 1200 & 0 & 0.08 & 0.31 & 0.33 & 0.32 & 0.02 \\
\hline $\mathrm{Apr}$ & 6 & 2005 & 1600 & 0 & 0.10 & 0.38 & 0.37 & 0.38 & 0.01 \\
\hline Apr & 12 & 2005 & 1400 & 0.1 & 0.23 & 11.45 & 12.03 & 11.74 & 0.58 \\
\hline $\mathrm{Apr}$ & 16 & 2005 & 1000 & 5.1 & 0.46 & 44.02 & 39.26 & 41.64 & 4.76 \\
\hline $\mathrm{Apr}$ & 17 & 2005 & 1200 & 0 & 0.21 & 4.48 & 4.32 & 4.40 & 0.16 \\
\hline $\mathrm{Apr}$ & 24 & 2005 & 1100 & 0 & 0.14 & 0.09 & 0.08 & 0.09 & 0.01 \\
\hline Apr & 29 & 2005 & 1000 & 0 & 0.05 & 0.03 & 0.02 & 0.03 & 0.01 \\
\hline May & 9 & 2005 & 1100 & 0 & 0.06 & 0.36 & 0.38 & 0.37 & 0.02 \\
\hline May & 16 & 2005 & 1300 & 2.5 & 0.13 & 1.14 & 1.28 & 1.21 & 0.14 \\
\hline May & 30 & 2005 & 1100 & 0 & 0.01 & 0.02 & 0.02 & 0.02 & 0.00 \\
\hline May & 31 & 2005 & 1400 & 0.6 & 0.01 & 0.12 & 0.11 & 0.11 & 0.01 \\
\hline Jun & 6 & 2005 & 1400 & 0 & 0.02 & 0.55 & 0.46 & 0.51 & 0.09 \\
\hline Jun & 16 & 2005 & 1100 & 0 & 0.02 & 0.07 & 0.06 & 0.07 & 0.01 \\
\hline Jun & 20 & 2005 & 1100 & 0 & 0.01 & 0.02 & 0.02 & 0.02 & 0.00 \\
\hline Jun & 21 & 2005 & 900 & 0 & 0.02 & 0.02 & 0.01 & 0.02 & 0.01 \\
\hline Jun & 22 & 2005 & 1000 & 0 & 0.02 & 0.08 & 0.14 & 0.11 & 0.06 \\
\hline Jul & 21 & 2005 & 1000 & 0 & 0.01 & 0.02 & 0.01 & 0.02 & 0.01 \\
\hline Jul & 31 & 2005 & 1100 & 0 & 0.01 & 0.02 & 0.03 & 0.03 & 0.01 \\
\hline Aug & 1 & 2005 & 900 & 0 & 0.01 & 0.14 & 0.12 & 0.13 & 0.02 \\
\hline Aug & 10 & 2005 & 900 & 0 & 0.01 & 0.03 & 0.03 & 0.03 & 0.00 \\
\hline Aug & 17 & 2005 & 800 & 0 & 0.01 & 0.88 & 0.85 & 0.87 & 0.03 \\
\hline Aug & 27 & 2005 & 1600 & 0 & 0.01 & 0.29 & 0.28 & 0.29 & 0.01 \\
\hline Aug & 28 & 2005 & 900 & 0.2 & 0.01 & 0.12 & & & \\
\hline Aug & 28 & 2005 & 1000 & 2.2 & 0.01 & 0.81 & & & \\
\hline Aug & 28 & 2005 & 1100 & 3.9 & 0.01 & 1.90 & & & \\
\hline Aug & 28 & 2005 & 1200 & 1.2 & 0.01 & 0.93 & 0.96 & 0.95 & 0.03 \\
\hline Aug & 28 & 2005 & 1300 & 0.1 & 0.01 & 0.89 & & & \\
\hline Aug & 28 & 2005 & 1400 & 0.3 & 0.01 & 1.13 & & & \\
\hline Aug & 28 & 2005 & 1500 & 0.1 & 0.01 & 0.86 & & & \\
\hline Aug & 28 & 2005 & 1600 & 0.1 & 0.01 & 0.72 & & & \\
\hline Aug & 29 & 2005 & 1100 & 0 & 0.00 & 0.70 & 0.67 & 0.69 & 0.03 \\
\hline Sep & 1 & 2005 & 1500 & 0 & 0.01 & 0.04 & & & \\
\hline Sep & 14 & 2005 & 1400 & 0 & 0.01 & 0.02 & & & \\
\hline Sep & 29 & 2005 & 1400 & 4.5 & 0.05 & 4.97 & & & \\
\hline Sep & 30 & 2005 & 1100 & 0 & 0.03 & 0.64 & & & \\
\hline Oct & 7 & 2005 & 800 & 0 & 0.04 & 5.08 & & & \\
\hline Oct & 13 & 2005 & 1200 & 0 & 0.03 & 5.26 & 5.24 & 5.25 & 0.02 \\
\hline Oct & 16 & 2005 & 1200 & 1.4 & 0.03 & 11.14 & & & \\
\hline Oct & 17 & 2005 & 1500 & 3.3 & 0.11 & 23.43 & & & \\
\hline Oct & 22 & 2005 & 900 & 0 & 0.04 & 0.74 & & & \\
\hline Nov & 1 & 2005 & 1200 & 1.5 & 0.18 & 1423 & & & \\
\hline Nov & 3 & 2005 & 1500 & 0.2 & 0.13 & 6.27 & & & \\
\hline Nov & 7 & 2005 & 1000 & 0 & 0.07 & 2.16 & & & \\
\hline Nov & 9 & 2005 & 1000 & 0 & 0.06 & 0.37 & & & \\
\hline Nov & 13 & 2005 & 1000 & 0.2 & 0.13 & 11.94 & & & \\
\hline Nov & 14 & 2005 & 1200 & 0 & & 0.22 & & & \\
\hline Nov & 15 & 2005 & 1100 & 0 & 0.07 & 0.13 & 0.12 & 0.13 & 0.01 \\
\hline Nov & 17 & 2005 & 1200 & 0 & 0.06 & 0.14 & & & \\
\hline Nov & 23 & 2005 & 1600 & 0 & 0.04 & 0.12 & & & \\
\hline Nov & 25 & 2005 & 1600 & 1 & 0.14 & 21.00 & & & \\
\hline Nov & 29 & 2005 & 800 & 0 & 0.06 & 0.16 & & & \\
\hline
\end{tabular}

Continued - 


\begin{tabular}{|c|c|c|c|c|c|c|c|c|c|}
\hline Month & Day & Year & $\begin{array}{l}\text { Hour of sampling } \\
\quad(0-2400 \mathrm{hrs})\end{array}$ & $\begin{array}{c}\text { Precipitation* } \\
(\mathrm{mm})\end{array}$ & $\begin{array}{c}Q \\
\left(\mathrm{~m}^{3} / \mathrm{s}\right)\end{array}$ & $\begin{array}{c}C_{1} \\
(g / L)\end{array}$ & $\begin{array}{l}\mathrm{C}_{2}^{* *} \\
(\mathrm{~g} / \mathrm{L})\end{array}$ & $\begin{array}{c}\text { Avg } C^{\star \star \star} \\
(g / L)\end{array}$ & $\begin{array}{c}C_{1}-C_{2}{ }^{\star * n \hbar k} \\
(g / L)\end{array}$ \\
\hline Dec & 4 & 2005 & 800 & 0 & 0.04 & 0.09 & & & \\
\hline Dec & 5 & 2005 & 1400 & 1.5 & 0.17 & 17.22 & & & \\
\hline Dec & 6 & 2005 & 1400 & 0.6 & 0.20 & 6.68 & 6.38 & 6.53 & 0.30 \\
\hline Dec & 7 & 2005 & 1400 & 0.2 & 0.17 & 1.17 & & & \\
\hline Dec & 8 & 2005 & 1000 & 0 & 0.11 & 0.41 & & & \\
\hline Dec & 15 & 2005 & 800 & 이 & & 0.14 & & & \\
\hline Jan & 3 & 2006 & 1500 & 0 & & 0.22 & & & \\
\hline Jan & 9 & 2006 & 1100 & 5.8 & & 14.05 & 14.27 & 14.16 & 0.22 \\
\hline Jan & 10 & 2006 & 1200 & 0 & & 13.16 & & & \\
\hline Jan & 11 & 2006 & 1200 & 0.4 & 0.26 & 8.26 & & & \\
\hline Jan & 11 & 2006 & 1400 & 1.8 & 0.25 & 6.98 & & & \\
\hline Jan & 11 & 2006 & 1500 & 4.3 & 0.48 & 33.64 & & & \\
\hline Jan & 11 & 2006 & 1600 & 0.3 & 0.51 & 7.18 & & & \\
\hline Jan & 12 & 2006 & 1100 & 0 & & 3.25 & 3.19 & 3.22 & 0.06 \\
\hline Jan & 13 & 2006 & 1000 & 0.2 & & 3.55 & & & \\
\hline Jan & 15 & 2006 & 1400 & 0 & & 0.18 & & & \\
\hline Jan & 17 & 2006 & 1400 & 0 & & 0.20 & & & \\
\hline Jan & 19 & 2006 & 800 & 0 & 0.06 & 0.26 & 0.23 & 0.25 & 0.03 \\
\hline Jan & 24 & 2006 & 1400 & 0 & & 0.49 & & & \\
\hline Jan & 26 & 2006 & 1400 & 0 & & 1.55 & & & \\
\hline Jan & 30 & 2006 & 800 & 0.3 & & 16.61 & & & \\
\hline Jan & 31 & 2006 & 1100 & 0 & & 2.53 & & & \\
\hline Feb & 2 & 2006 & 1100 & 1.6 & & 3.18 & & & \\
\hline Feb & 2 & 2006 & 1500 & 0 & & 0.77 & 0.83 & 0.80 & 0.06 \\
\hline Feb & 13 & 2006 & 1400 & 0 & & 0.04 & & & \\
\hline Feb & 18 & 2006 & 900 & 0 & & 0.02 & & & \\
\hline Feb & 21 & 2006 & 1300 & 아 & & 0.03 & & & \\
\hline Feb & 23 & 2006 & 900 & 1 & & 4.74 & & & \\
\hline Feb & 24 & 2006 & 1100 & 0 & & 1.56 & & & \\
\hline
\end{tabular}

*Precipitation - Total precipitation during the hour the sample was collected

${ }^{*} \mathrm{C}_{2}$ - Concentration of second suspended sediment sample taken along the same transect. Taken for quality control.

**Avg C - Average concentration of both sediment samples taken along the same transect.

When two samples were taken, it was used as the SSC at that given time.

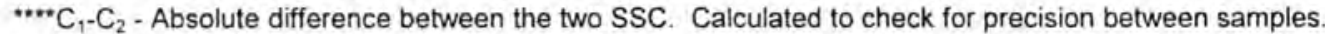

Table G2. Hydrologic data for the Swift Creek watershed. 

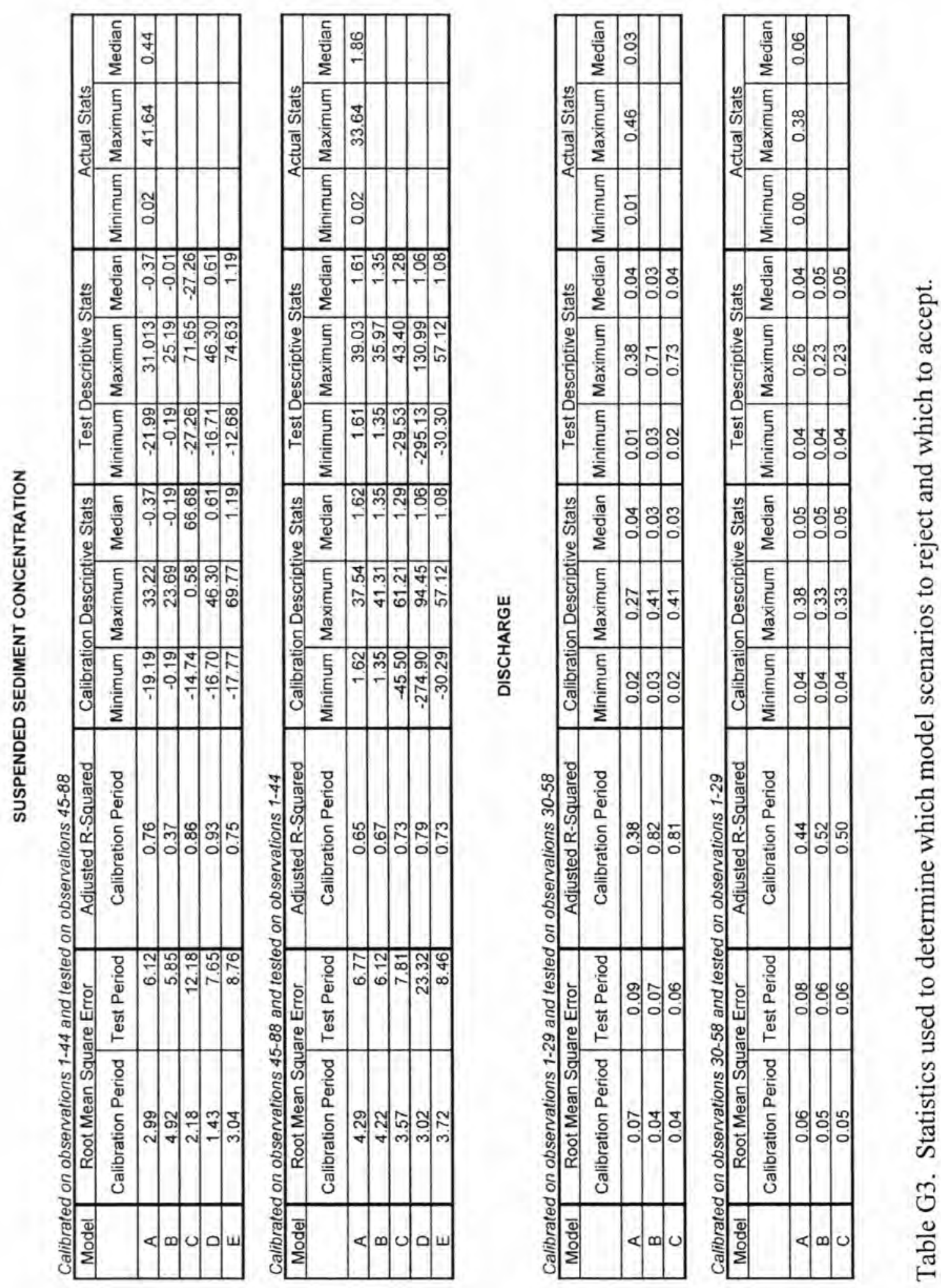


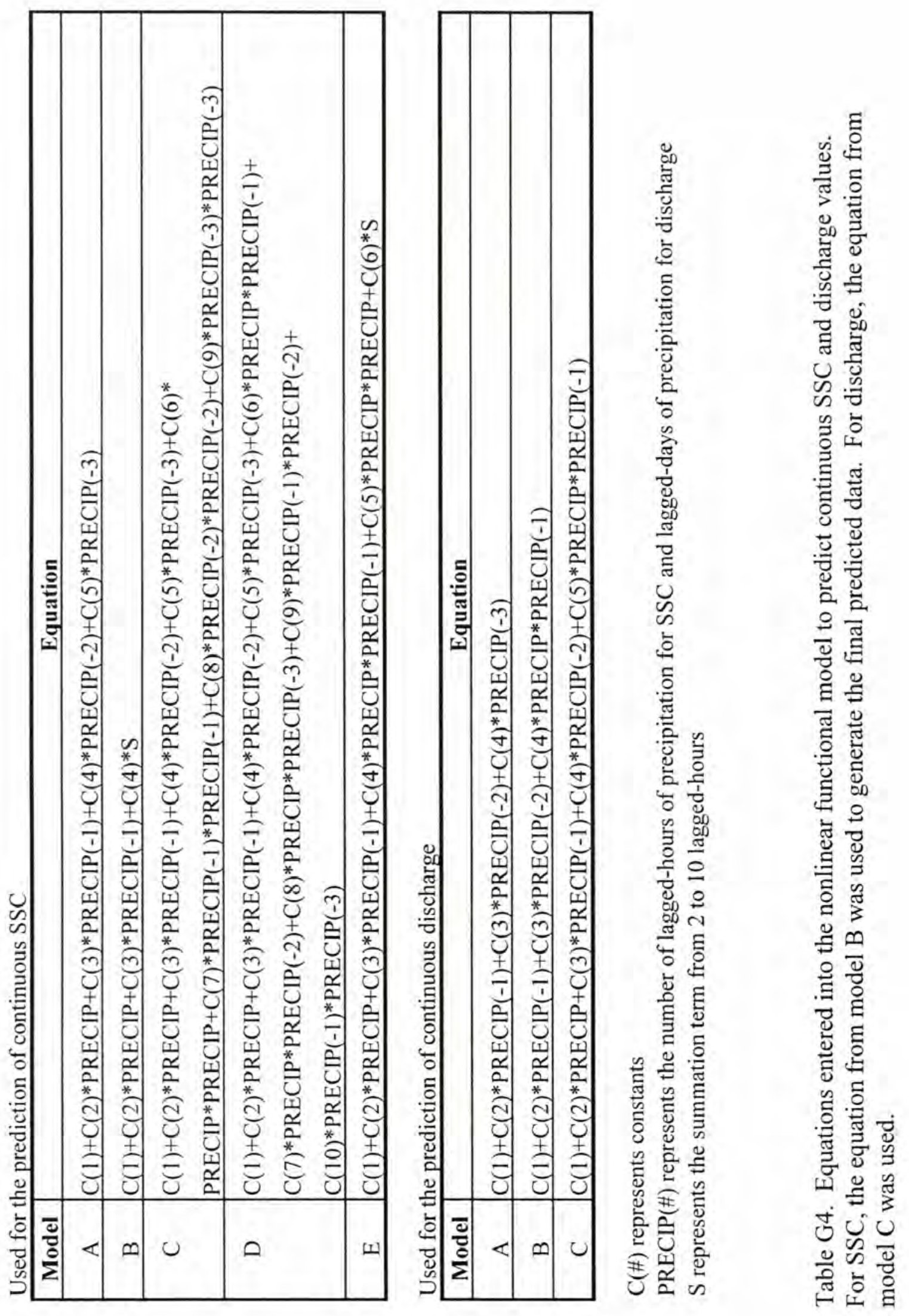




\section{APPENDIX H}

$\mathrm{X}$-ray diffraction graphs 

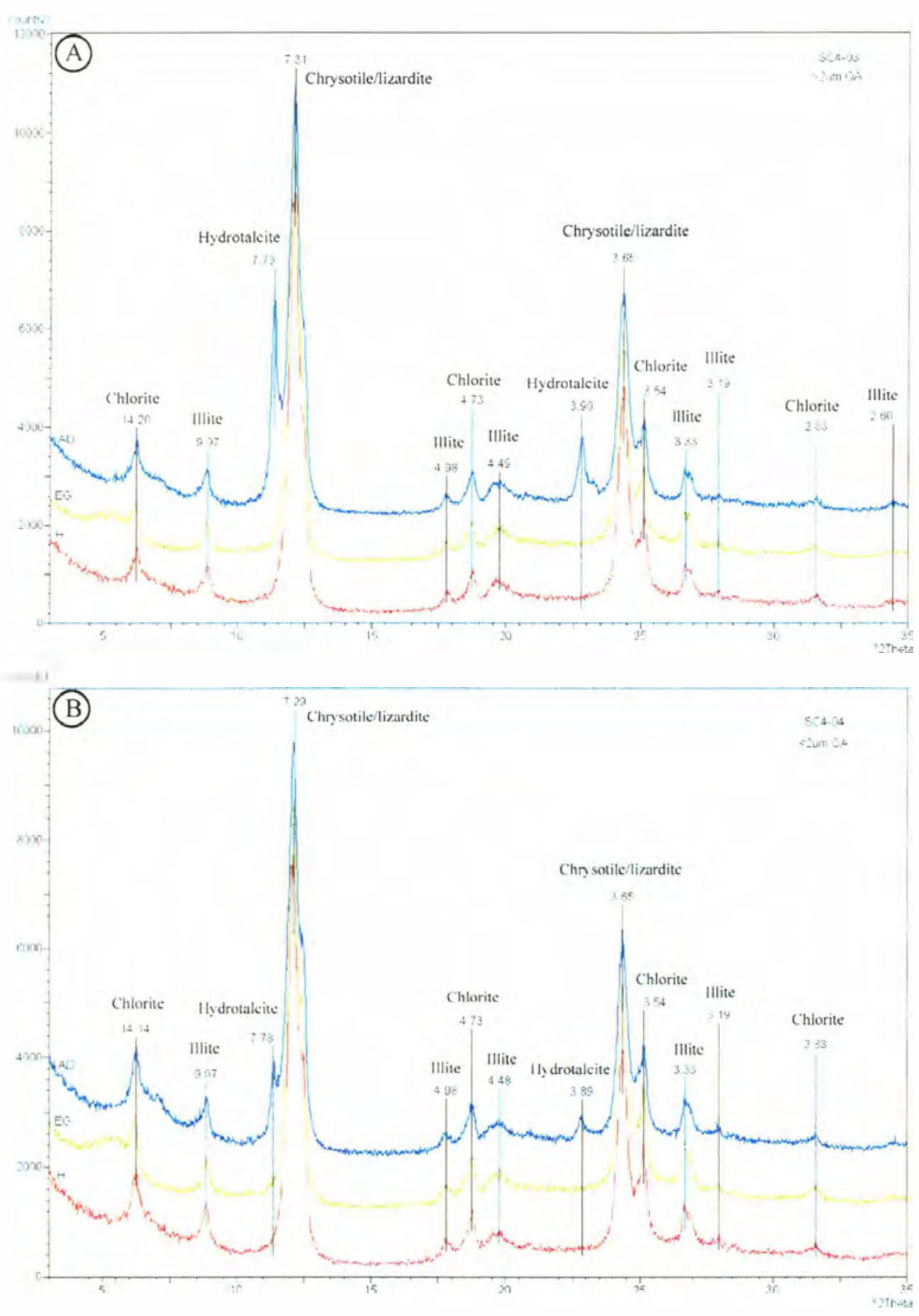

Figure H1. XRD patterns for the $<2 \mu \mathrm{m}$ fraction of (A) sample \#3 (B) sample \#4. The prepared slides were oriented aggregates using the Millipore filtration method. Each graph has 3 superimposed patterns for the same sample in order to show the 3 different stages that every sample underwent. $\mathrm{AD}=$ air dried; $\mathrm{EG}=$ ethylene-glycol; $\mathrm{H}=$ heated. The individual peaks are labeled with their d-spacing and mineral name. 

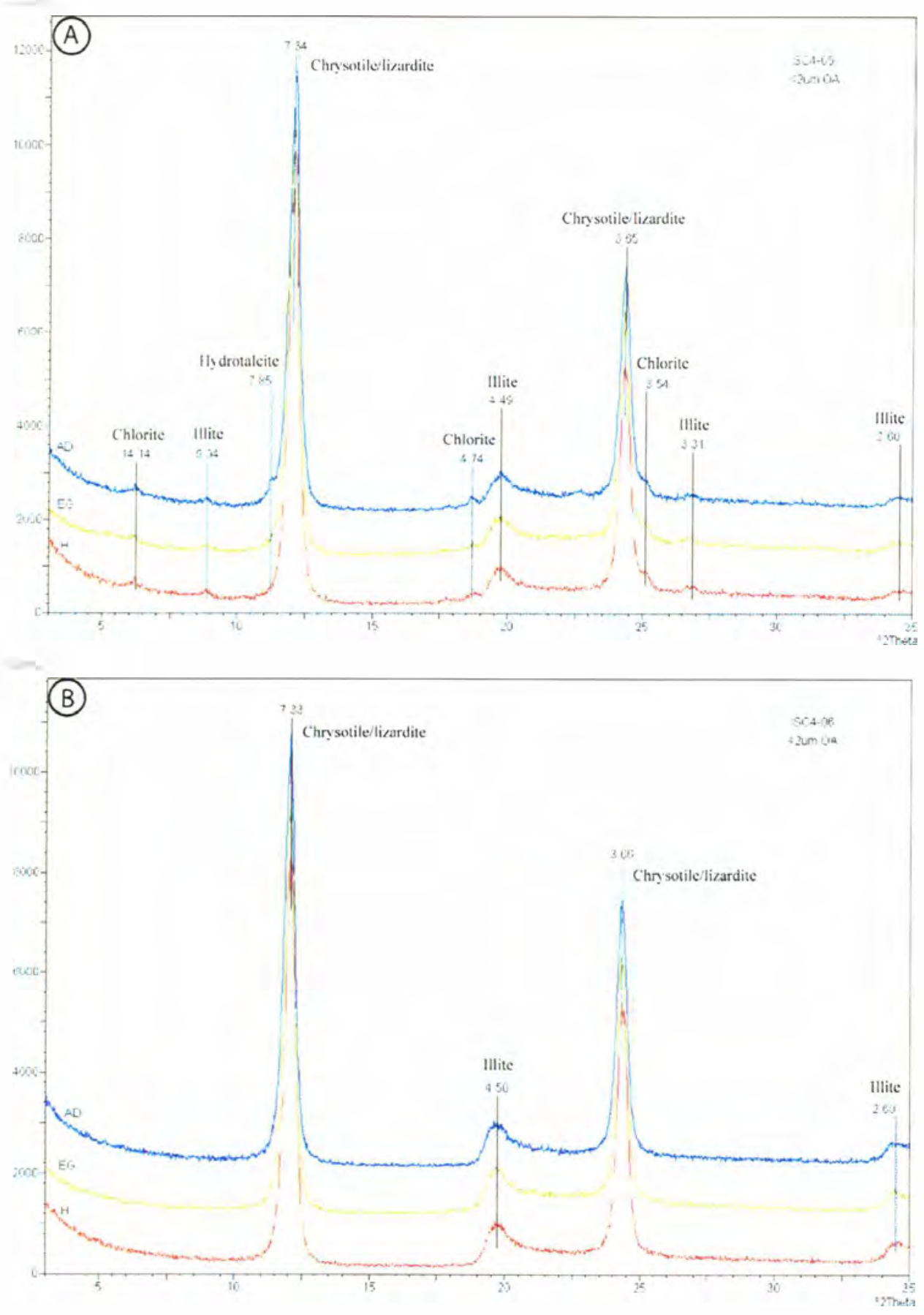

Figure H2. XRD patterns for the $<2 \mu \mathrm{m}$ fraction of (A) sample \#5 (B) sample \#6. The prepared slides were oriented aggregates using the Millipore filtration method. Each graph has 3 superimposed patterns for the same sample in order to show the 3 different stages that every sample underwent. $\mathrm{AD}=$ air dried; $\mathrm{EG}=$ ethylene-glycol; $\mathrm{H}=$ heated. The individual peaks are labeled with their d-spacing and mineral name. 

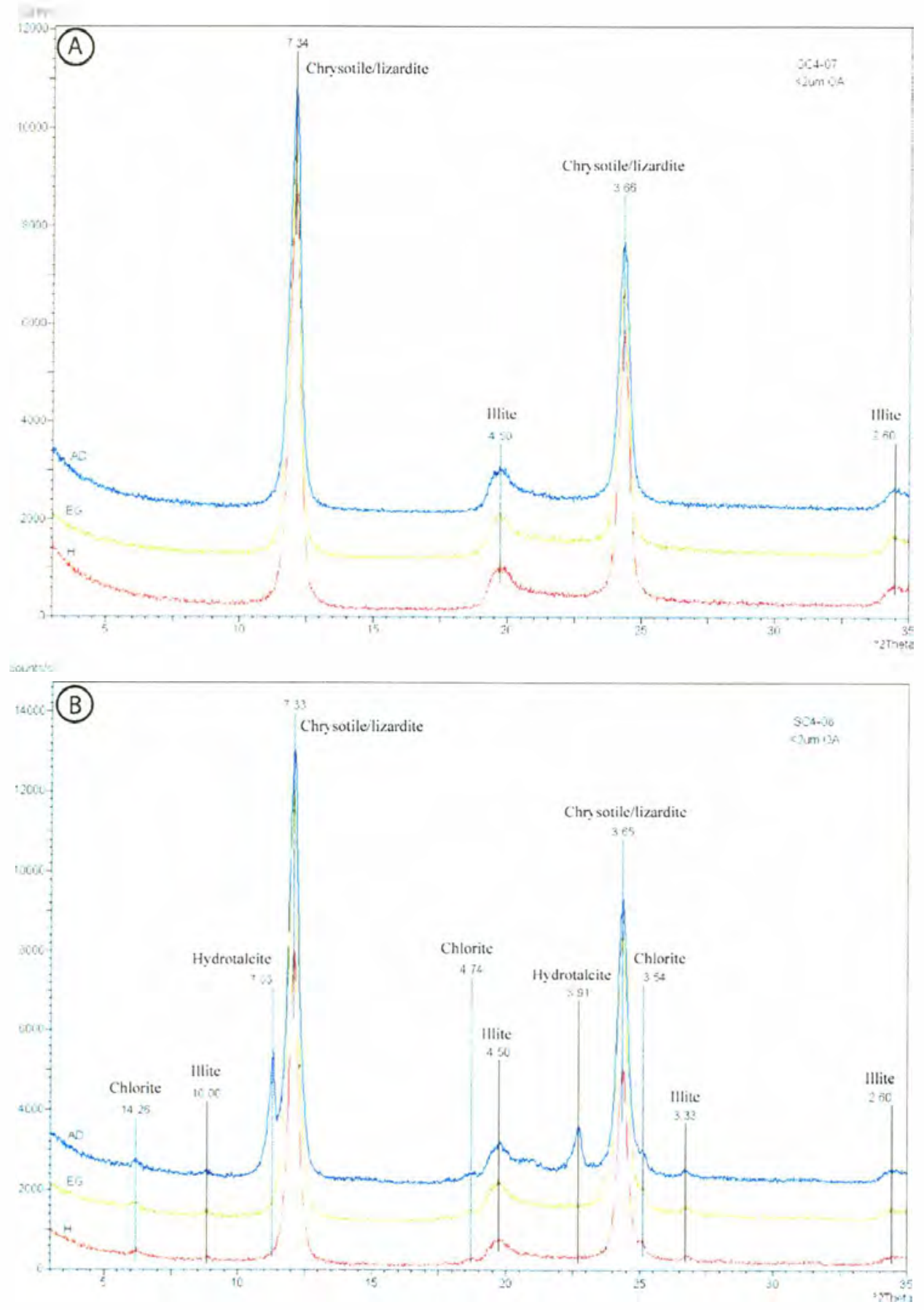

Figure H3. XRD patterns for the $<2 \mu \mathrm{m}$ fraction of (A) sample \#7 (B) sample \#8. The prepared slides were oriented aggregates using the Millipore filtration method. Each graph has 3 superimposed patterns for the same sample in order to show the 3 different stages that every sample underwent. $\mathrm{AD}=$ air dried; $\mathrm{EG}=$ ethylene-glycol; $\mathrm{H}=$ heated. The individual peaks are labeled with their d-spacing and mineral name. 

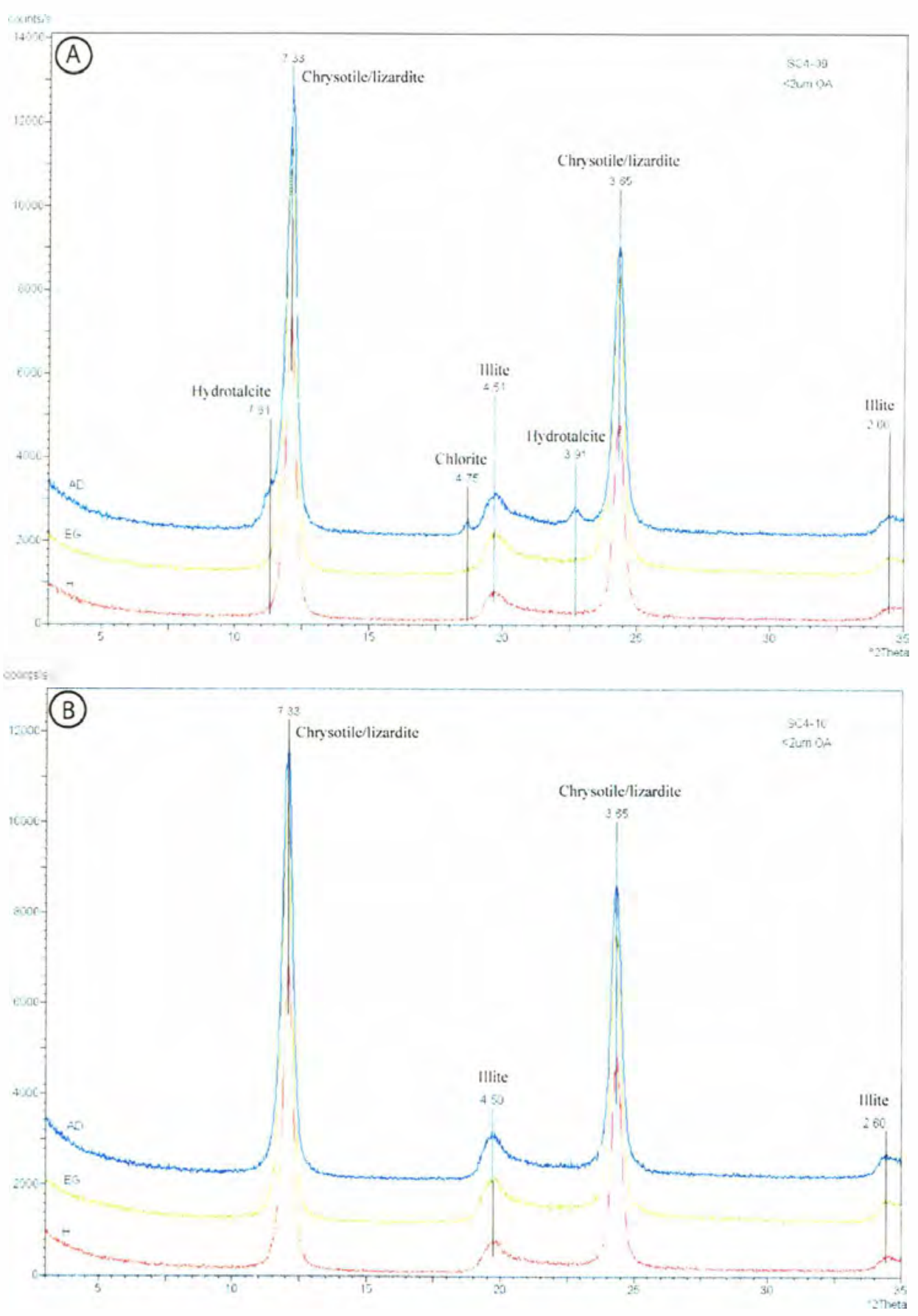

Figure H4. XRD patterns for the $<2 \mu \mathrm{m}$ fraction of (A) sample \#9 (B) sample \#10. The prepared slides were oriented aggregates using the Millipore filtration method. Each graph has 3 superimposed patterns for the same sample in order to show the 3 different stages that every sample underwent. $\mathrm{AD}=$ air dried; $\mathrm{EG}=$ ethylene-glycol; $\mathrm{H}=$ heated. The individual peaks are labeled with their d-spacing and mineral name. 

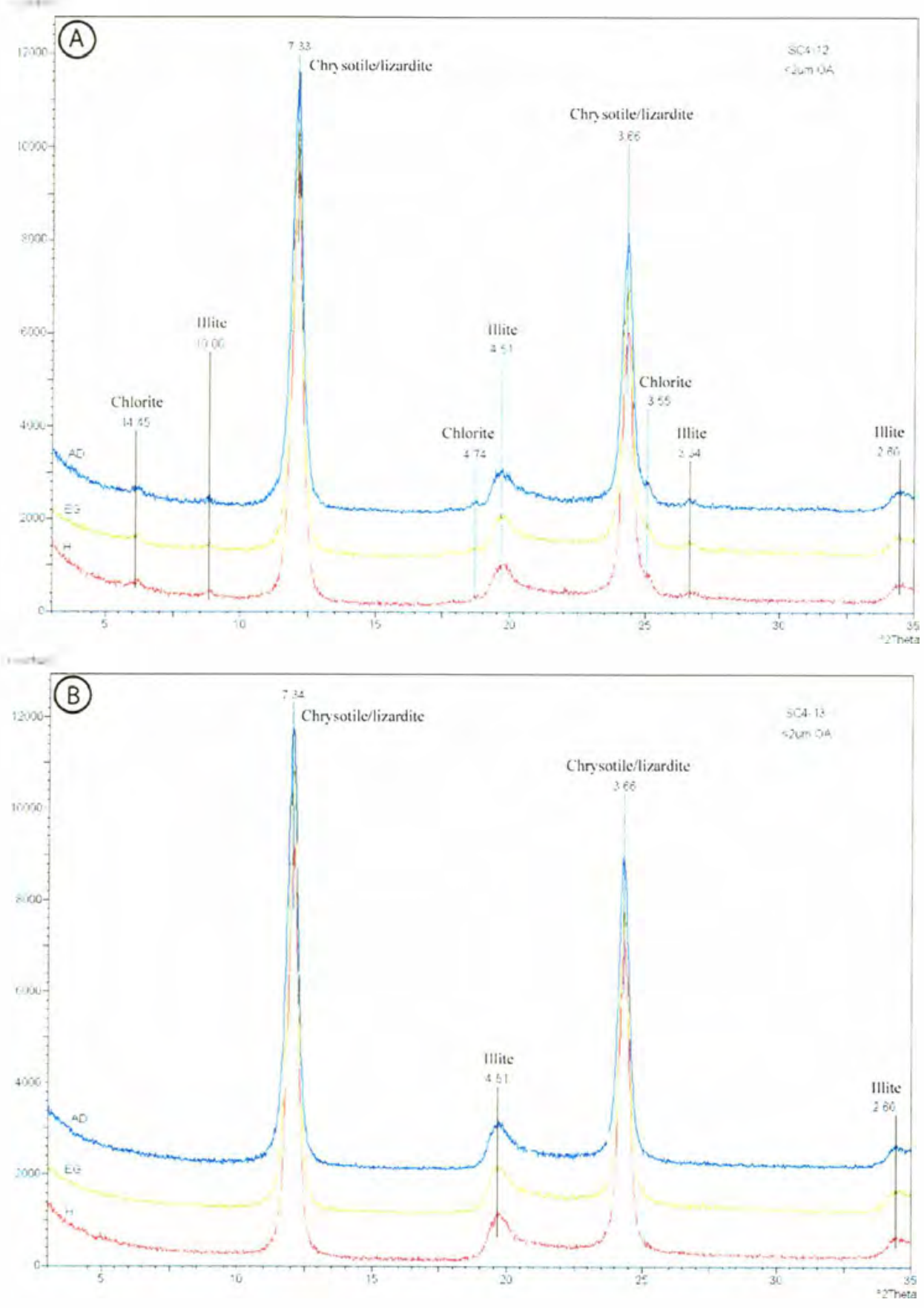

Figure H5. XRD patterns for the $<2 \mu \mathrm{m}$ fraction of (A) sample \#12 (B) sample \#13. The prepared slides were oriented aggregates using the Millipore filtration method. Each graph has 3 superimposed patterns for the same sample in order to show the 3 different stages that every sample underwent. $\mathrm{AD}=$ air dried; $\mathrm{EG}=$ ethylene-glycol; $\mathrm{H}=$ heated. The individual peaks are labeled with their d-spacing and mineral name. 

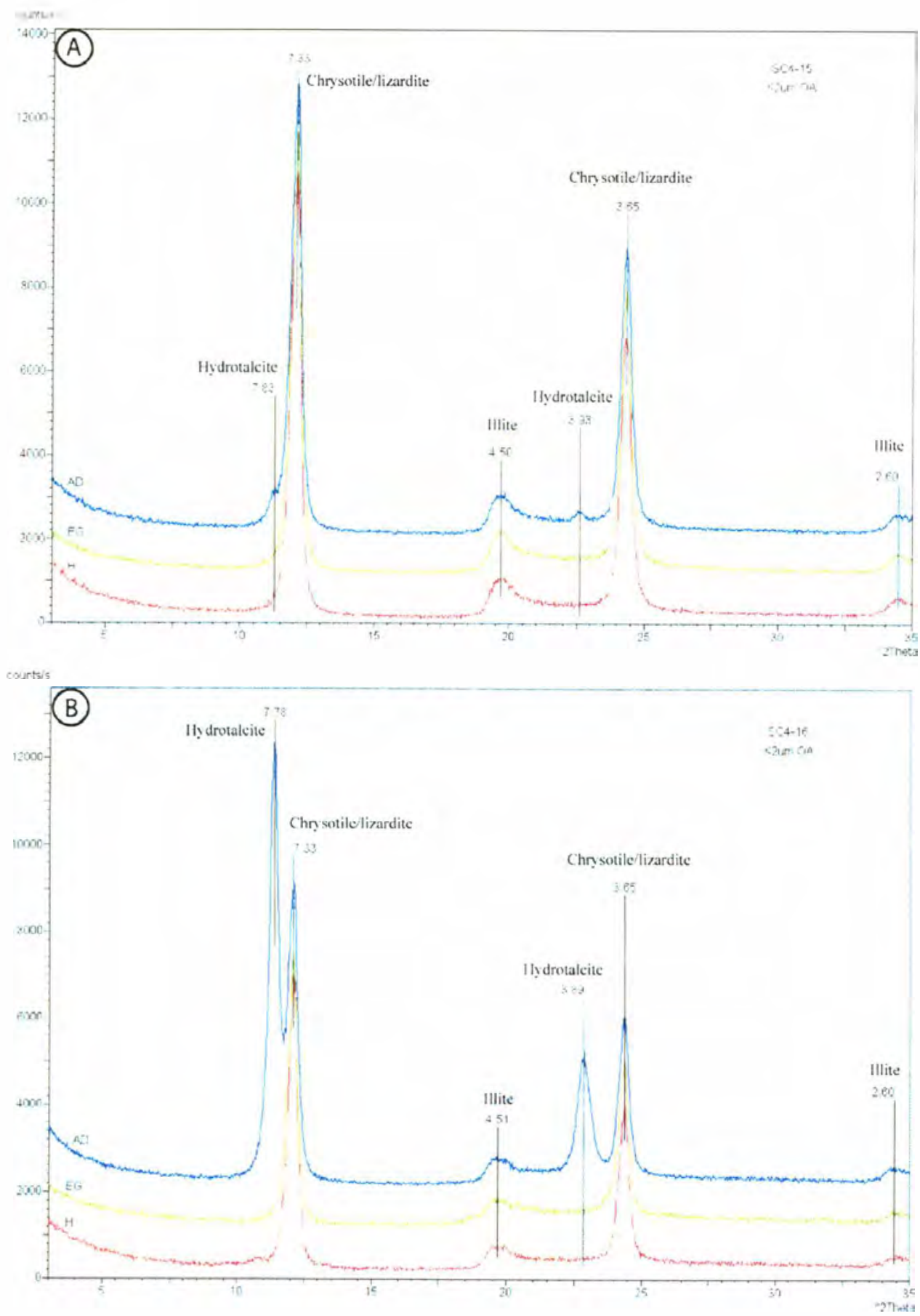

Figure H6. XRD patterns for the $<2 \mu \mathrm{m}$ fraction of (A) sample \#15 (B) sample \#16. The prepared slides were oriented aggregates using the Millipore filtration method. Each graph has 3 superimposed patterns for the same sample in order to show the 3 different stages that every sample underwent. $\mathrm{AD}=$ air dried; $\mathrm{EG}=$ ethylene-glycol; $\mathrm{H}=$ heated. The individual peaks are labeled with their $\mathrm{d}$-spacing and mineral name. 

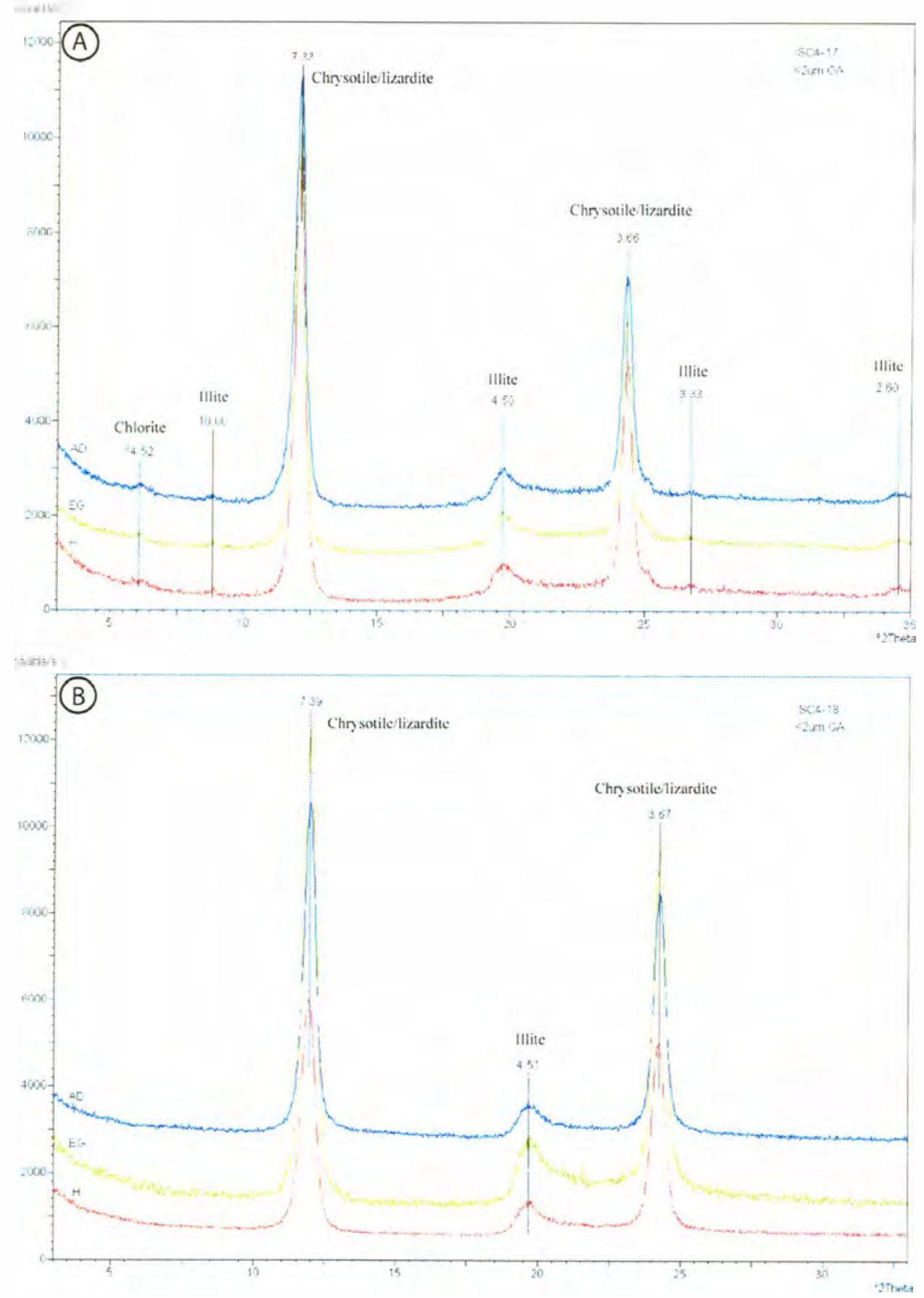

Figure H7. XRD patterns for the $<2 \mu \mathrm{m}$ fraction of (A) sample \#17 (B) sample \#18. The prepared slides were oriented aggregates using the Millipore filtration method. Each graph has 3 superimposed patterns for the same sample in order to show the 3 different stages that every sample underwent. $\mathrm{AD}=$ air dried; $\mathrm{EG}=$ ethylene-glycol; $\mathrm{H}=$ heated. The individual peaks are labeled with their $\mathrm{d}$-spacing and mineral name. 

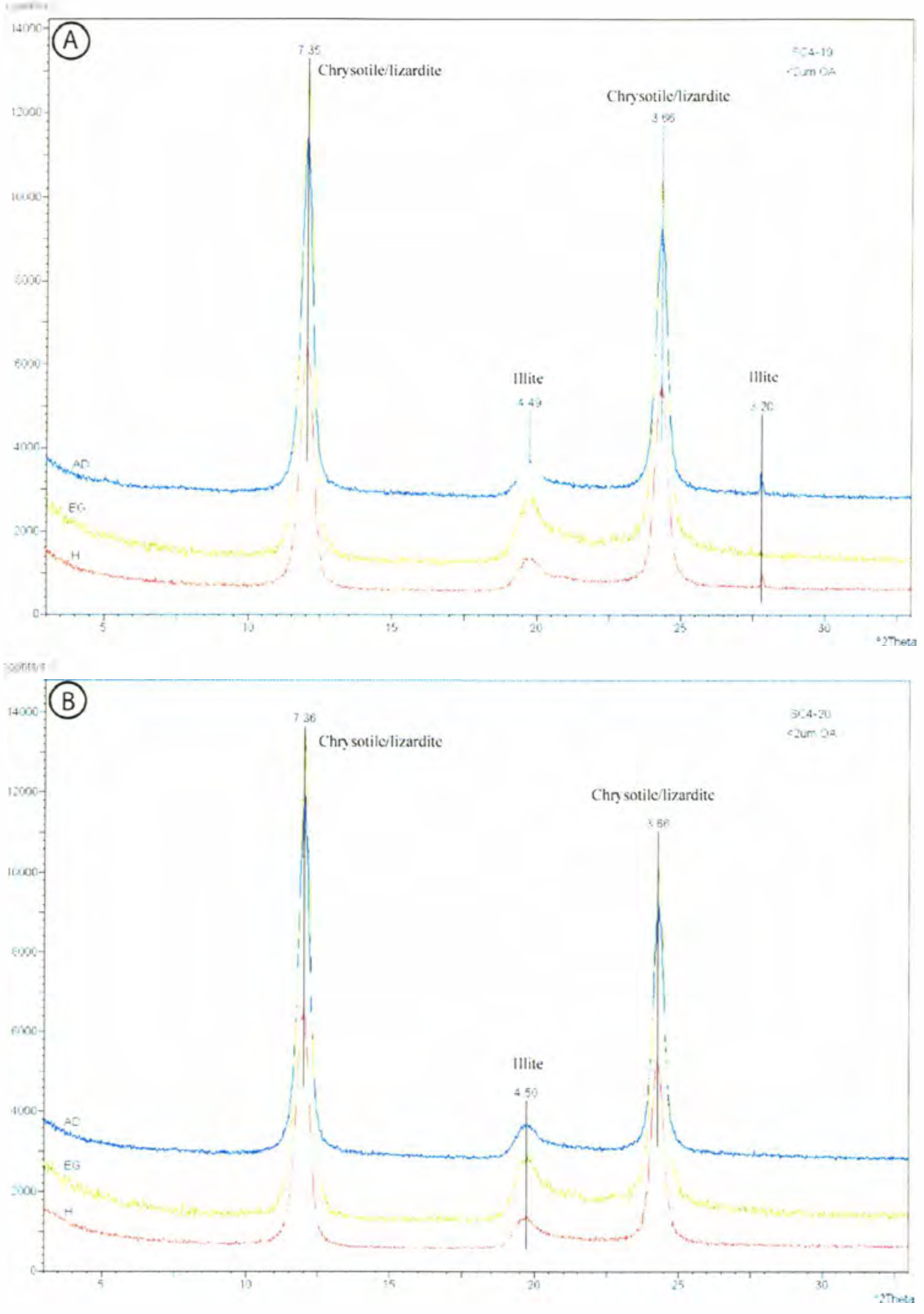

Figure H8. XRD patterns for the $<2 \mu \mathrm{m}$ fraction of (A) sample \#19 (B) sample \#20. The prepared slides were oriented aggregates using the Millipore filtration method. Each graph has 3 superimposed patterns for the same sample in order to show the 3 different stages that every sample underwent. $\mathrm{AD}=$ air dried; $\mathrm{EG}=$ ethylene-glycol; $\mathrm{H}=$ heated. The individual peaks are labeled with their d-spacing and mineral name. 

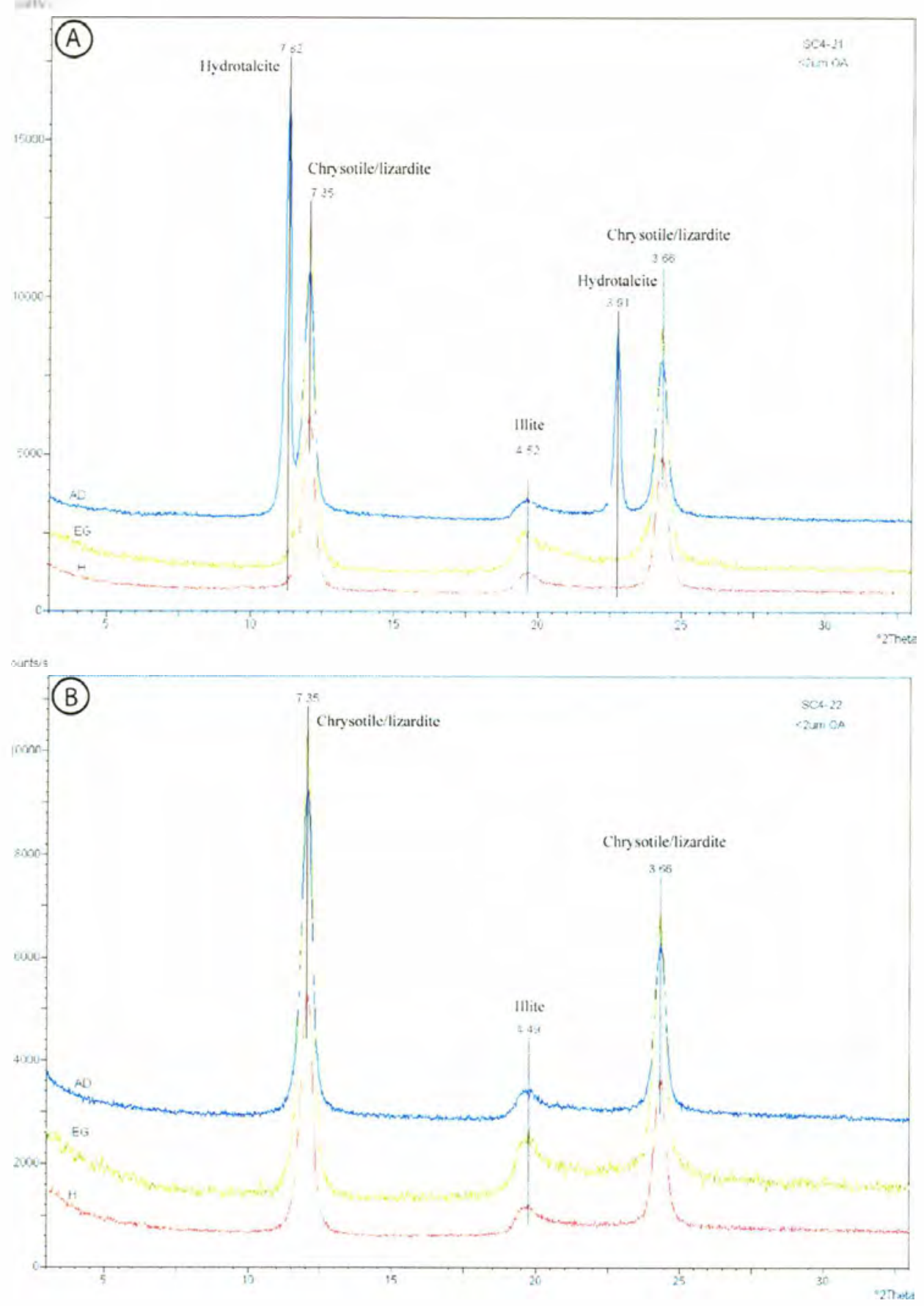

Figure H9. XRD patterns for the $<2 \mu \mathrm{m}$ fraction of (A) sample \#21 (B) sample \#22. The prepared slides were oriented aggregates using the Millipore filtration method. Each graph has 3 superimposed patterns for the same sample in order to show the 3 different stages that every sample underwent. $\mathrm{AD}=$ air dried; $\mathrm{EG}=$ ethylene-glycol; $\mathrm{H}=$ heated. The individual peaks are labeled with their $\mathrm{d}$-spacing and mineral name. 

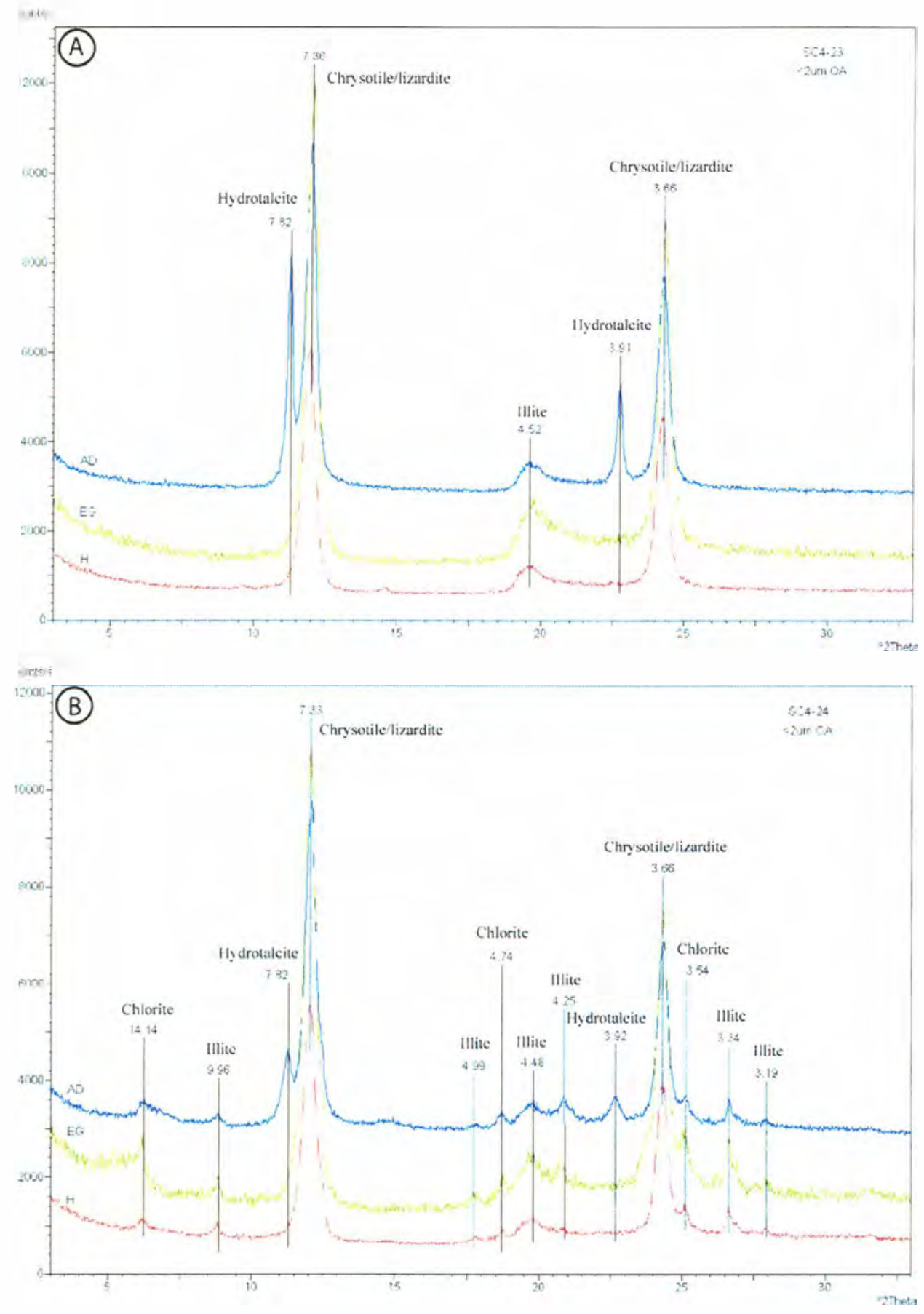

Figure H10. XRD patterns for the $<2 \mu \mathrm{m}$ fraction of (A) sample \#23 (B) sample \#24. The prepared slides were oriented aggregates using the Millipore filtration method. Each graph has 3 superimposed patterns for the same sample in order to show the 3 different stages that every sample underwent. $\mathrm{AD}=$ air dried; $\mathrm{EG}=$ ethylene-glycol; $\mathrm{H}=$ heated. The individual peaks are labeled with their d-spacing and mineral name. 

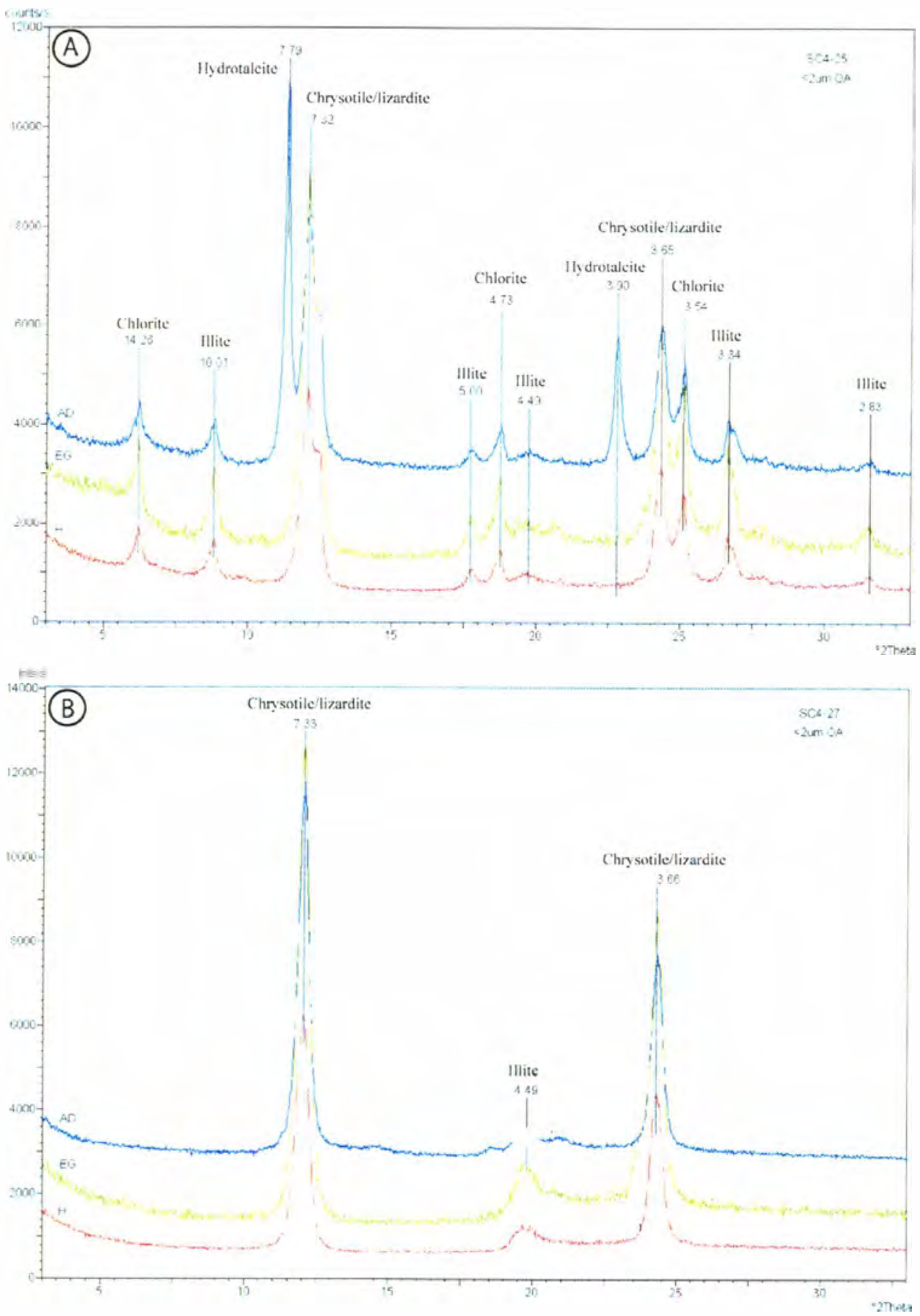

Figure H11. XRD patterns for the $<2 \mu \mathrm{m}$ fraction of (A) sample \#25 (B) sample \#27. The prepared slides were oriented aggregates using the Millipore filtration method. Each graph has 3 superimposed patterns for the same sample in order to show the 3 different stages that every sample underwent. $A D=$ air dried; $E G=$ ethylene-glycol; $H=$ heated. The individual peaks are labeled with their d-spacing and mineral name. 

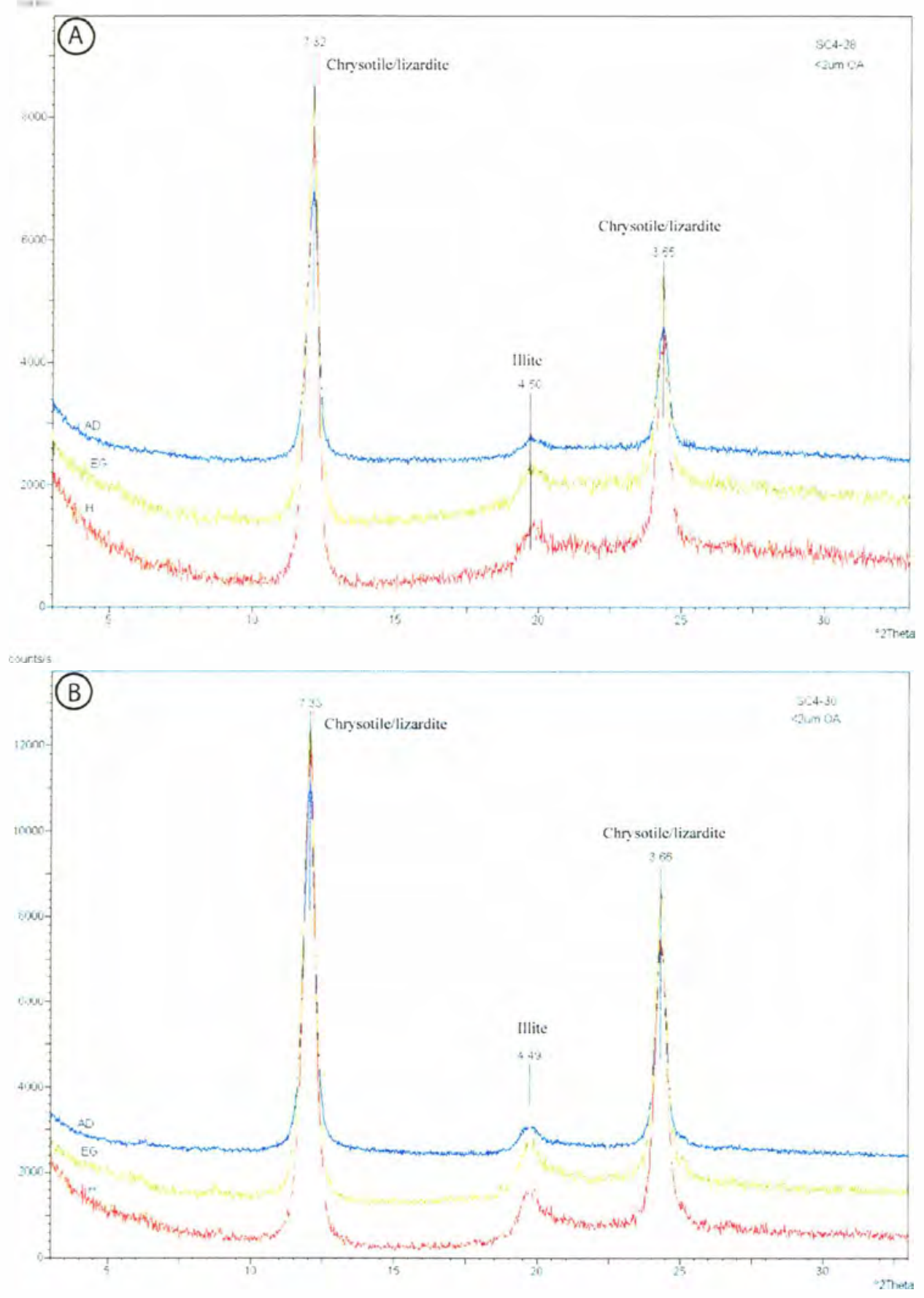

Figure H12. XRD patterns for the $<2 \mu \mathrm{m}$ fraction of (A) sample \#28 (B) sample \#30. The prepared slides were oriented aggregates using the Millipore filtration method. Each graph has 3 superimposed patterns for the same sample in order to show the 3 different stages that every sample underwent. $\mathrm{AD}=$ air dried; $\mathrm{EG}=$ ethylene-glycol; $\mathrm{H}=$ heated. The individual peaks are labeled with their d-spacing and mineral name. 

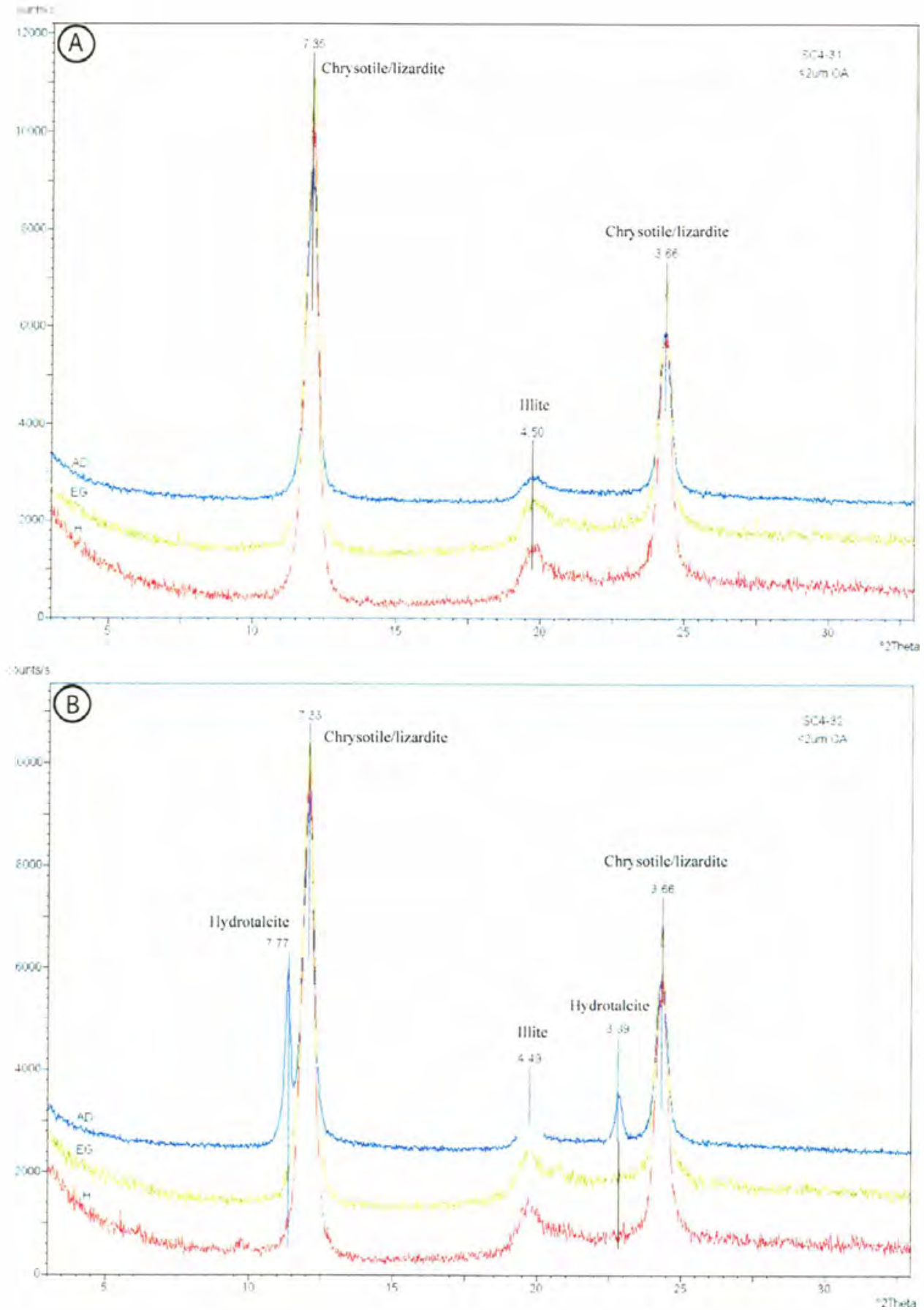

Figure H13. XRD patterns for the $<2 \mu \mathrm{m}$ fraction of (A) sample \#31 (B) sample \#32. The prepared slides were oriented aggregates using the Millipore filtration method. Each graph has 3 superimposed patterns for the same sample in order to show the 3 different stages that every sample underwent. $\mathrm{AD}=$ air dried; $\mathrm{EG}=$ ethylene-glycol; $\mathrm{H}=$ heated. The individual peaks are labeled with their d-spacing and mineral name. 


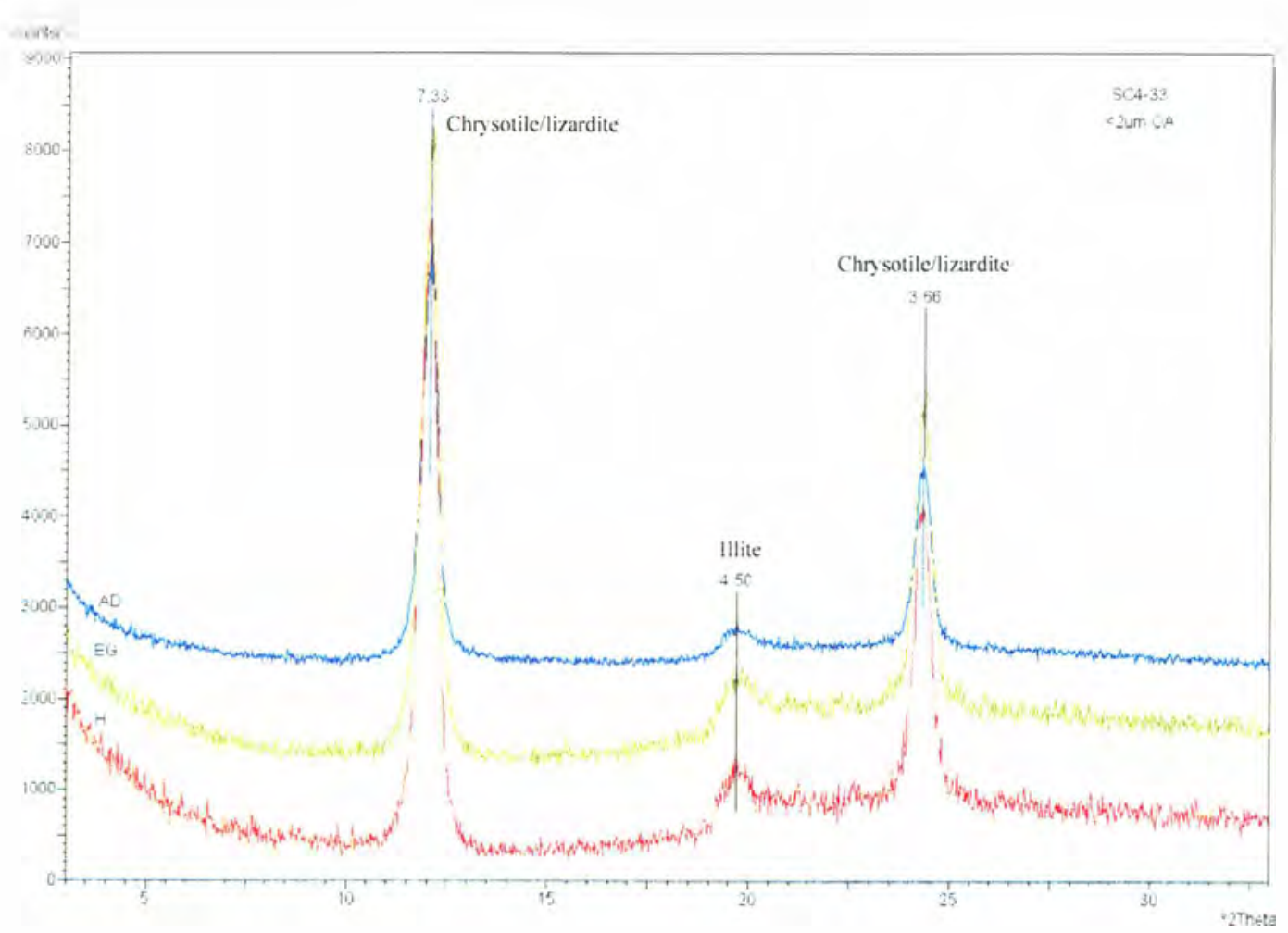

Figure H14. XRD patterns for the $<2 \mu \mathrm{m}$ fraction of sample \#33. The prepared slide was an oriented aggregate using the Millipore filtration method. The graph has 3 superimposed patterns for the sample in order to show the 3 different stages that the sample underwent. $\mathrm{AD}=$ air dried $; \mathrm{EG}=$ ethylene-glycol; $\mathrm{H}=$ heated. The individual peaks are labeled with their d-spacing and mineral name. 

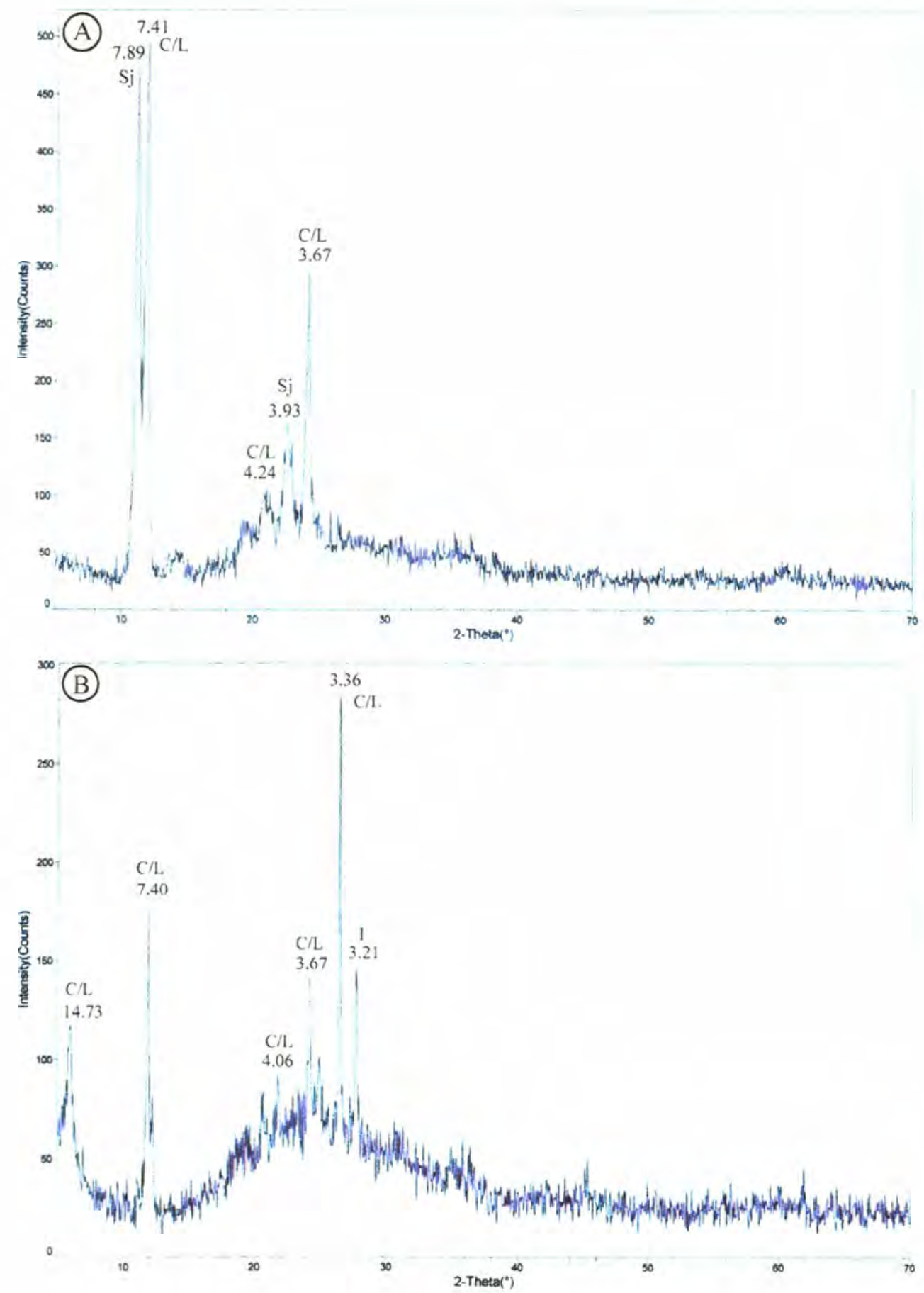

Figure H15. XRD patterns for the $<2 \mu \mathrm{m}$ fraction of (A) sample \#36 (B) sample \#38. The prepared slides were oriented aggregates using the glass slide method. The individual peaks are labeled with their $\mathrm{d}$-spacing and mineral name. $\mathrm{C} / \mathrm{L}=$ chrysotile/lizardite; $\mathrm{I}=$ illite; $\mathrm{Sj}=$ sjogrenite. 


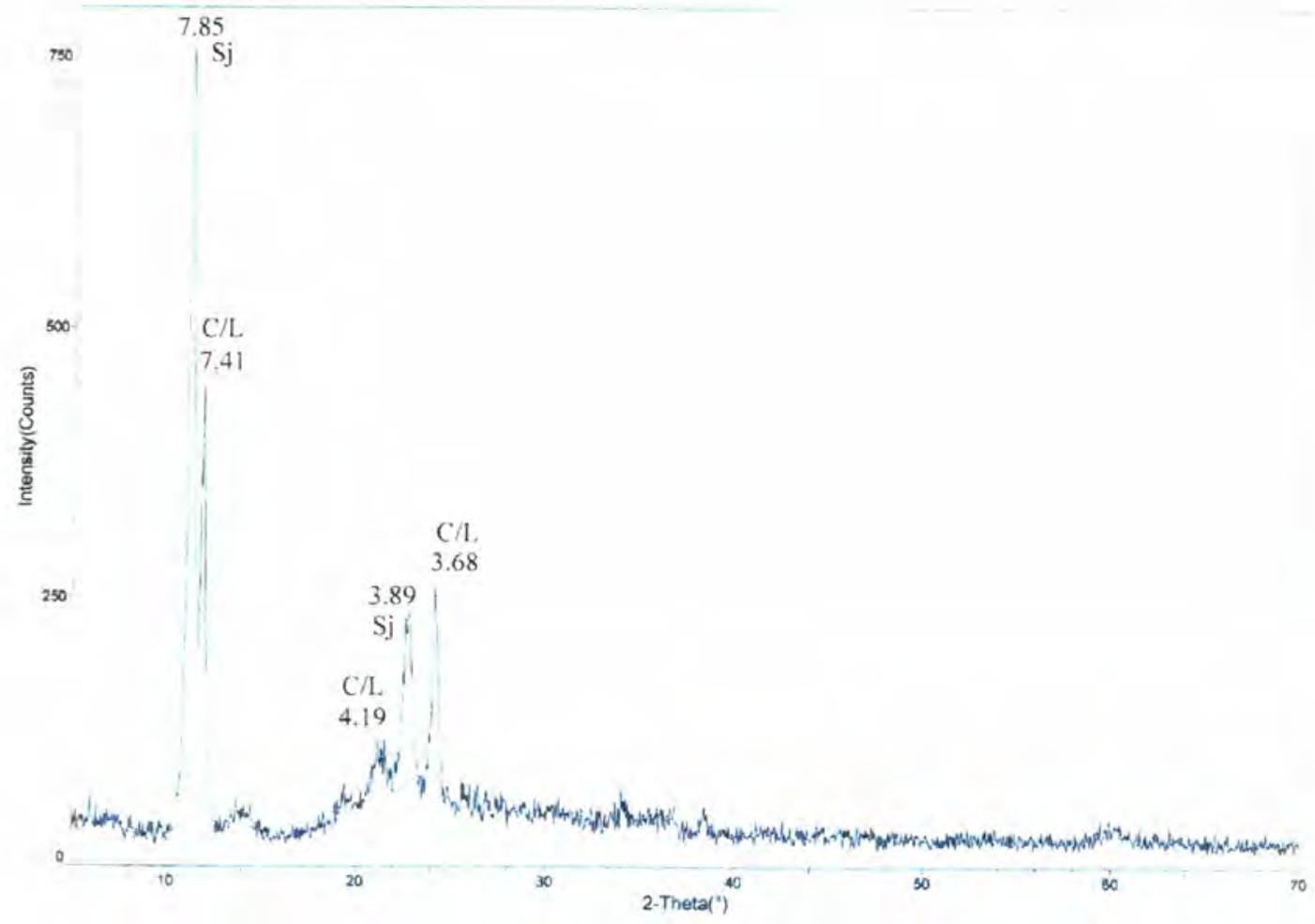

Figure H16. XRD pattern for the $<2 \mu \mathrm{m}$ fraction of sample \#40. The prepared slide was an oriented aggregate using the glass slide method. The individual peaks are labeled with their d-spacing and mineral name. $\mathrm{C} / \mathrm{L}=$ chrysotile/lizardite; $\mathrm{Sj}=$ sjogrenite. 


\section{APPENDIX I}

Atterberg limit graphs 

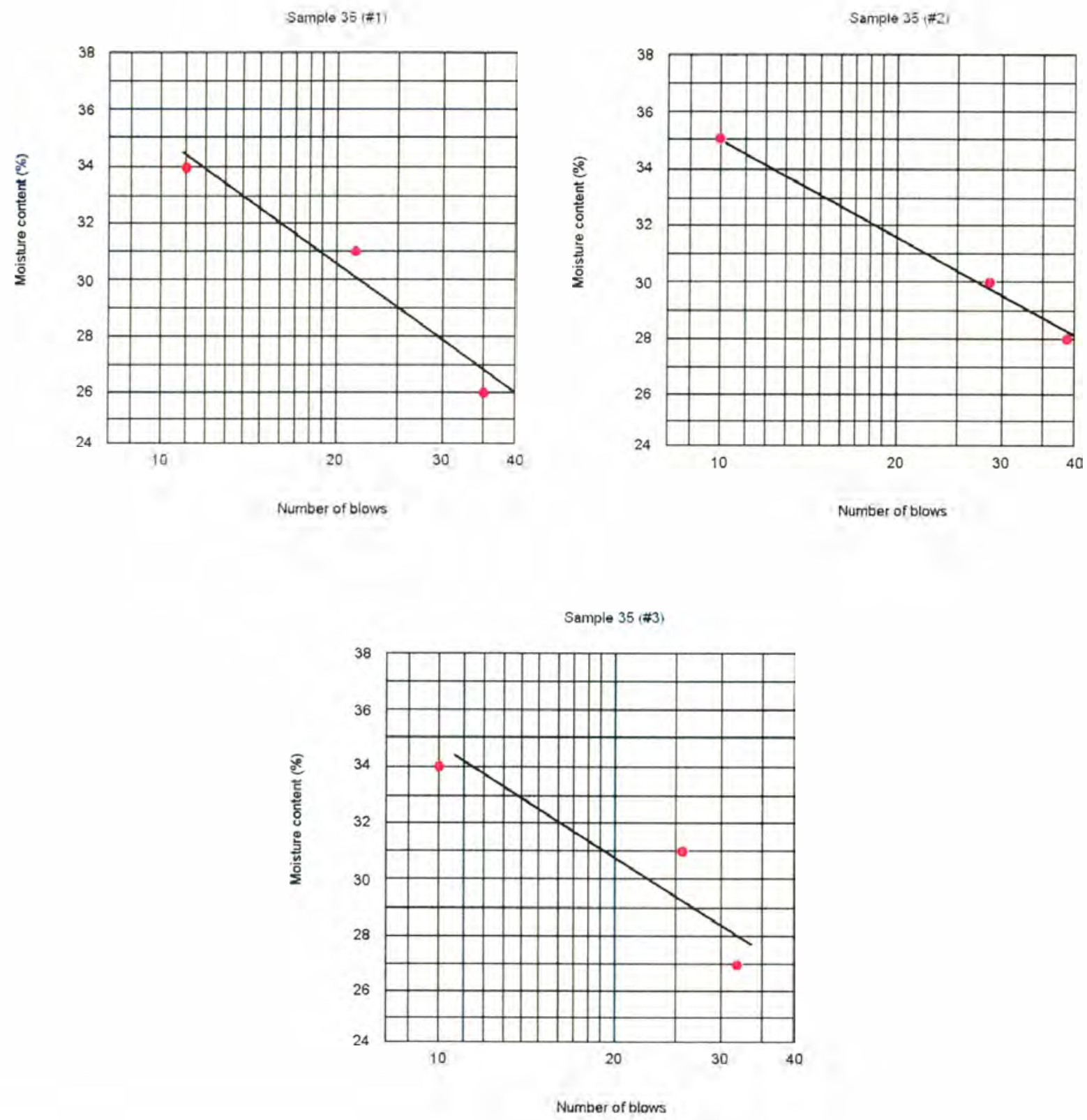

Figure I1. Liquid limit (LL) graphs for sample 35. The sample was analyzed three times. The trial number is in parentheses. The LL is taken to be where the moisture content corresponds to 25 blows. The LL for this sample was the average over the three trials. 
Sample 36 \#1)

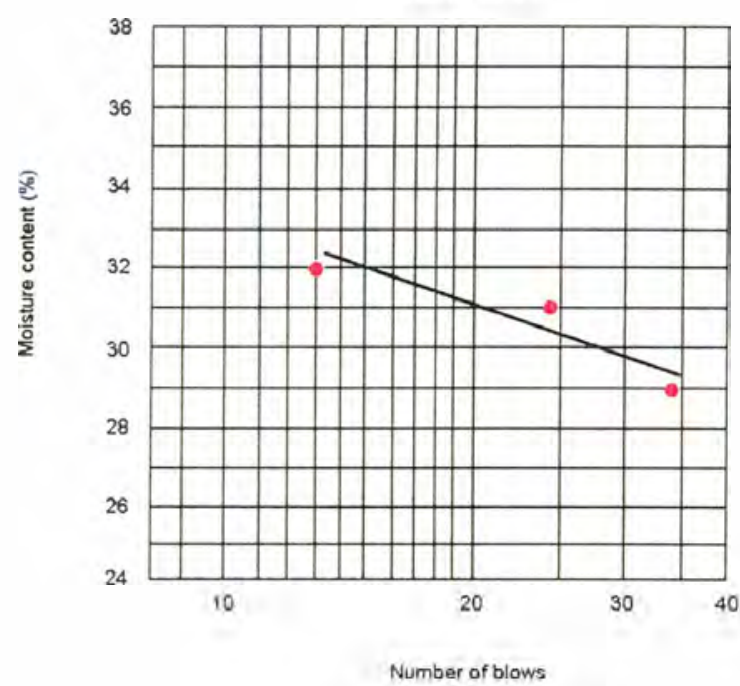

Sample 36 (\#2)

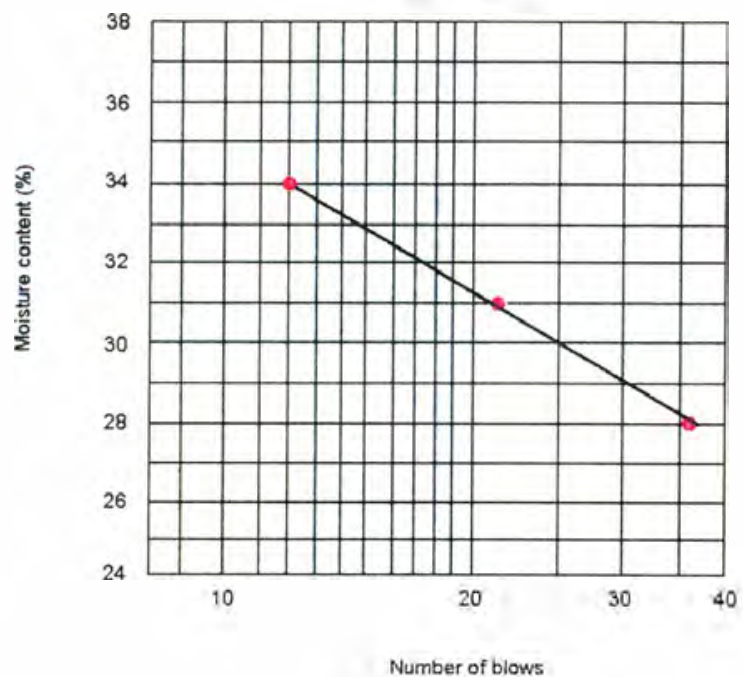

Sample $36(\# 3)$

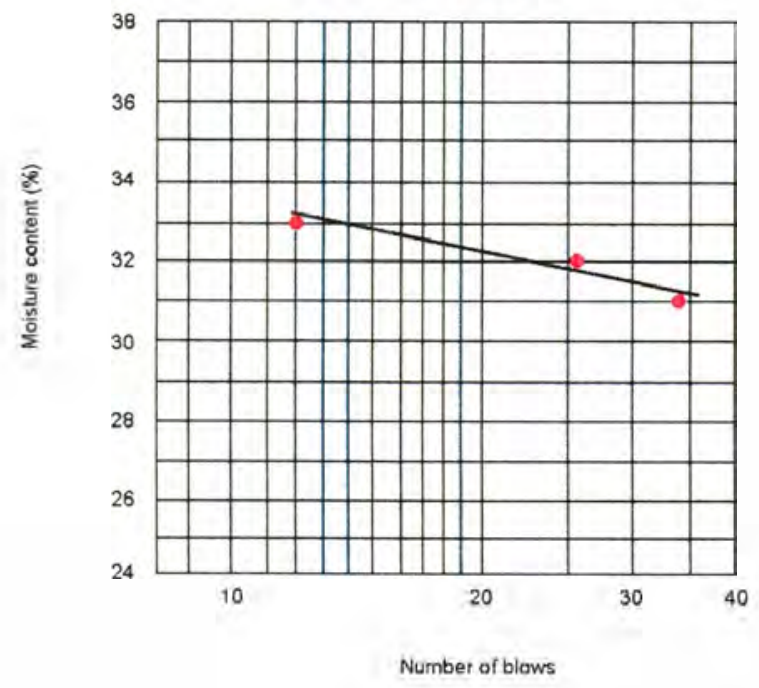

Figure I2. Liquid limit (LL) graphs for sample 36. The sample was analyzed three times. The trial number is in parentheses. The LL is taken to be where the moisture content corresponds to 25 blows. The LL for this sample was the average over the three trials. 
Sample $37(\# 1)$

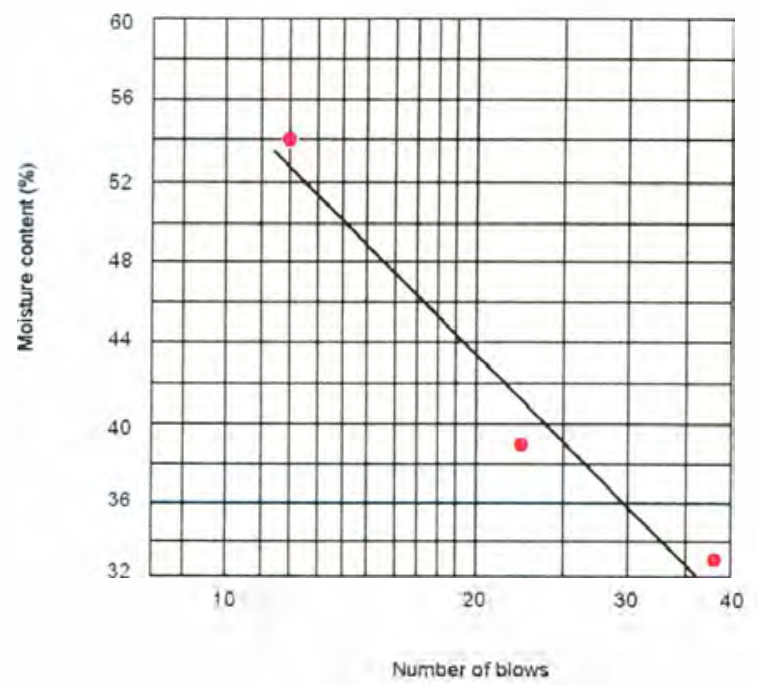

Sample $37(42)$

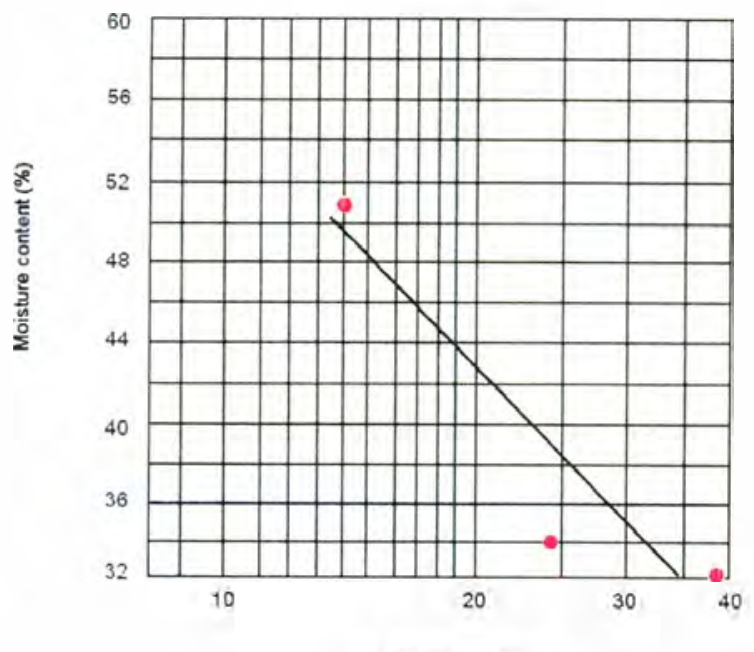

Number of blows

Sample $37(\# 3)$

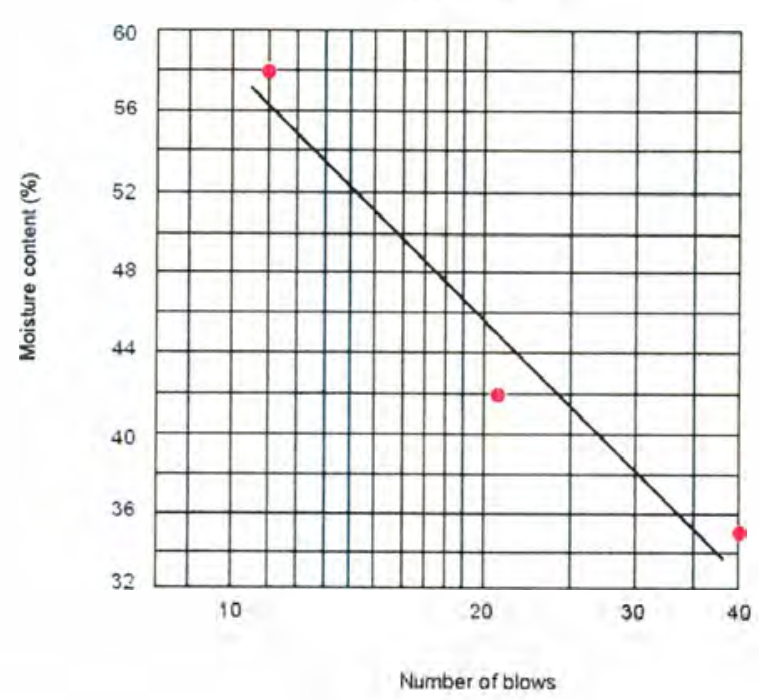

Figure I3. Liquid limit (LL) graphs for sample 37. The sample was analyzed three times. The trial number is in parentheses. The LL is taken to be where the moisture content corresponds to 25 blows. The LL for this sample was the average over the three trials. 

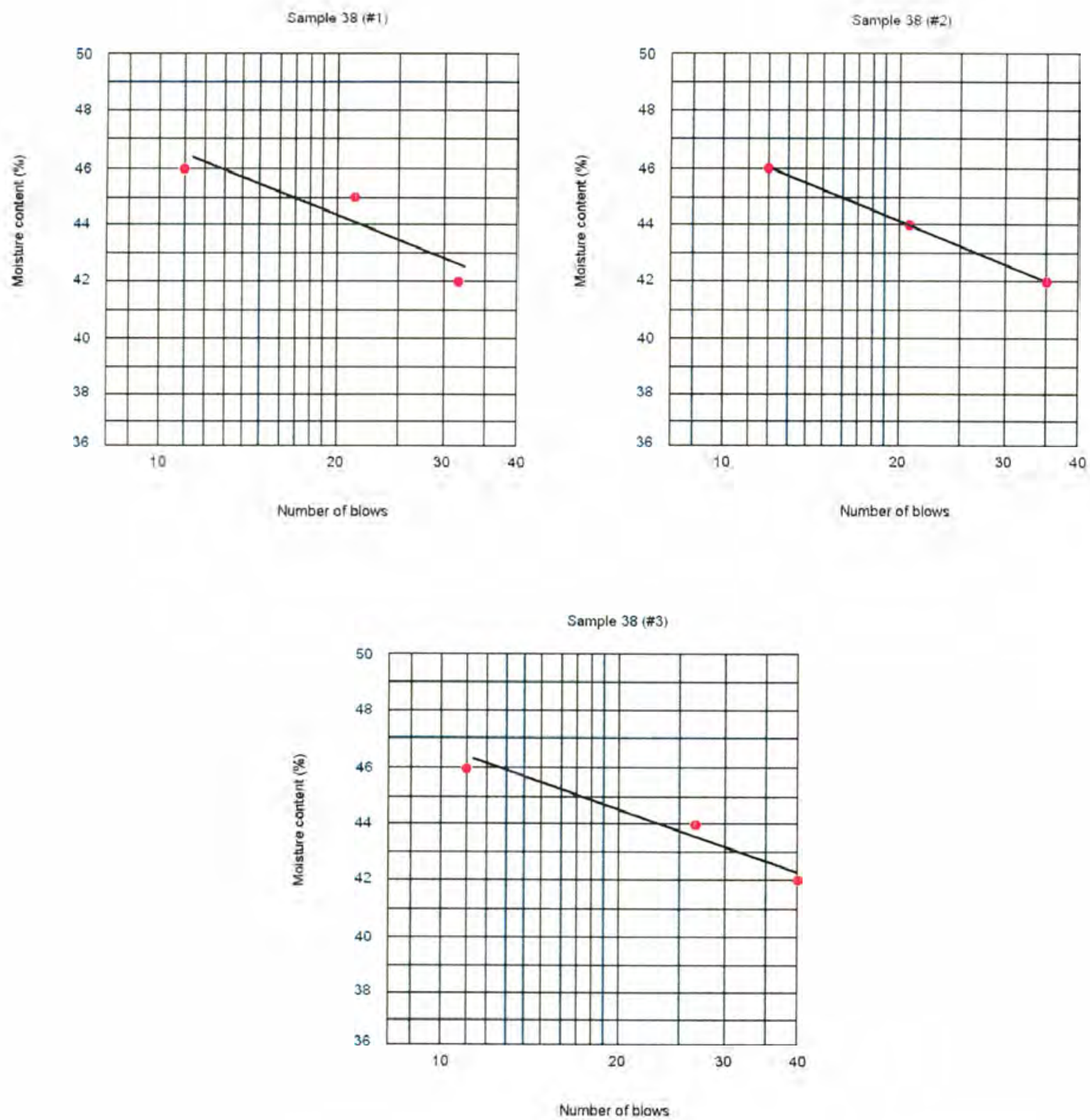

Figure I4. Liquid limit (LL) graphs for sample 38. The sample was analyzed three times, The trial number is in parentheses. The LL is taken to be where the moisture content corresponds to 25 blows. The LL for this sample was the average over the three trials. 
Sample 39 ; \#1)

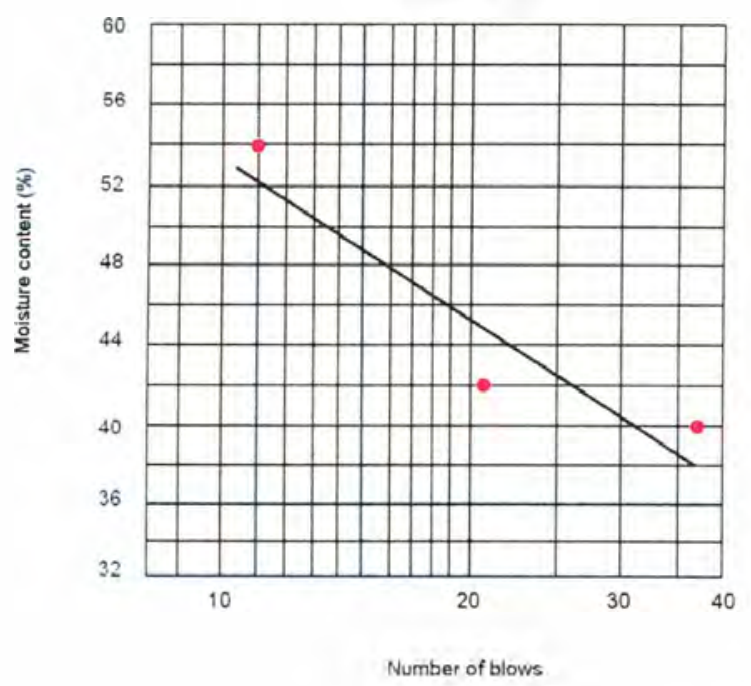

Sample 39 (\#2)

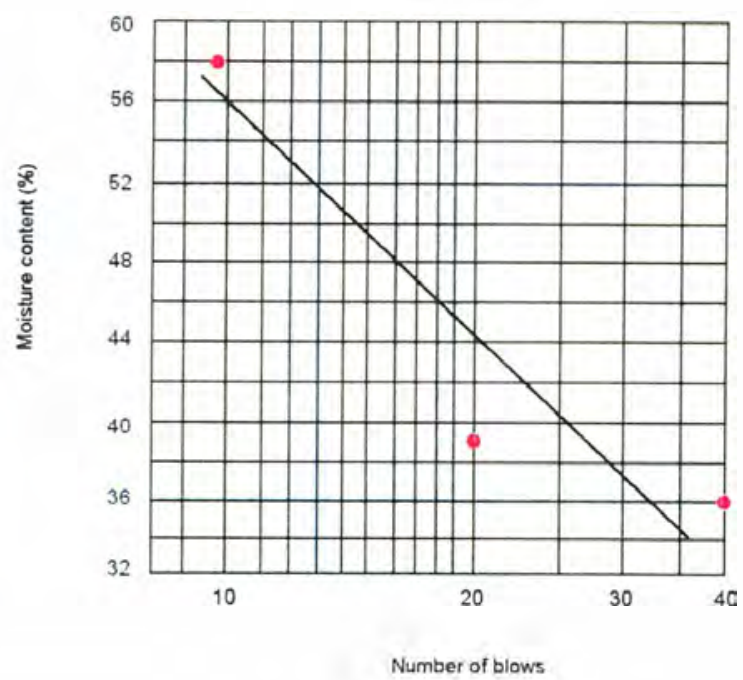

Sample $39: \# 3$

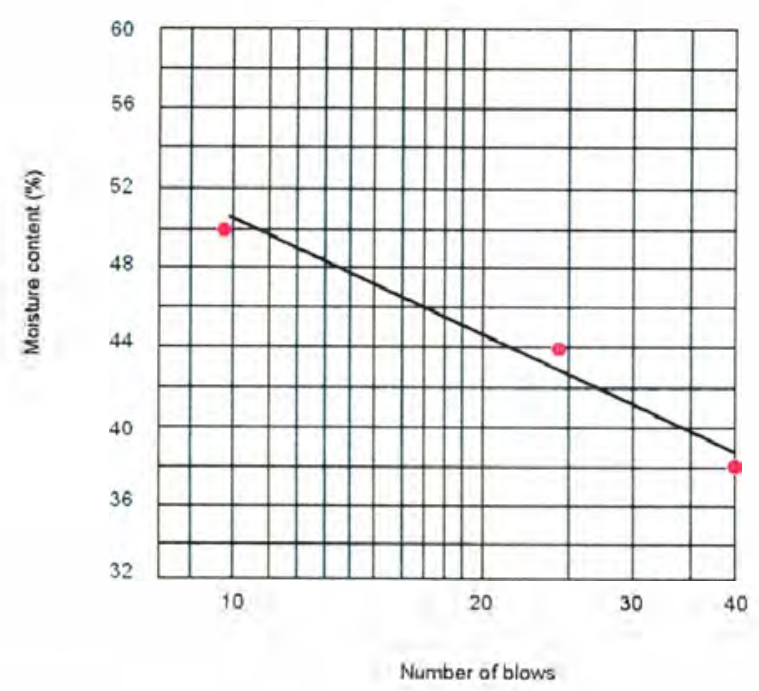

Figure I5. Liquid limit (LL) graphs for sample 39. The sample was analyzed three times. The trial number is in parentheses. The LL is taken to be where the moisture content corresponds to 25 blows. The LL for this sample was the average over the three trials. 
Sample to

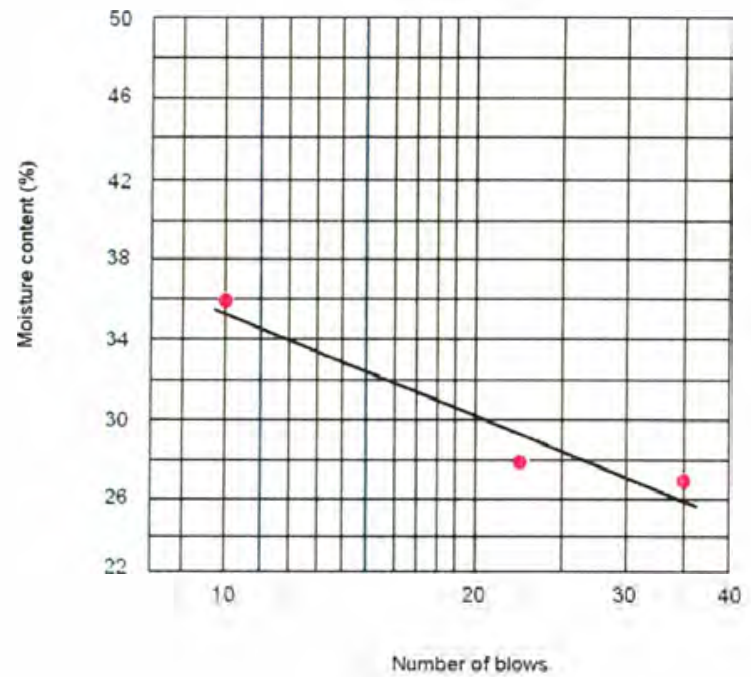

Sample $40(\# 2)$

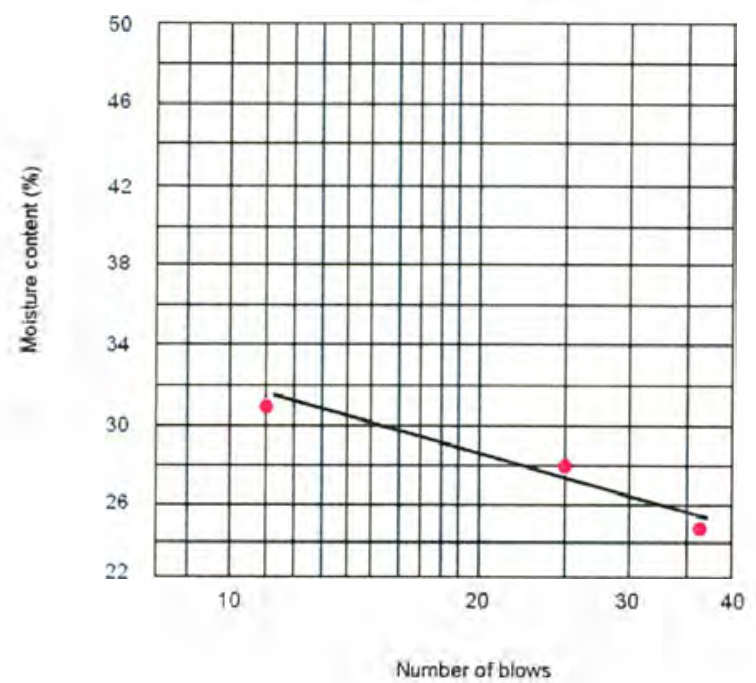

Sample $40(\# 3)$

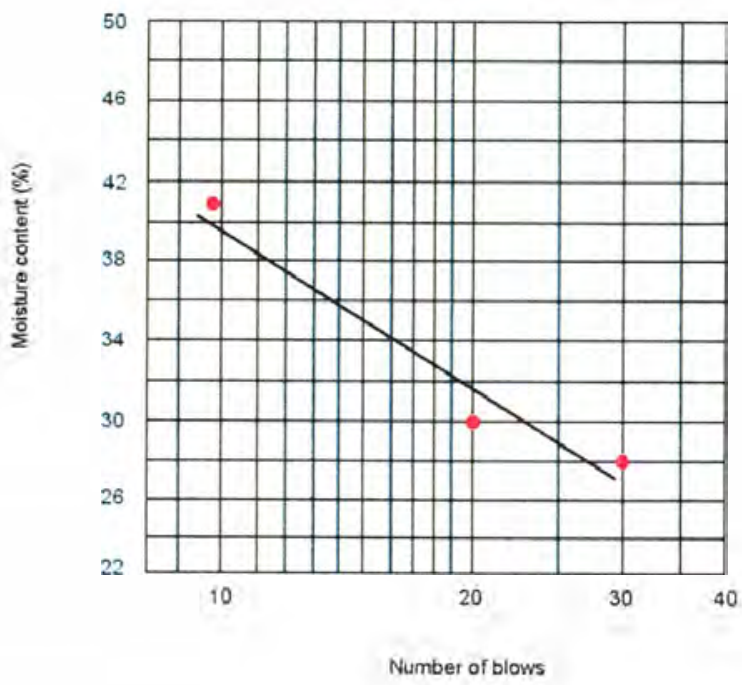

Figure I6. Liquid limit (LL) graphs for sample 40. The sample was analyzed three times. The trial number is in parentheses. The LL is taken to be where the moisture content corresponds to 25 blows. The LL for this sample was the average over the three trials. 
Sample 4 i $\{\# 1\}$

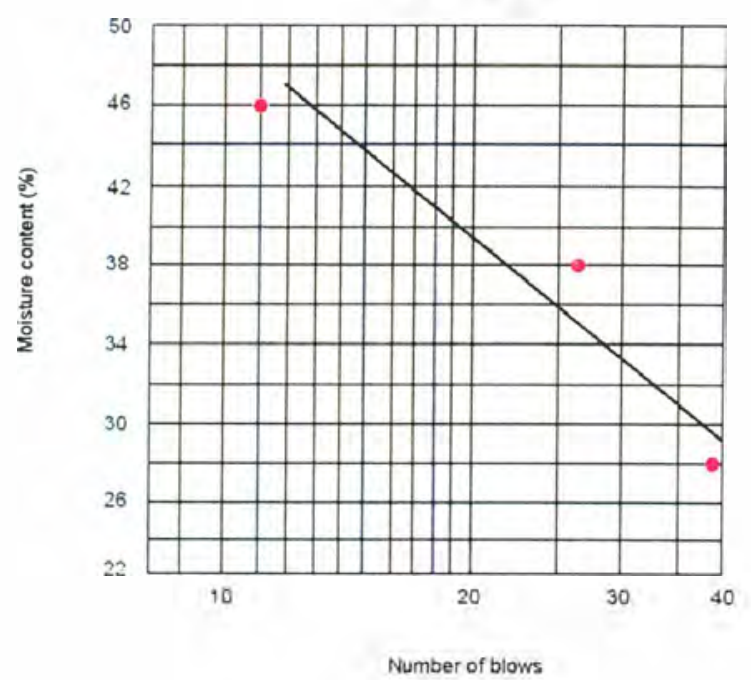

Sample $4 i(\# 2)$

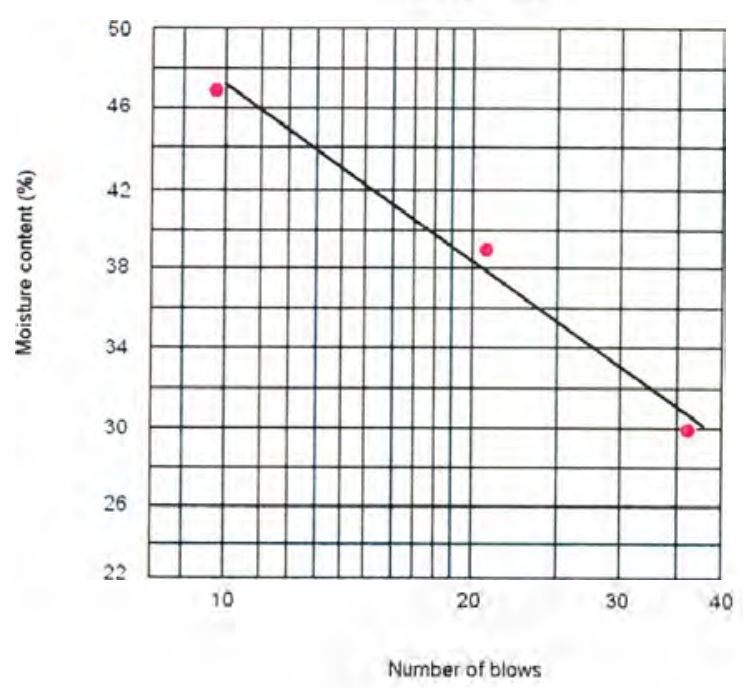

Sample $41(\# 3)$

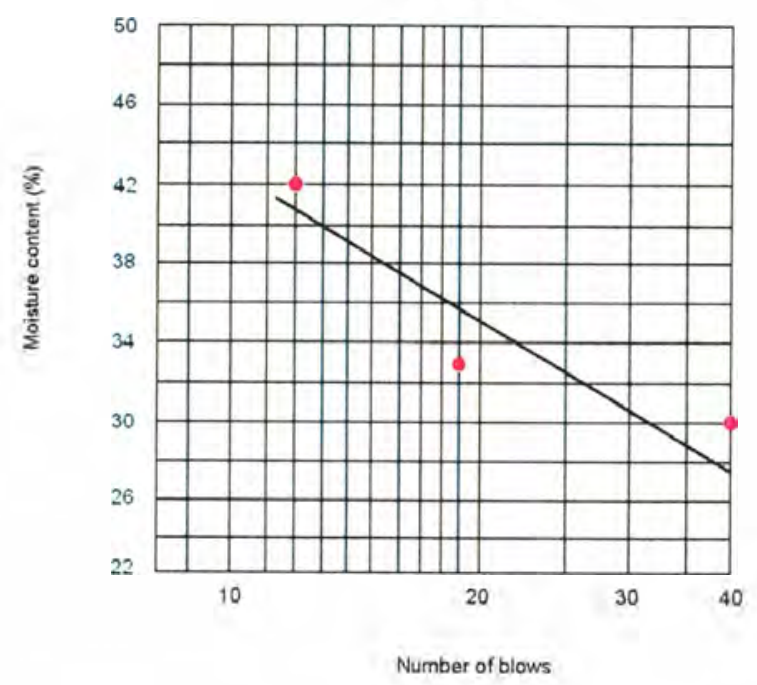

Figure I7. Liquid limit (LL) graphs for sample 41. The sample was analyzed three times. The trial number is in parentheses. The LL is taken to be where the moisture content corresponds to 25 blows. The LL for this sample was the average over the three trials. 
APPENDIX J

Hydrologic graphs 


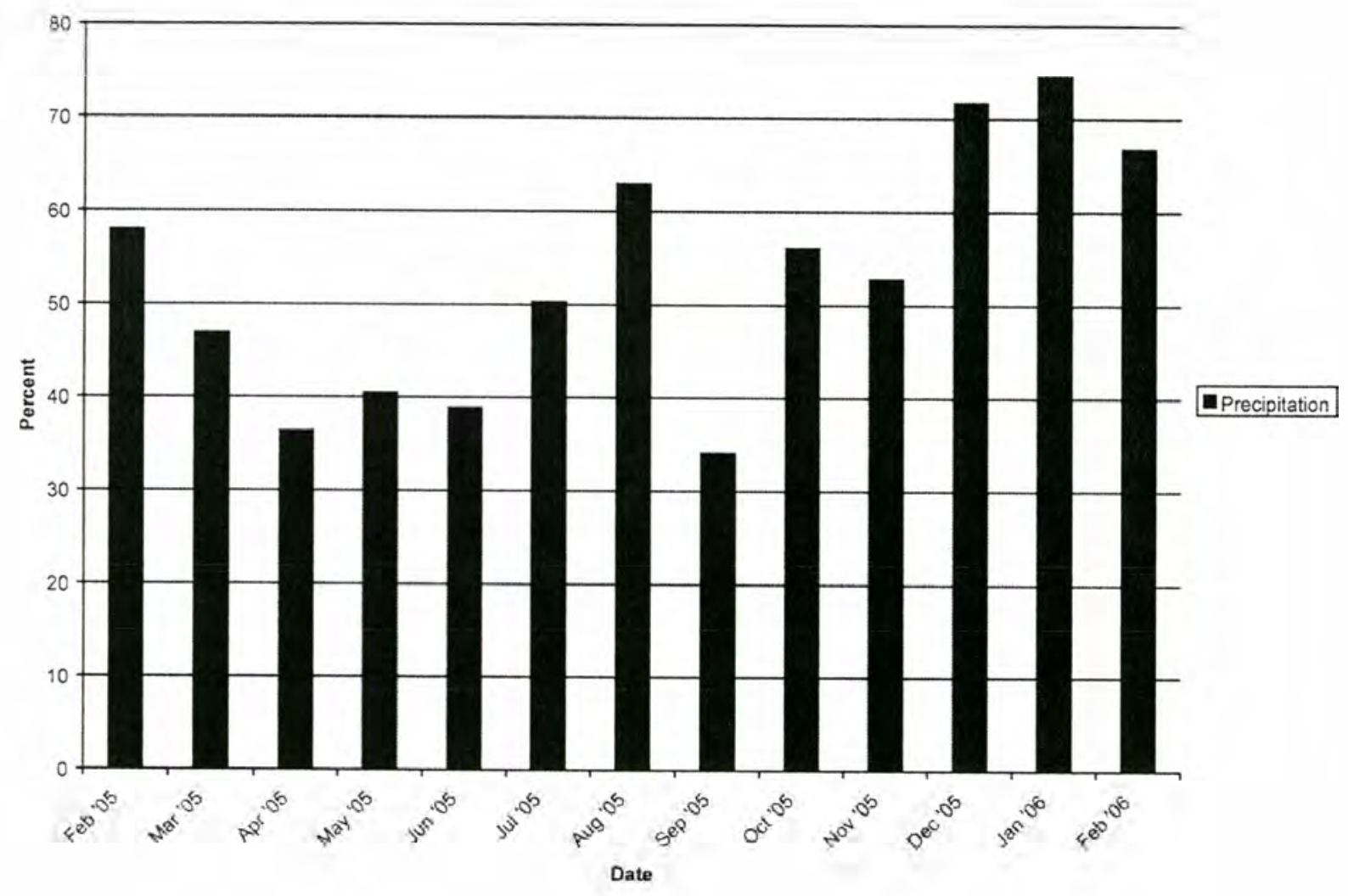

Figure J1. Precipitation, as a percent of the monthly total, that occurred during nighttime hours. 

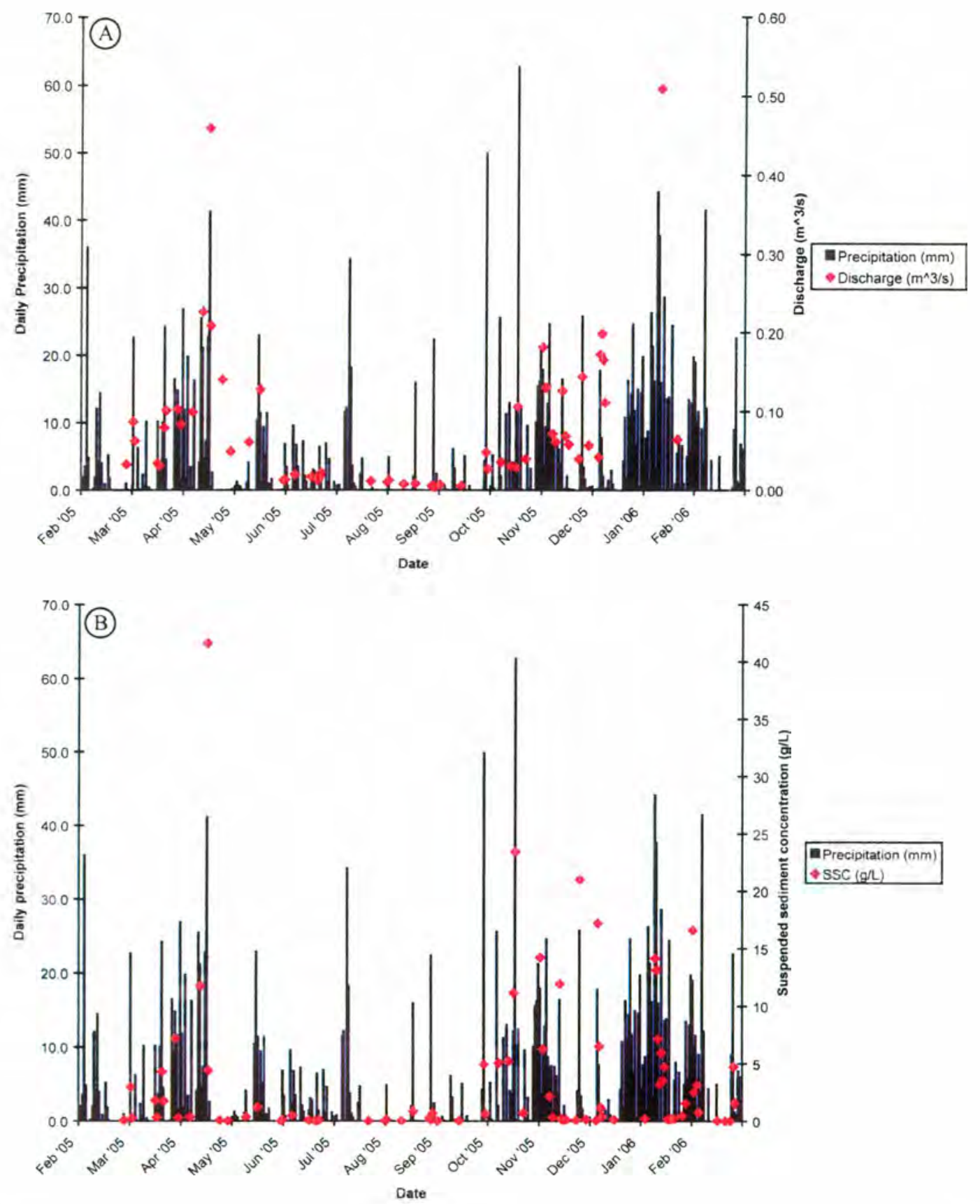

Figure J2. Relationship between precipitation and (A) discharge and (B) SSC during 20052006. 

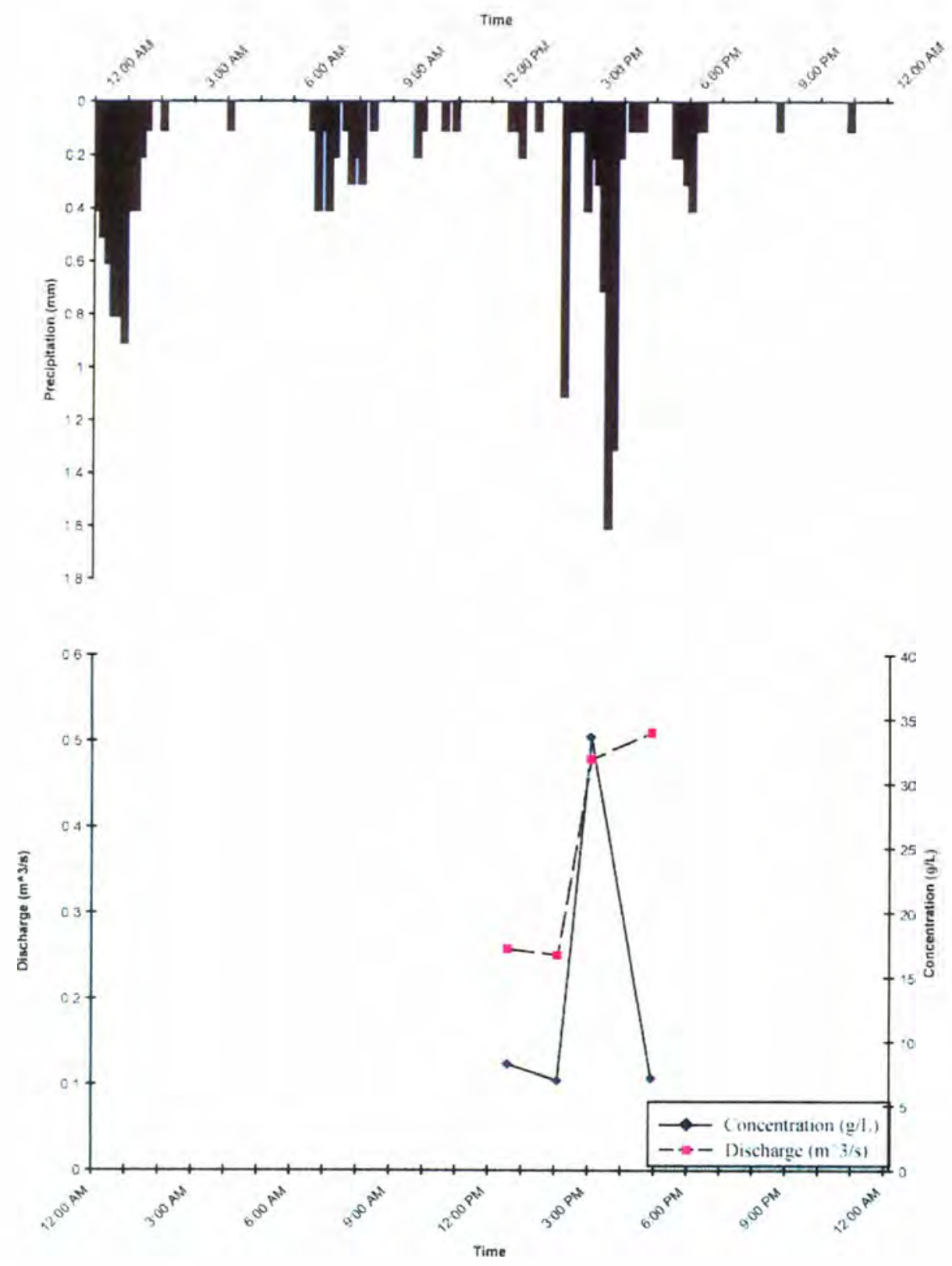

Figure J3. Relationship between precipitation, suspended sediment concentration and discharge for 1-11-06. The four discrete discharge and SSC measurements are connected with lines to help visualize the data. 